\author{
UNIVERSIDADE DE SÃO PAULO \\ Escola de Engenharia de São Carlos \\ Departamento de Engenharia de Transportes \\ Programa de Pós-Graduação em Engenharia de Transportes
}

Fernando José Piva

\title{
Fatores de equivalência de veículos pesados em rodovias de pista dupla
}



Fernando José Piva

\title{
Fatores de equivalência de veículos pesados em rodovias de pista dupla
}

\author{
Dissertação de Mestrado submetida à Escola de Enge- \\ nharia de São Carlos, da Universidade de São Paulo, \\ como parte dos requisitos para a obtenção do título de \\ Mestre em Ciências, Programa de Pós-Graduação em \\ Engenharia de Transportes. Área de Concentração: \\ Planejamento e Operação de Sistemas de Transporte
}

Orientador: Prof. Titular José Reynaldo Setti

São Carlos

2015 
AUTORIZO A REPRODUÇÃO TOTAL OU PARCIAL DESTE TRABALHO, POR QUALQUER MEIO CONVENCIONAL OU ELETRÔNICO, PARA FINS DE ESTUDO E PESQUISA, DESDE QUE CITADA A FONTE.

Piva, Fernando José

Fatores de equivalência de veículos pesados em rodovias de pista dupla / Fernando José Piva; orientador José Reynaldo Anselmo Setti. São Carlos, 2015 .

Dissertação (Mestrado) - Programa de Pós-Graduação em Engenharia de Transportes e Área de Concentração em Planejamento e Operação de Sistemas de Transporte -Escola de Engenharia de São Carlos da Universidade de São Paulo, 2015.

1. Rodovias de pista dupla. 2. Qualidade de serviço. 3. Fator de equivalência. 4. Dados empíricos. I. Título. 


\section{FOLHA DE JULGAMENTO}

Candidato: Engenheiro FERNANDO JOSÉ PIVA.

Título da dissertação: "Fatores de equivalência de veículos pesados em rodovias de pista dupla".

Data da defesa: 19/06/2015

\section{Comissão Julgadora:}

Prof. Titular José Reynaldo Anselmo Setti (Orientador)

(Escola de Engenharia de São Carlos/EESC)

\section{Dr. Sérgio Henrique Demarchi}

(Logit Engenharia Consultiva - São Paulo/SP)

Prof. Dr. Flávio José Craveiro Cunto

(Universidade Federal do Ceará/UFC)

\section{Resultado:}
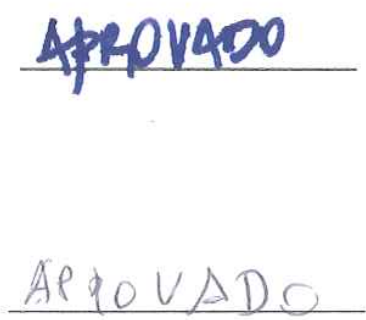

Coordenador do Programa de Pós-Graduação em Engenharia de Transportes: Prof. Associado Paulo César Lima Segantine

Presidente da Comissão de Pós-Graduação:

Prof. Associado Paulo César Lima Segantine 

Aos meus pais, Celso e Teresinha. 



\section{Agradecimentos}

Em primeiro lugar devo agradecer à minha família. Meus pais, Celso e Teresinha, meus irmãos Marcelo e Fábio, minhas cunhadas Regiane e Carla e meus sobrinhos Luís Felipe, Henrique e Amanda por estarem presentes em todos os momentos.

Aos meus tios Celso, Teresa e Cida, por sempre colaborar nessa e em outras fases da minha vida. Também agradeço aos meus primos Rogério e Ricardo, pelo apoio desde quando éramos criança.

Agradeço à ARTESP e às concessionárias CCR ViaOeste e CCR AutoBan por cederem os dados de tráfego. Também agradeço ao IPMet, por ter fornecido imagens das condições do tempo, utilizadas nesta pesquisa. Do mesmo modo, agradeço ao suporte financeiro dado pela CAPES, através da bolsa de mestrado.

Ao Professor José Reynaldo Setti, por todos os ensinamentos. Seu conhecimento crítico no tema da pesquisa, bem como em outras áreas, foram de vital importância para a melhora e finalização dessa pesquisa.

Aos atuais e ex-alunos do grupo de estudo orientado pelo professor Setti, principalmente ao Gustavo Andrade e a Bruna Pizzol, por tirarem incontáveis dúvidas sobre os dados coletados e nunca demonstrarem impaciência nas suas respostas.

Por participarem da banca de qualificação, agradeço ao André Cunha e ao Sergio Demarchi, que deram importantes contribuições para o andamento da pesquisa. Além disso, o Sergio foi o grande incentivador para que eu viesse cursar o mestrado em São Carlos.

Aos professores, funcionários e alunos do Departamento de Transportes da EESC-USP por todo conhecimento e pelas ajudas, dentro e fora das salas de aula.

Por fim, agradeço a todos os meus amigos. Aqui me reservo ao direito de não citar nomes para não ser injusto com nenhum deles. Tenham certeza que, direta ou indiretamente, todos foram muito importantes para a concretização deste trabalho. 



\section{Resumo}

Piva, F. J. Fatores de equivalência de veículos pesados em rodovias de pista dupla. 98 p. Dissertação de Mestrado - Escola de Engenharia de São Carlos, Universidade de São Paulo, 2015.

Este trabalho visa avaliar o impacto de veículos pesados na qualidade de serviço de rodovias de pista dupla através de equivalentes veiculares. Para isso, foram feitas estimativas dos fatores de equivalência veicular em rodovias paulistas de pista dupla, com três ou mais faixas de tráfego em cada sentido. Essas estimativas foram obtidas a partir de dados empíricos coletados separadamente para cada faixa de tráfego, em intervalos de curta duração (5 ou 6 minutos). Foram utilizadas 53.655 observações, coletadas em oito estações de monitoramento, nos anos 2010 e 2011. O fator de equivalência foi calculado para cada intervalo através de uma equação obtida a partir do método de Huber, admitindo-se que a qualidade de serviço é a mesma para todas as faixas de tráfego naquele intervalo. Foi considerado como fluxo básico o da faixa da esquerda, nos intervalos em que são detectados apenas automóveis, e fluxo misto o da faixa da direita, em que passam automóveis e caminhões. Os resultados sugerem que: (1) em uma parte significativa do tempo (52\%), a qualidade de serviço não é a mesma em todas as faixas da rodovia; (2) o impacto marginal dos caminhões decresce à medida que a porcentagem de caminhões na corrente aumenta; e (3) as diferenças que existem no fator de equivalência em função do nível de serviço são menos evidentes em rampas mais íngremes, onde o efeito das limitações de desempenho dos caminhões é mais notado. A comparação deste estudo com outras duas pesquisas, em que foram utilizados dados gerados em simuladores de tráfego para estimar os fatores de equivalência, mostrou que as estimativas dos equivalentes veiculares obtidos usando dados empíricos são consistentemente maiores que as obtidas através de simulação.

Palavras-chave: Rodovias de pista dupla. Qualidade de serviço. Fator de equivalência. Dados empíricos. 



\section{Abstract}

Piva, F. J. Passenger-car equivalents for heavy vehicles on expressways. 98 p. Master Thesis - São Carlos School of Engineering, University of São Paulo, 2015.

The objective of this study is to evaluate the impact of heavy vehicles on the quality of service on Brazilian expressways (freeways and divided multilane highways), using passengercar equivalents (PCEs) for heavy vehicles (trucks and buses). PCE estimates for expressways with three or more traffic lanes in each direction were obtained using traffic data collected over short time intervals (5 or 6 minutes) on expressways in the state of São Paulo. A total of 53,655 speed-flow observations, made at eight permanent traffic sensor installations during 2010 and 2011, were used in this study. A PCE estimate was calculated for each time interval, using an equation derived from Huber's method, based on the assumption that the quality of service is the same across all traffic lanes during the time interval over which the traffic data is collected. Basic flow (passenger cars only) was assumed to be the observed traffic flow on the lane closest to the median, whereas mixed flow (passenger cars and heavy vehicles) was assumed to be the observed traffic flow on the lane closest to the shoulder. The results indicate that: (1) in a significant portion of the time (52\% of the observations) the quality of service is not the same across all traffic lanes; (2) the marginal impact of heavy vehicles decreases as the fraction of heavy vehicles in the traffic stream increases; and (3) the variations in PCE estimates due to the level of service are less evident on steeper grades, where the effect of heavy vehicles' poorer performance is greater. PCE estimates obtained in this study were compared with PCEs obtained using simulation. The results indicate that PCE from empirical data are consistently higher than those estimated from simulation results.

Keywords: Expressways. Quality of service. Passenger-car equivalentes. Traffic data. 



\section{Lista de ilustrações}

Figura 2.1 Conceito de equivalência entre uma corrente de tráfego básica e mista (HUBER, 1982) . . . . . . . . . . . . . . . . . 36

Figura 3.1 Velocidade média em função do fluxo, em cada faixa de tráfego, na SP348,

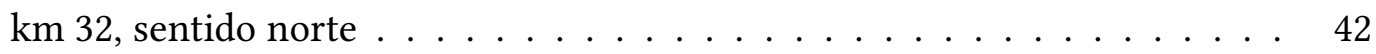

Figura 3.2 Porcentagem de veículos, para cada uma das faixas de tráfego, em função do fluxo total observado na rodovia $(\mathrm{SP} 348, \mathrm{~km} 32 \mathrm{~N}) \ldots . \ldots 43$

Figura 3.3 Comparação das médias de porcentagem de veículos por faixa de tráfego em função do fluxo da rodovia . . . . . . . . . . . . . . . . . . . . 44 44

Figura 3.4 Representação das diferenças entre os fluxos $q_{e}(i)$ e $q_{d}(i)$ para a mesma densidade . . . . . . . . . . . . . . . . . . . 45

Figura 4.1 Exemplo de laço indutivo utilizado na coleta dos dados de tráfego . . . . 50

Figura 4.2 Localização dos pontos de coleta de dados de tráfego . . . . . . . . . . . . 51

Figura 4.3 Imagem dos radares meteorológicos do IPMet . . . . . . . . . . . . . . 52

Figura 5.1 Observações removidas em função de tempo chuvoso ou indeterminado . . 56

Figura 5.2 Observações descartadas por operação em regime de fluxo congestionado . 56

Figura 5.3 Observações removidas em função da presença de caminhões na faixa da esquerda .......................... 57

Figura 5.4 Observações removidas pela presença de motos na corrente de tráfego . . . 57

Figura 5.5 Observações descartadas pela ausência ou totalidade de caminhões na faixa da direita . . . . . . . . . . . . . . . . . . . 58

Figura 5.6 Variação do fator de equivalência veicular em função da porcentagem de caminhões após a aplicação dos primeiros cinco filtros . . . . . . . . . . . 59

Figura 5.7 Ocorrência de $E(i) \leq 1$ para densidade na faixa de fluxo básico $\ldots \ldots$. . . . 60

Figura 5.8 Fração de observações removidas em função da densidade mínima nas faixas de fluxo básico ou misto . . . . . . . . . . . . . . . . . . . 60 
Figura 5.9 Observações descartadas em função da densidade limite $k<3$ veic(km·faixa) 61

Figura 5.10 Variação do fator de equivalência veicular em função da porcentagem de caminhões após a remoção dos dados com $k<3$ veic/(km·faixa) . . . . . 61

Figura 5.11 Quantidade de dados removidos por $E(i) \leq 1 \ldots$. . . . . . . . . . . 62

Figura 5.12 Variação do fator de equivalência veicular em função da porcentagem de caminhões após a remoção dos dados com $E(i)<1 \ldots \ldots 2$

Figura 6.1 Relação entre fator de equivalência veicular e porcentagem de caminhões na faixa da direita para quatro densidades na faixa da esquerda, $k_{d}=5 \mathrm{veic} /(\mathrm{km} \cdot$ faixa $) 68$

Figura 6.2 Relação entre fator de equivalência veicular e porcentagem de caminhões obtidos através de dados empíricos para $4,5 \leq k_{d} \leq 5,5 \mathrm{veic} /(\mathrm{km} \cdot$ faixa $)$. . 69

Figura 6.3 Frequência acumulada relativa em função do fator de equivalência veicular 70

Figura 6.4 Funções obtidas para o fator de equivalência veicular para a classe de inclinação $1(0 \%<I \leq 2 \%)$, para os níveis de serviço A a D . . . . . . . . 70

Figura 6.5 Funções obtidas para aproximar uma curva às estimativas do fator de equivalência veicular obtidas para o greide $2(2 \%<I \leq 4 \%)$, para os diferentes níveis de serviço . . . . . . . . . . . . . . . . . . . 71

Figura 6.6 Funções obtidas para aproximar uma curva às estimativas do fator de equivalência veicular obtidas para o greide $3(4 \%<I)$, para os diferentes níveis de serviço . . . . . . . . . . . . . . . . 72

Figura 6.7 Comparação entre as curvas dos níveis de serviço para a mesma classe de greide . . . . . . . . . . . . . . . . . . 75

Figura 6.8 Comparação entre as curvas das classes de greide para um mesmo nível de

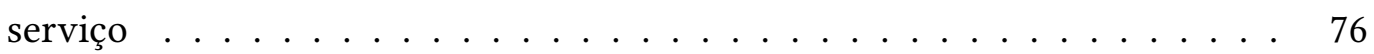

Figura 6.9 Comparação entre os estudos para a classe de greide 1, para os diferentes níveis de serviço . . . . . . . . . . . . . . . . . . . . . . 79

Figura 6.10 Comparação entre os estudos para a classe de greide 2, para os diferentes níveis de serviço . . . . . . . . . . . . . . . .

Figura 6.11 Comparação entre os estudos para a classe de greide 3, para os diferentes níveis de serviço . . . . . . . . . . . . . . . . . . . . . 


\section{Lista de tabelas}

Tabela 4.1 Pontos de coleta utilizados . . . . . . . . . . . . . . . . 51

Tabela 5.1 Velocidade média crítica na faixa da esquerda para o fluxo congestionado . 56

Tabela 6.1 Limites de declividades para cada classe de greide . . . . . . . . . . . 66

Tabela 6.2 Identificação da classe de greide para cada local de coleta . . . . . . . . . 66

Tabela 6.3 Limites de densidade para os níveis de serviço . . . . . . . . . . . . . . 67

Tabela 6.4 Observações em cada um dos grupos de nível de serviço e greides . . . . . 68

Tabela 6.5 Parâmetros de $a$ e $b$ das funções $E(i)=a \cdot p(i)^{-b}$ das Figuras 6.4 a $6.6 \ldots 73$

Tabela 6.6 Fator de equivalência para greides, níveis de serviço e porcentagem de caminhões . . . . . . . . . . . . . . . . 73

Tabela 6.7 Características do local de instalação dos laços indutivos: extensão do greide, distância entre o laço e o início do trecho inclinado . . . . . . . . . . 78

Tabela 6.8 Comparação dos cálculos do nível de serviço . . . . . . . . . . . . . 82

Tabela A.1 Formatação dos dados da Rodovia Castelo Branco . . . . . . . . . . . . . 96

Tabela A.2 Formatação dos dados da Rodovia dos Bandeirantes . . . . . . . . . . . 96

Tabela B.1 Quantidade de ocorrências com $E(i) \leq 1$ para densidade na faixa de fluxo básico . . . . . . . . . . . . . . . . . . . 97

Tabela B.2 Quantidade de observações removidas em função da densidade mínima nas faixas de fluxo básico ou misto . . . . . . . . . . . . . . . . 98 



\section{Sumário}

1 Introdução 19

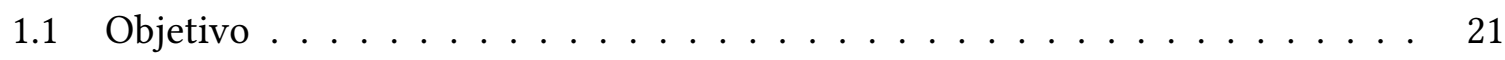

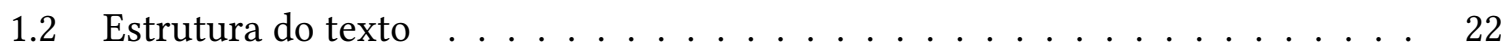

2 Revisão bibliográfica 23

2.1 Estudos na mesma linha de pesquisa no Brasil . . . . . . . . . . . . . 23

2.2 Teoria do fluxo de tráfego . . . . . . . . . . . . . . . . . . 24

2.3 Distribuição nas faixas de tráfego em uma mesma seção . . . . . . . . . . . . 24

2.4 Equivalência veicular . . . . . . . . . . . . . . . . . 26

2.4 .1 Os fatores de equivalência no tráfego . . . . . . . . . . . 26

2.4.2 Equivalente veicular na qualidade de serviço . . . . . . . . . . . 27

$3 \quad$ Estimativa dos fatores de equivalência veicular 41

3.1 Características do tráfego nas rodovias de pista dupla observadas . . . . . . . 41

3.2 Equivalência veicular a partir do método de Huber . . . . . . . . . . . . . . . 45

4 Dados Coletados $\quad 49$

4.1 Dados de tráfego . . . . . . . . . . . . . . . . . . . . . 49

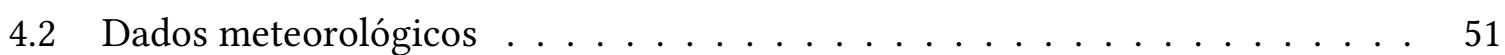

4.3 Estruturação do banco de dados . . . . . . . . . . . . . . . . . . . 52

$5 \quad$ Tratamento de Dados $\quad 55$

5.1 Filtro 1: Observações sob tempo chuvoso . . . . . . . . . . . . 55

5.2 Filtro 2: Observações sob fluxo congestionado . . . . . . . . . . . . 55

5.3 Filtro 3: Existência de veículos comerciais na faixa da esquerda . . . . . . . 57

5.4 Filtro 4: Motos na corrente de tráfego . . . . . . . . . . . . . 57 
5.5 Filtro 5: Intervalos com $\mathrm{p}(\mathrm{i})=100 \%$ ou $0 \%$ na faixa da direita . . . . . . 57

5.6 Remoção das observações em que a qualidade de serviço não é a mesma nas faixas de tráfego ........................... 58

5.6.1 Filtro 6: Remoção de observações em função da densidade . . . . . . . 59

5.6.2 Filtro 7: Equivalentes veiculares menores ou iguais a $1,0 \ldots \ldots 2$

6 Resultados $\quad 65$

6.1 Parâmetros de agrupamento . . . . . . . . . . . . . . . 65

6.1 .1 Agrupamento em função dos greides . . . . . . . . . . . . . 65

6.1.2 Definição dos limites dos níveis de serviço . . . . . . . . . . . . . 67

6.2 Variação do fator de equivalência em função da porcentagem de veículos pesados . . . . . . . . . . . . . . . . . . . . 68

6.3 Análise dos resultados . . . . . . . . . . . . . . . . . . . . 73

6.3.1 Comparação por greide . . . . . . . . . . . . . . . . . 74

6.3.2 Comparação por nível de serviço . . . . . . . . . . . . . . . 75

6.4 Análise comparativa com outros estudos . . . . . . . . . . . . . . . . 77

6.5 Considerações finais . . . . . . . . . . . . . . . . . . 80

7 Conclusões e Recomendações $\quad 83$

7.1 Recomendações . . . . . . . . . . . . . . . . . . . . . 85

$\begin{array}{ll}\text { Referências } & 87\end{array}$

$\begin{array}{ll}\text { Apêndices } & 91\end{array}$

APÊNDICE A Apêndice A $\quad 93$

A.1 Dados da Rodovia Castelo Branco . . . . . . . . . . . . . . . . . . . . . . . 93

A.2 Dados da Rodovia dos Bandeirantes . . . . . . . . . . . . . . . . . . . . . 94

$\begin{array}{lll}\text { APÊNDICE B } & \text { Apêndice B } & 97\end{array}$ 


\section{Capítulo}

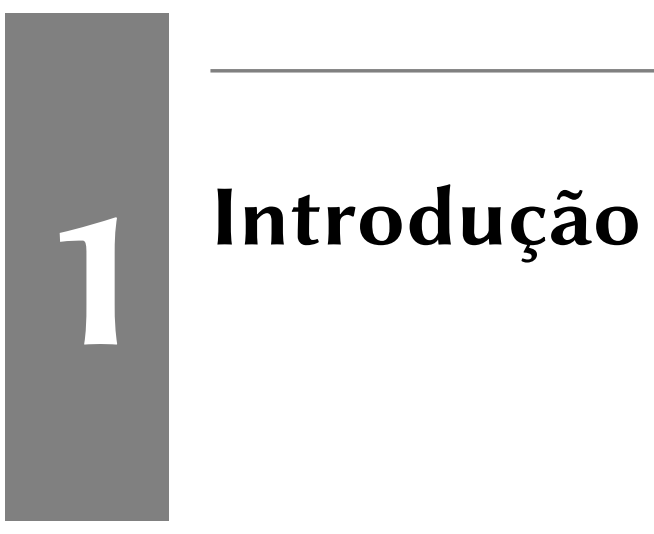

O modo rodoviário é o mais importante na matriz de transporte brasileira, representando mais de $60 \%$ do volume transportado, com quase 500 milhões de TKU (tonelada quilômetro útil) por ano (CNT, 2015). Este modo de transporte é de vital importância para a locomoção de passageiros, especialmente à curta e média distância. No estado de São Paulo, mais de 5.000 quilômetros estão sob a responsabilidade de concessionárias rodoviárias. Mais de 75\% dessa extensão é composta por rodovias de pista dupla, representando os principais eixos de transporte do estado (DER, 2014).

Dentro desse cenário, identificar aquelas rodovias que apresentam pior qualidade de serviço e que devem receber investimentos para as suas ampliações se faz essencial para garantir as condições necessárias ao bom desenvolvimento do país. A otimização do sistema viário e o aumento da sua eficiência requerem métodos que permitam avaliar, com confiança, as condições operacionais das rodovias. Do ponto de vista dos gestores, a avaliação das condições operacionais serve para determinar a qualidade de serviço em cada trecho ou para facilitar o planejamento de intervenções (tais como estimar os efeitos de interrupção de faixas para execução de obras); planejar a realização de operações especiais (por exemplo, operação subida ou descida com reversão de faixas), etc. Para os planejadores, a avaliação das condições operacionais fornece subsídios para identificar trechos que necessitam de ampliação da capacidade, estimar a velocidade média e o tempo médio de viagem da corrente de tráfego, ou ainda, planejar características de novos segmentos da rede viária (número de faixas). 
Para verificar os níveis de serviço dos diferentes trechos de rodovia e assim identificar onde devem ser construídas faixas adicionais pelos concessionários de rodovias, os órgãos reguladores das rodovias brasileiras utilizam procedimentos de diferentes versões do HCM (Highway Capacity Manual), como 2000, 1994 e até 1985 (ANDRADE; RODRIGUES-SILVA; PUTY FILHO, 2011). Em alguns editais, são utilizados métodos de versões recentes do HCM, em conjunto com equivalentes veiculares de versões antigas. Isso demonstra que não existe um consenso na escolha da versão do manual a ser utilizada no Brasil.

O próprio HCM ressalta que a maioria das bases de dados, parâmetros e aplicações existentes em suas versões são da América do Norte, particularmente dos Estados Unidos. A utilização dos valores e métodos de análise fora da América do Norte requer a calibração das equações e procedimentos para condições locais. Desta forma, deve-se avaliar diferenças na composição do tráfego, nas características dos condutores e nos parâmetros relacionados à geometria das rodovias (TRB, 2010).

Nos Estados Unidos, o Departamento de Transporte da Flórida, desenvolve e mantém o seu próprio manual de qualidade/nível de serviço (FDOT, 2013). O documento fornece as diretrizes gerais de como os métodos de análise do HCM devem ser utilizados na avaliação e desenvolvimento do nível de serviço e capacidade em rodovias da Flórida. Além disso, são fornecidas orientações das variações dos valores que devem ser utilizados nas variáveis de entrada nos métodos de análise (MODI et al., 2014).

As rodovias brasileiras apresentam peculiaridades tanto em relação à composição do tráfego (com grande porcentagem de veículos pesados), às características dos caminhões (relação massa/potência maiores que as encontradas nas rodovias dos EUA), como na imposição de um limite de velocidade menor para veículos pesados. Assim, a utilização direta do HCM para rodovias brasileiras não apresenta um embasamento técnico-cientifico desejável (SETTI, 2009). Dessa forma, torna-se essencial definir valores de parâmetros que poderão ser utilizados na avaliação da qualidade de serviço de rodovias locais.

No Brasil, já foram realizados estudos para adaptar parâmetros e equações adotadas no HCM. Os fatores de equivalência veicular de caminhões em rodovias de pista dupla estão entre os parâmetros estudados. Esses fatores foram obtidos a partir de cenários rodados em 
simuladores de tráfego, que foram calibrados a partir de dados coletados em campo (DEMARCHI, 2000; CUNHA, 2007). No presente estudo, para calcular os equivalentes veiculares, foram utilizados dados empíricos, ou seja, utilizaram-se diretamente os dados de tráfego coletados nas rodovias, sem a utilização dos simuladores. Desta forma, foi possível comparar os resultados dos fatores obtidos através de simulações de tráfego com os calculados através de dados empíricos.

\subsection{Objetivo}

A meta desta pesquisa consiste em estudar o impacto combinado do limite de velocidade diferenciado por tipo de veículo e das características de desempenho dos caminhões nos fatores de equivalência de veículos pesados, através da análise de dados de tráfego coletados em rodovias de pista dupla no estado de São Paulo. Para alcançar a meta proposta, foram estabelecidos os seguintes objetivos complementares:

1. Definir um método para estimar o fator de equivalência veicular para cada um dos intervalos em que os dados foram coletados, a partir de observações diretas de fluxos veiculares, admitindo que o nível de serviço é o mesmo em todas as faixas de tráfego durante cada intervalo de tempo;

2. Selecionar um conjunto de locais, em rodovias de pista dupla, cujas características permitam obter dados de fluxo e velocidade adequados para aplicar o método proposto;

3. Estudar a variação do fator de equivalência veicular em função da porcentagens de caminhões na faixa da direita, para diferentes níveis de serviço da via e distintos grupos de declividades da pista; e

4. Comparar os fatores de equivalência veicular obtidos nesta pesquisa com outros estudos, verificando as diferenças entre os resultados obtidos por dados empíricos e os obtidos em simuladores de tráfego. 


\subsection{Estrutura do texto}

O presente documento foi dividido em sete capítulos. Este primeiro capítulo define a justificativa e os objetivos da pesquisa. No capítulo 2 é apresentada a revisão bibliográfica sobre o tema abordado. Foi desenvolvida uma equação para o cálculo dos fatores de equivalência veicular, sendo que a dedução está apresentada no capítulo 3.

A criação de um banco com os dados de tráfego e as respectivas condições meteorológicas é descrita no capítulo 4 . O capítulo 5 apresenta a sequência de filtros utilizada a fim de obter apenas os intervalos que continham dados coerentes. No capítulo 6 foram determinadas as diferentes curvas de fator de equivalência veicular em função da porcentagem de caminhões na faixa da direita. Este capítulo também apresenta a análise e comparação dos resultados obtidos em outros estudos. Por fim, no capítulo 7, foram descritas as conclusões obtidas nessa pesquisa e as recomendações dadas para futuras investigações acadêmicas. 


\section{Capítulo}

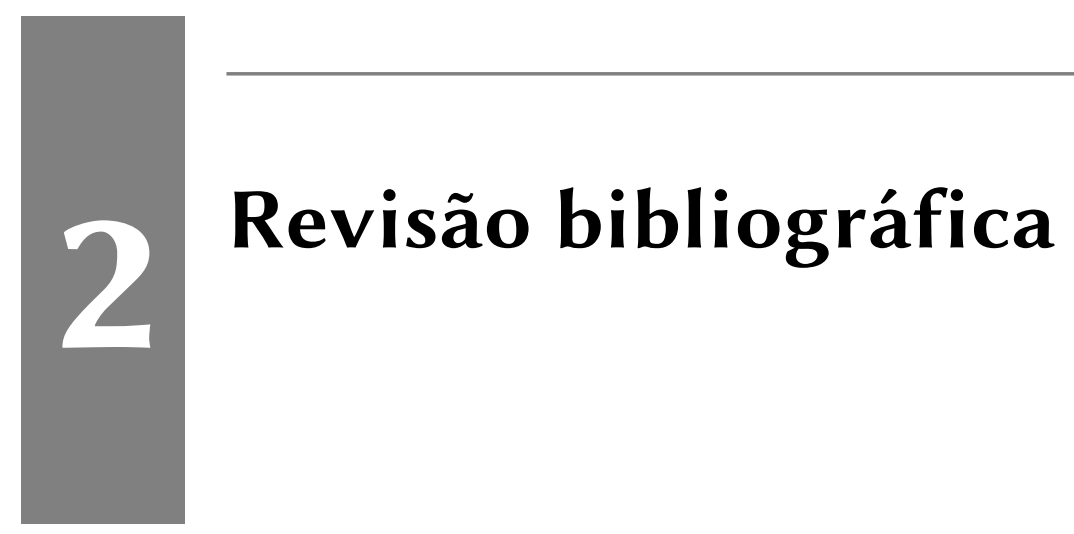

Neste capítulo é apresentado o levantamento da literatura referente ao tema proposto nesta pesquisa. São apresentadas referências bibliográficas sobre a teoria do fluxo de tráfego, a distribuição de veículos em uma mesma seção de rodovia e as diferentes formas de cálculo dos equivalentes veiculares na qualidade de serviço de rodovias.

\subsection{Estudos na mesma linha de pesquisa no Brasil}

Na mesma linha de pesquisa deste trabalho, no Brasil, é possível citar três fontes relacionadas com a pesquisa aqui apresentada. Demarchi (2000) estudou a influência que os veículos pesados exercem tanto na capacidade quanto no nível de serviço de rodovias de pista dupla. Através de simulações com o software INTEGRATION foram obtidos equivalentes veiculares para diversas combinações de comprimentos e magnitudes de greides, porcentagens de caminhões e volumes de tráfego. Cunha (2007) avaliou o impacto da velocidade dos automóveis como medida de desempenho alternativa à densidade para estimar fatores de equivalência veicular de caminhões. Através do simulador CORSIM, foram obtidos os equivalentes veiculares para diferentes magnitudes de greides, comprimentos de rampas, velocidade de fluxo livre, níveis de serviço e porcentagens de caminhões considerando como critério de equivalência velocidade e densidade. Andrade (2012) calibrou um modelo que descreve a relação fluxo velocidade em autoestradas e rodovias de pista dupla, considerando as recomendações indicadas quando da elaboração do modelo do HCM 2010. 
Nesse contexto, o estudo apresentado neste documento avaliou o impacto dos veículos pesados em rodovias de pista dupla. Diferentemente das pesquisas de Demarchi (2000) e Cunha (2007), utilizaram-se diretamente dados de fluxo e velocidade coletados em campo. Ou seja, não foram utilizadas simulações para calcular os fatores de equivalência veicular. Os dados utilizados provém da mesma base de dados usada no estudo desenvolvido por Andrade (2012).

\subsection{Teoria do fluxo de tráfego}

A teoria do fluxo de tráfego procura descrever, com modelos matemáticos, a interação entre veículos, motoristas e a infraestrutura viária, como o sistema de rodovias e todos os seus elementos operacionais. Essa teoria é indispensável para os modelos e ferramentas que são usados no projeto e na operação de ruas e estradas (GARTNER; MESSER; RATHI, 1997). Os estudos científicos desta teoria iniciaram-se por volta de 1930. Um dos primeiros foi conduzido por Greenshields. Em sua pesquisa foi identificada a hipótese de que a relação entre velocidade e densidade é linear (GREENSHIELDS, 1935).

O método de análise do nível de serviço em rodovias sugerido pelo HCM é definido por curvas fluxo-velocidade para condições básicas, em que alguns fatores de ajustes são aplicados para determinar a velocidade de fluxo livre e a taxa de fluxo, em carros de passeio equivalente (cpe). Essas curvas fazem parte das relações existente entre a densidade, o fluxo e a velocidade (ROESS; PRASSAS; McSHANE, 2004). A equação fundamental do tráfego relaciona essas três variáveis, identificadas em uma corrente de tráfego. Portanto, obtendo-se duas dessas variáveis é possível determinar a relação entre as três. Como a velocidade e o fluxo são os parâmetros mais fáceis de serem coletados em campo, costuma-se calcular a densidade a partir das duas variáveis.

\subsection{Distribuição nas faixas de tráfego em uma mesma seção}

Alguns estudos investigam a distribuição dos veículos nas faixas de tráfego em uma mesma seção da rodovia. Destacam-se estudos realizados na Europa, onde a legislação prevê que, em rodovias com duas ou mais faixas de tráfego, os motoristas devem trafegar pela faixa mais 
próxima ao acostamento, sendo que as faixas mais próximas ao canteiro central devem ser utilizadas apenas para ultrapassagem. Alguns fatores que podem afetar esses modelos estão relacionados com a diferença de limites de velocidades estabelecidos. Diferenças culturais entre os comportamentos dos motoristas e a permissão da ultrapassagem também afetam a distribuição dos veículos nas faixas de tráfego (YOUSIF; AL-OBAEDI; HENSON, 2012).

Wu (2006) estudou a distribuição dos veículos nas faixas de tráfego através de funções matemáticas. O modelo proposto foi calibrado para dados coletados em rodovias de duas e três faixas por sentidos localizadas na Alemanha. Para os dados coletados, em rodovias com duas faixas por sentido, quando o fluxo se aproxima da capacidade, $32 \%$ dos veículos utilizam a faixa mais próxima ao acostamento. Em rodovias com três faixas por sentido esse valor é de $21 \%$. Esses valores estão abaixo da distribuição homogênea, que seria de 50\% em rodovias com duas faixas e $33 \%$ em rodovias com três faixas. Em observações com fluxo baixo (1.000 veic/h), em rodovias com duas faixas, aproximadamente $55 \%$ dos veículos utilizam a faixa mais próxima ao canteiro central. Em rodovias com três faixas, para o mesmo fluxo, as duas faixas mais próximas ao acostamento apresentam mais de $40 \%$ dos veículos cada, enquanto a faixa mais próxima ao canteiro central apresenta menos de $20 \%$ dos veículos.

Duret, Ahn e Buisson (2012) estudaram a distribuição dos veículos nas faixas de tráfego em rodovias com três faixas por sentido, utilizando observações coletadas em rodovias francesas. Além disso, estudou-se o efeito da redução do limite de velocidade quando a rodovia atinge um determinado carregamento. Observou-se que o fluxo na faixa mais próxima ao acostamento é muitas vezes menor do que a sua capacidade e diminui ou estabiliza conforme o fluxo total aumenta. Foram descartadas observações com fluxo menor do que 1800 veic/h, uma vez que não foi observada uma tendência no comportamento dos motoristas nessa faixa de volume.

O limite de velocidade nas rodovias em que foram coletadas as observações é de $130 \mathrm{~km} / \mathrm{h}$. Porém, os autores identificaram que as velocidades de fluxo livre observadas são $125 \mathrm{~km} / \mathrm{h}$ para a faixa mais próxima ao canteiro central, $110 \mathrm{~km} / \mathrm{h}$ para a faixa central e $90 \mathrm{~km} / \mathrm{h}$ para a faixa próxima ao acostamento. Por questões operacionais e de segurança, quando o fluxo ultrapassa os $3000 \mathrm{veic} / \mathrm{h}$, o limite de velocidade é reduzido para $110 \mathrm{~km} / \mathrm{h}$. Após a implementação desse limite de velocidade diferenciado, as velocidades de fluxo livre caíram para $110 \mathrm{~km} / \mathrm{h}$ na 
faixa da esquerda, $100 \mathrm{~km} / \mathrm{h}$ na faixa central e $90 \mathrm{~km} / \mathrm{h}$ na faixa da direita. Verificou-se que, com esse limite de velocidade diferenciado, a utilização da faixa mais próxima ao canteiro central aumenta. Observou-se também que, esse efeito é menor quando os caminhões não estão presentes na corrente de tráfego.

A distribuição dos veículos em rodovias de duas, três e quatro faixas por sentido do Reino Unido foi pesquisada por Yousif, Al-Obaedi e Henson (2012). Foram gerados modelos matemáticos, que utilizavam três variáveis para a obtenção das porcentagens de veículos em uma determinada faixa: quantidade de caminhões na rodovia, fluxo total dos veículos e velocidade da corrente de tráfego. Os modelos que utilizaram fluxo total e fluxo de caminhões, ou essas duas variáveis em conjunto com a velocidade, foram os modelos que apresentaram os melhores resultados.

Os resultados obtidos sugerem que em rodovias com duas faixas por sentido, a utilização das faixas é igual (50\% em cada faixa de tráfego) quando o fluxo atinge 2.000 veic/h. Em rodovias com três ou mais faixas de tráfego, o carregamento fica mais concentrado na faixa mais próxima ao canteiro central quando o carregamento está abaixo de 500 veic/h. Quanto mais o fluxo estiver próximo à capacidade, mais bem distribuído se torna o carregamento das faixas.

\subsection{Equivalência veicular}

O fator de equivalência veicular é usado em diversas áreas da engenharia de transportes, para transformar uma população formada por vários tipos de veículos numa população uniforme, composta por um veículo padrão, visando facilitar a análise de um problema. A forma de calcular o fator de equivalência depende do propósito de cada tipo de análise.

\subsubsection{Os fatores de equivalência no tráfego}

No dimensionamento de pavimentos, o fator de equivalência de carga converte os danos causados pela carga de diferentes configurações de eixos comerciais em danos causados por um eixo padrão (eixo simples de rodas duplas de $80 \mathrm{kN}$ ). Esse fator permite projetar o pavimento com base na previsão de passagens desse eixo padrão durante o tempo de serviço da rodovia (BALBO, 2007). 
Para fins de cobrança de pedágio, a equivalência veicular toma como base a tarifa cobrada dos veículos de passeio; o valor cobrado de um veículo comercial é o produto da tarifa básica de pedágio pelo fator de equivalência para uma dada classe veicular. Nos pedágios do estado de São Paulo, adota-se como fator de equivalência o número de eixos do veículo pesado (ST-SP, 1997).

$\mathrm{Na}$ análise da operação de rodovias e vias urbanas, o veículo padrão é o carro de passeio (automóvel). Através de fatores de equivalência veicular, os caminhões, ônibus e veículos de recreação são convertidos em carros de passeio equivalentes. A estimativa de valores para esses equivalentes veiculares pode ser feita com base no headway, no atraso, na formação de pelotões, na velocidade, no tipo de veículo, no fluxo ou no tempo de viagem (ELEFTERIADOU; TORBIC; WEBSTER, 1997).

Chandra, Zala e Kumar (apud MEHAR; CHANDRA; VELMURUGAN, 2014) compararam cinco métodos para estimar fatores de equivalência veicular, utilizando dados de campo coletados em uma seção de pista simples em uma rodovia na Índia. Foi encontrada uma grande variação dos valores dos equivalentes veiculares para cada um dos métodos calculados, indicando que os resultados dependem do método escolhido.

\subsubsection{Equivalente veicular na qualidade de serviço}

A qualidade de serviço descreve como quão bem a infraestrutura ou o serviço que uma rodovia opera, sob a perspectiva do usuário. O HCM define os níveis de serviço em seis categorias, em uma escala de A até $\mathrm{F}$, sendo que o nível de serviço A representa a melhor condição e $\mathrm{F}$ a pior. Esse conceito está associado a faixas de medidas de desempenho, determinadas de forma quantitativa pelo HCM (TRB, 2010).

O termo fator de equivalência veicular foi usado pela primeira vez na segunda edição do HCM (HRB, 1965). Foi definido como "o número de carros de passeio deslocados no fluxo de tráfego por um caminhão ou ônibus nas condições de rodovia e tráfego existentes” (HRB, 1965, p. 19). Nessa versão, os fatores foram fornecidos para rodovias de pista simples, rodovias de pista dupla e autopistas. Para as rodovias de pista dupla, os fatores foram calculados no atraso devido a caminhões, baseado no método Walker, em combinação com curvas de desempe- 
nho de caminhões em rampas (velocidade-distância percorrida em rampas). O atraso causado por caminhões em diferentes rampas foram estimadas e usadas como base para o cálculo dos fatores de equivalência veicular.

Na versão mais recente do HCM (TRB, 2010), esse fator é definido como "o número de carros de passeio que resultam nas mesmas condições operacionais que um único veículo pesado, em um tipo particular de rodovia, tráfego e condição de controle” (TRB, 2010, p. 9-13). Esses são valores numéricos que convertem a corrente de tráfego composta por diferentes tipos de veículos em uma corrente de tráfego equivalente, composta exclusivamente por carros de passeio (veículo padrão).

Nos próximos itens são apresentados diferentes modelos em que são obtidos os equivalentes veiculares. O HCM apresenta tabelas com os fatores de equivalência calculados para rodovias norte-americanas. Outros modelos mostram como variáveis o atraso, o headway, a velocidade, as áreas ocupadas pelos veículos, as taxas de fluxo e a densidade. Por fim, é apresentado o método proposto por Huber (1982), que foi o método utilizado no desenvolvimento desta pesquisa.

\subsubsection{Cálculo do fluxo equivalente em rodovias de pista dupla pelo HCM (TRB, 2010)}

O HCM é uma das principais referências no cálculo de capacidade e nível de serviço das rodovias de pista dupla. Desta forma, os volumes de tráfego observados nas rodovias devem ser convertidos para a unidade padrão (carros de passeio equivalentes), cpe/(h·faixa), utilizando-se a expressão

$$
v_{p}=\frac{V}{P H F \cdot N \cdot f_{H V} \cdot f_{p}},
$$

em que $\quad v_{p}: \quad$ taxa de fluxo equivalente, em cpe/(h.faixa);

$V: \quad$ volume horário observado, em veic/h;

$P H F$ : fator de hora pico;

$N: \quad$ número de faixas de tráfego;

$f_{H V}:$ fator de ajuste para veículos pesados; e

$f_{p}: \quad$ fator de ajuste para tipo de motorista. 
Para obter-se a taxa de fluxo equivalente, através da Equação 2.1, é necessário calcular o fator de ajuste para veículos pesados, que permite converter caminhões, ônibus e veículos de recreação em carros de passeio equivalentes, através da expressão

$$
f_{H V}=\frac{1}{1+P_{T}\left(E_{T}-1\right)+P_{R}\left(E_{R}-1\right)}
$$

em que $\quad P_{T}:$ fração de caminhões e ônibus na corrente de tráfego;

$P_{R}: \quad$ fração de veículos de recreação na corrente de tráfego;

$E_{T}$ : fator de equivalência de um caminhão ou ônibus na corrente de tráfego; e

$E_{R}:$ fator de equivalência de um veículo de recreação na corrente de tráfego.

O HCM (TRB, 2010) apresenta tabelas com o fator de equivalência veicular para caminhões, ônibus e veículos de recreação para trechos com diferentes declividades, comprimento dos aclives e porcentagens de veículos pesados na corrente de tráfego (TRB, 2010, Tabelas 1111 e 11-12). Dessa forma, aplicando-se as Equações 2.1 e 2.2 é possível converter o fluxo misto, composto por automóveis e caminhões, em fluxo básico (composto apenas por automóveis). Utiliza-se esse fluxo, em conjunto com as curvas velocidade-fluxo, para obter os níveis de serviço em diferentes segmentos de rodovias.

\subsubsection{Estudos baseados no atraso}

Alguns estudos usam o atraso relativo entre os veículos para calcular o equivalente veicular. Nesse contexto, Cunagin e Messer (1983) calcularam fatores de equivalência veicular através da análise de 14 tipos de veículos, em rodovias de pista dupla. Foram avaliados a geometria da rodovia (comprimento, inclinação e número de faixas), as características de desempenho dos veículos (comprimento, peso e potência) e o fluxo de tráfego (volume, separação direcional, porcentagem e velocidade dos veículos). O fator de equivalência veicular foi estimado utilizando a relação entre atraso causado em um carro de passeio por outro tipo de veículo 
e o atraso causado por um carro de passeio em um outro carro de passeio. Essa relação é apresentado na seguinte expressão:

$$
E_{i j}=\frac{\left(D_{i j}-D_{b a s e}\right)}{D_{b a s e}}
$$

em que $\quad E_{i j}: \quad$ fator de equivalência do veículo tipo $i$ sob a condição $j$;

$D_{i j}$ : atraso de carro de passeio por causa do veículo tipo $i$ sob a condição $j$; e

$D_{\text {base }}$ : atraso de carro de passeio por causa de outro carro mais lento.

Os autores não apresentaram o fator de equivalência de cada um dos veículos, devido a quantidade de observações obtidas para alguns tipos de veículos. Na grande maioria dos resultados apresentados, conforme aumenta a porcentagem de caminhões, menor o equivalente veicular. Também foi constatado que, conforme aumenta a inclinação da pista ou o volume de veículos na rodovia, maior o $E_{i j}$.

Uma das desvantagens desse método é a necessidade de uma função que permita calcular o atraso veicular causado na ultrapassagem de veículos mais lentos.

\subsubsection{Estudos baseados no headway}

Outro método utilizado para o calculo dos equivalentes veiculares é relacionando os headways dos veículos. Krammes e Crowley (1986) sugerem que o efeito causado pelos caminhões na corrente de tráfego pode ser atribuído a três fatores: (1) os caminhões são maiores do que os automóveis; (2) têm desempenho operacional inferior ao dos automóveis; e (3) além de ter um impacto físico nos veículos próximos e um impacto psicológico nos motoristas desses veículos.

Quando o estudo foi elaborado, o HCM fornecia fatores de equivalência veicular para três tipos de rodovias: autoestradas, rodovias rurais e vias urbanas. O estudo indicou que a importância relativa dos três fatores citados anteriormente diferem entre os tipos de rodovias. Portanto, a formulação para estimar os fatores de equivalência veicular para um tipo de rodovia, deve incorporar variáveis que refletem as condições que contribuem para o impacto dos veículos pesados na qualidade de serviço para aquele tipo de rodovia. 
O cálculo do $E_{T}$ deste estudo utilizou a expressão que considera os headways entre os veículos como variáveis, apresentado pela seguinte expressão:

$$
E_{T}=\frac{\left[(1-p)\left(\bar{h}_{M_{P T}}+\bar{h}_{M_{T P}}-\bar{h}_{M_{P P}}\right)+p \cdot \bar{h}_{M_{T T}}\right]}{\bar{h}_{M_{P P}}},
$$

em que $\quad E_{T}:$ fator de equivalência veicular;

p: fração de caminhões na corrente de tráfego; e

$\bar{h}_{M_{j k}}$ : headways para cada combinação de veículos, sendo $j$ o veículo seguidor e $k$ o veículo líder (P para carro de passeio e T para caminhões).

Duas considerações foram feitas sobre a Equação 2.4:

$$
\begin{gathered}
\bar{h}_{M_{P}}=\bar{h}_{M_{P T}}=\bar{h}_{M_{P P}}, \\
\bar{h}_{M_{T}}=\bar{h}_{M_{T P}}=\bar{h}_{M_{T T}} .
\end{gathered}
$$

Desta forma, substituindo-se as Equações 2.5 e 2.6 na Equação 2.4, tem-se a seguinte expressão:

$$
E_{T}=\frac{\bar{h}_{M_{T}}}{\bar{h}_{M_{P}}} .
$$

Porém, as considerações das Equações 2.5 e 2.6 podem não estar corretas. Aghabayk, Sarvi e Young (2012) verificaram que, quando são comparadas as quatro combinações possíveis (automóvel-automóvel, automóvel-caminhão, caminhão-automóvel e caminhão-caminhão), a distância entre dois veículos pesados é a maior. Também concluiu-se que o espaçamento entre dois automóveis é o menor. Quando são comparados os outros dois casos restantes, se a velocidade da corrente é inferior a $30 \mathrm{~km} / \mathrm{h}$, o caso automóvel-caminhão é maior que caminhãoautomóvel. A relação caminhão-automóvel é menor caso a velocidade ultrapasse os $30 \mathrm{~km} / \mathrm{h}$. Desta forma, as simplificações feitas no estudo de Krammes e Crowley (1986) podem induzir erros importantes na estimativa do $E_{T}$. 


\subsubsection{Estudos baseados na velocidade e área projetada dos veículos}

Estudos realizados na Índia utilizam a relação entre a velocidade e a área projetada dos veículos na rodovia como forma de se obter os equivalentes veiculares. Chandra (2004) apresentou uma forma de cálculo do fator de equivalência veicular com a divisão da relação entre as velocidades dos automóveis e dos veículos pesados pela relação da área ocupada por esses veículos. Desta forma, para o cálculo do fator de equivalência foi utilizada a seguinte equação:

$$
E_{T}=\frac{V_{c} / V_{i}}{A_{c} / A_{i}}
$$

em que $E_{T}$ : fator de equivalência do veículo do tipo $i$;

$V_{c}: \quad$ velocidade dos automóveis;

$V_{i}: \quad$ velocidade do veículo do tipo $i$;

$A_{c}: \quad$ área retangular projetada de um carro; e

$A_{i}: \quad$ área retangular projetada do veículo do tipo $i$.

Bains, Ponnu e Arkatkar (2012) modelaram o tráfego de rodovias expressas da Índia no microssimulador de tráfego VISSIM. Esse software permite modelar automóveis e caminhões em rodovias e vias arteriais, possuindo parâmetros que definem o comportamento dos motoristas e o desempenho dos veículos. Sobre essas simulações, foram estudadas as variações de fatores de equivalência para diferentes categorias de veículos, utilizando-se a Equação 2.8. Foram simuladas diferentes condições de tráfego para seções de rodovias expressas em terreno plano.

Os autores calcularam fatores para os caminhões de dois eixos, ônibus, veículos comerciais leves e caminhões com mais de dois eixos. Em todas as categorias estudadas, os fatores decrescem com o aumento do fluxo de veículos. Também foi verificado que os valores decrescem quando a proporção dos veículos estudados aumenta na corrente de tráfego.

Mehar, Chandra e Velmurugan (2014) utilizaram o simulador VISSIM para gerar dados de fluxo-velocidade em rodovias interurbanas de pista dupla indianas. Alguns parâmetros do simulador foram calibrados para refletir o comportamento do fluxo misto, obtidos por observações de campo. Depois de calibrado, o simulador foi usado para obter a relação fluxovelocidade para carros e para cada uma das categorias de veículos estudados. Com a geração 
das simulações para diferentes carregamentos, foi possível calcular os fatores de equivalência em situações de tráfego que são pouco comuns de serem obtidas em coletas de campo. Através da Equação 2.8, os fatores de equivalência foram obtidos para diferentes carregamentos, porcentagens de veículos estudados na corrente, em rodovias com duas ou três faixas por sentido. Para os veículos pesados, conforme aumenta a sua porcentagem na corrente, menor o equivalente veicular. O fator de equivalência também é menor conforme aumenta o carregamento da rodovia.

\subsubsection{Estudos baseados nas taxas de fluxos e densidade}

Reilly e Seifert (1969) calcularam o fator de equivalência veicular comparando o fluxo de uma rodovia de pista dupla expressa, apenas com automóveis, e uma via local, na mesma seção, com automóveis e caminhões. Para cada uma das vias, foram coletados dados de fluxo-velocidade. Essas coletas não foram executadas ao mesmo tempo, sendo realizadas em dias diferentes para cada uma das vias. Os dados de fluxo-velocidades foram ajustados por polinômios de segundo grau que representam a velocidade $(u)$ em função do fluxo de tráfego $(q)$ :

$$
u=a \cdot q^{2}+b \cdot q+c
$$

O fluxo da via expressa, composto apenas por automóveis, foi considerado como o volume de carros de passeio equivalente. Para porcentagens de caminhões de 20, 40, 60 e 80\%, foram utilizadas as curvas referentes à via local. Assim, foi construído o gráfico com fluxo básico na ordenada e fluxo misto na abscissa. Utilizando esse gráfico, o fator de equivalência veicular foi calculado através da expressão

$$
q_{b}=C+E_{T}(T)
$$

em que $\quad q_{b}:$ quantidade de veículos, em carros de passeio equivalente;

$C: \quad$ quantidade de automóveis;

$E_{T}$ : fator de equivalência veicular; e

$T: \quad$ quantidade de caminhões. 
Os fatores de equivalência veicular, calculados para 20, 40, 60 e $80 \%$ de caminhões, variaram entre 1,6 e 1,9. Os autores identificaram que para volumes abaixo de 500 veic/(h·faixa) não foi possível determinar a relação entre o fluxo básico e o fluxo misto.

Linzer, Roess e McShane (1979) recalibraram o fator de equivalência veicular apresentado na edição de 1965 do HCM. Essa recalibração foi baseada em resultados de simulações conduzidos pelo MRI (Midwest Research Institute). Além disso, foram utilizados estudos de relação peso-potência e características de desempenho de caminhões conduzidas pela Pennsylvania State University. Através de ábacos gerados a partir das simulações feitas no MRI, os fatores de equivalência veicular foram calculados para diferentes porcentagens de caminhões, inclinações e comprimento de rampa. Foram calculados fatores para rodovias de pista dupla, com duas ou três faixas por sentido. A expressão utilizada no cálculo foi

$$
E_{T}=\frac{\left(q_{b}-q_{m} \cdot p\right)}{p \cdot q_{m}}
$$

em que $E_{T}$ : fator de equivalência veicular;

$q_{b}$ : fluxo básico, em automóveis/h;

$q_{m}: \quad$ fluxo misto, em veic/h; e

p: $\quad$ porcentagem de caminhões.

Os $E_{T}$ obtidos indicam que os valores decrescem quando a porcentagem de caminhões ultrapassa $10 \%$. Foi sugerido que, para altas porcentagens de caminhões, esses tendem a juntar-se, separando-se do resto do tráfego. Assim, seu fluxo torna-se menos interrompido e, embora o efeito cumulativo continua a aumentar, o efeito de cada caminhão decresce.

Alecsandru, Ishak e Qi (2012) fizeram um estudo simulando, através do software VISSIM, diferentes limites de velocidades para automóveis e caminhões. Também foi investigada a restrição do uso da faixa mais próxima ao canteiro central pelos caminhões. Diversos estudos sobre o impacto operacional e os benefícios de segurança relacionados com essas políticas de restrição são apresentados. Porém, não foram realizados estudos que capturem o efeito dessas políticas nos equivalentes veiculares. Foram examinados os efeitos dos fatores de equivalência para diferentes fluxos, composição de tráfego e a porcentagem de caminhões que não podem 
utilizar a faixa da esquerda. As diferenças consideradas nos limites de velocidades foram de $97 \mathrm{~km} / \mathrm{h}$ (60 milhas/h) para automóveis e $89 \mathrm{~km} / \mathrm{h}$ (55 milhas/h) para caminhões.

Para o cálculo do $E_{T}$, foram feitas simulações apenas com automóveis. Dessas simulações, foi coletado o tempo necessário para que uma quantidade determinada de automóveis percorresse toda a rede de tráfego. Quando foram introduzidos os caminhões nas simulações, foi observado quantos veículos percorreram essa rede durante o mesmo período. Dessa forma, foram calculados os fatores de equivalência veicular. Exemplo: em 45 minutos percorreram toda a rede de tráfego 2000 carros. No mesmo intervalo, em uma simulação com fluxo misto, passaram 1800 automóveis e 100 caminhões. Desta forma o $E_{T}=(2000-1800) / 100=2$.

Verificou-se que a proibição de caminhões em utilizar a faixa da esquerda pode aumentar o seu impacto no tráfego. Os autores apresentaram como possível explicação que a obrigatoriedade dos caminhões utilizarem a faixa da direita induz a maiores diferenças de velocidade entre as faixas da rodovia. Isso gera maior restrição tanto nas condições de condução, como na limitação de mudança de faixa e manobras de ultrapassagem.

Os autores fizeram modelos de regressão linear para definir os fatores de equivalência em função da porcentagem de caminhões na corrente de tráfego e da porcentagem de caminhões restritos à faixa mais próxima ao canteiro central, através da expressão:

$$
E_{T}=a+b \cdot P_{T}+c \cdot R C
$$

em que $\quad E_{T}$ : fator de equivalência veicular;

$a, b$ e $c$ : Constantes de ajustes da equação;

$P_{T}: \quad$ porcentagem de caminhões na corrente de tráfego; e

$R C: \quad$ porcentagem de caminhões proibidos na faixa da esquerda.

Os modelos foram obtidos para diferentes carregamentos da rodovia. A constante $a$ aumenta conforme o carregamento aumenta. A constante $b$ é negativa, indicando que conforme a porcentagem de caminhões aumenta na corrente de tráfego, menor o fator de equivalência. Além disso, geralmente o seu módulo é maior, conforme o carregamento aumenta. Por fim, a constante $c$ é positiva e aumenta com o crescimento do carregamento da rodovia. 


\subsubsection{Estudos baseados em impedância e taxas de fluxo}

Os fatores de equivalência estimados de acordo com o método originalmente proposto por Huber (1982), podem ser calculados através da relação entre os fluxos de duas correntes de tráfego, uma contendo caminhões trafegando junto com automóveis (fluxo misto) e outra corrente de tráfego apenas com automóveis (fluxo básico), considerando-se que as duas correntes apresentam um mesmo nível de impedância. A Figura 2.1 ilustra a relação fluxo-impedância, com a representação das curvas do fluxo misto e básico.

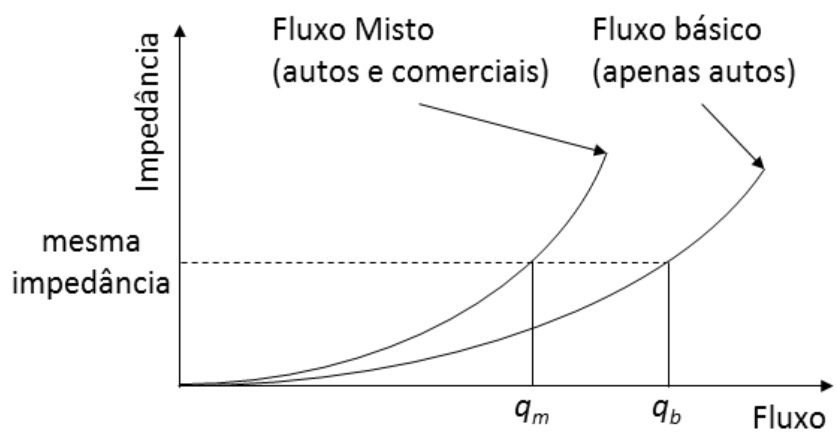

Figura 2.1 - Conceito de equivalência entre uma corrente de tráfego básica e mista (HUBER, 1982)

A impedância deve estar relacionada com a qualidade de serviço na rodovia. Para um dado valor da impedância, conhece-se o fluxo básico $q_{b}$ e o fluxo misto $q_{m}$. Admitindo-se que, para esses fluxos, as duas correntes de tráfego operam com qualidade de serviço idênticas, pode-se escrever que

$$
q_{b}=(1-p) q_{m}+p \cdot q_{m} \cdot E_{T},
$$

em que $\quad q_{b}$ : fluxo básico, somente com automóveis;

p: $\quad$ fração de caminhões na corrente de tráfego;

$q_{m}$ : fluxo misto, composto por $p$ caminhões e $(1-p)$ automóveis; e

$E_{T}$ : equivalente veicular dos caminhões na corrente de tráfego.

O estudo ainda demonstrou que os fatores de equivalência veicular podem ser calculados pela Equação 2.14

$$
E_{T}=\frac{1}{p}\left(\frac{q_{b}}{q_{m}}-1\right)+1 .
$$


Sumner, Hill e Shapiro (1984) generalizaram o método de Huber, para incluir mais de um tipo de caminhão na corrente de tráfego. Foi proposta a Equação 2.15, em que é possível calcular o equivalente veicular de um determinado veículo a ser analisado.

$$
E_{s}=\frac{1}{\Delta p}\left(\frac{q_{b}}{q_{s}}-\frac{q_{b}}{q_{m}}\right)+1
$$

em que $\quad E_{s}$ : fator de equivalência do veículo analisado;

$\Delta p$ : porcentagem do veículo analisado no fluxo $q_{m}$ e retirada da porcentagem de automóveis;

$q_{b}: \quad$ fluxo composto só por automóveis;

$q_{s}$ : fluxo para o qual deseja-se determinar os fatores de equivalência; e

$q_{m}$ : fluxo composto por automóveis e um ou mais tipos de caminhões.

Os autores utilizaram simulação de tráfego para a obtenção dos resultados. Os dados foram coletados em vias arteriais urbanas, entre interseções semaforizadas consecutivas. Foi feita a coleta de dados para 15 tipos de veículos, porém os dados foram agregados e apresentados fatores de equivalência veicular para nove veículos.

Elefteriadou, Torbic e Webster (1997) desenvolveram um método para calcular os fatores de equivalência veicular em rodovias de pista simples, autopistas e vias arteriais urbanas. Também foram apresentados valores de equivalentes veiculares para diferentes tipos de caminhões. Além disso, foi identificado o impacto nos fatores para diferentes variáveis de simulação. A medida de desempenho usada foi a velocidade, utilizando-se o simulador de tráfego NETSIM para a avaliação dos três tipos de vias.

No método, foi utilizado o mesmo modelo proposto por Sumner, Hill e Shapiro (1984). Assim, foram executadas quatro etapas para o cálculo do modelo: (1) formular a curva de fluxovelocidade para o fluxo apenas com automóveis na corrente de tráfego; (2) identificar a corrente mista de veículos para a seção examinada; (3) formular a curva fluxo-velocidade para essa corrente mista; e (4) selecionar os veículos tipo (veículo de estudo), níveis de fluxo e operações de tráfego simulados após inserir o volume do veículo de estudo e remover o mesmo volume em automóveis. 
Foram determinados diferentes parâmetros para as simulações, como inclinação e comprimento de rampa, porcentagem de caminhões e fluxo de tráfego. Nas autoestradas, foram obtidos resultados de equivalente veiculares variando entre 1 e 55 . Identificou-se que os fatores de equivalência veicular são maiores quanto maior e mais íngreme for uma rampa. Também verificou-se uma grande variação nos fatores em função da relação peso-potência e do comprimento do caminhão. Os fatores ficaram em sua maioria inalterados com o aumento do fluxo de tráfego, especialmente para veículos com desempenho baixo. Além disso, com o aumento da porcentagem de caminhões na corrente de tráfego, os fatores decresceram ou se mantiveram inalterados.

Webster e Elefteriadou (1999), que também usaram o método proposto por Sumner, Hill e Shapiro (1984), calcularam o valor do fator de equivalência através do simulador FRESIM. Foi utilizada a densidade como forma de cálculo, uma vez que a densidade de tráfego foi considerada um bom indicador da liberdade de manobras dos motoristas e da proximidade com outros veículos. Além disso, a densidade é consistente com a medida de eficácia para rodovias de pista dupla usada pelo HCM.

Foram testadas oito variáveis diferentes: (1) relação massa/potência dos caminhões; (2) comprimento dos caminhões; (3) inclinação da rampa; (4) comprimento da rampa; (5) número de faixas por sentido; (6) velocidade de fluxo-livre de operação do tráfego; (7) porcentagem de caminhões na corrente de tráfego; e (8) fluxo do tráfego.

Com base na investigação proposta no artigo, as seguintes afirmações foram apresentadas: os fatores de equivalência veicular são sensíveis às oito variáveis; os fatores tendem a aumentar com o fluxo, velocidade de fluxo-livre e inclinação/comprimento da rampa; tendem a diminuir com o aumento da porcentagem de caminhões na corrente de tráfego e o número de faixas; a relação massa/potência e o comprimento dos caminhões tem maior influência nos equivalentes veiculares para rampas longas e íngremes do que em seções planas; a mudança de número de faixas em rampas longas e íngremes resultaram em mudanças de fatores menores do que 0,5, para o caminhão com pior performance; a mudança na velocidade de fluxo-livre em rampas longas e íngremes resultaram em diferenças de fatores menores do que 0,5; mudando cada 
uma das outras seis variáveis consideradas, em rampas íngremes e longas, os resultados na mudança do fator para caminhão com menor performance foi no mínimo 0,65.

Demarchi e Setti (2003) calcularam fatores de equivalência veicular, baseados na densidade, utilizando o método proposto por Huber (1982) e o método proposto por Sumner, Hill e Shapiro (1984). Foi considerada uma corrente com automóveis e duas classes de caminhão (tipos $C_{1} \mathrm{e}$ $C_{2}$ ). Pelo método proposto por Huber (1982), pôde-se calcular os equivalentes veiculares, $e_{1}$ e $e_{2}$, separadamente, para cada um dos caminhões $C_{1}$ e $C_{2}$. Através do método proposto por Sumner, Hill e Shapiro (1984), foi calculado o fator de equivalência $E_{2}$, considerando-se uma corrente mista (automóveis e caminhões $C_{1}$ ) e utilizando como veículo de estudo o caminhão $C_{2}$. Porém, observou-se que os valores obtidos para $e_{2}$ e $E_{2}$ não eram iguais. O mesmo ocorreu quando calcula-se o fator de equivalência $E_{1}$, para a corrente mista composta por automóveis e caminhões $C_{2}$, sendo $C_{1}$ o veículo de estudo. Desta forma, pelo método proposto por Sumner, Hill e Shapiro (1984), constatou-se que o fator de equivalência do veículo de estudo é calculado para o seu impacto marginal em uma corrente mista já existente. Os autores propuseram uma fórmula, que calcula um único equivalente veicular quando são considerados mais de um veículo pesado na corrente de tráfego, eliminando possíveis erros:

$$
E_{m}=\frac{1}{\sum_{i=1}^{n} p_{i}}\left(\frac{q_{b}}{q_{s}}-1\right)+1
$$

em que $\quad E_{m}:$ fator de equivalência agregado para todos os caminhões na corrente de fluxo misto;

$p_{i}$ : $\quad$ porcentagem de caminhões do tipo $i$

da corrente de fluxo mista;

$q_{b}$ : fluxo composto só por automóveis; e

$q_{s}$ : fluxo para o qual deseja-se determinar os fatores de equivalência.

Para a avaliação da fórmula proposta, foram simulados no software INTEGRATION diversos cenários, considerando-se dois tipos diferentes de caminhões na corrente de tráfego. Para avaliar o erro dos equivalentes veiculares, foi proposta uma corrente de tráfego tipica $(80 \%$ de automóveis, $10 \%$ para o tipo $C_{1}$ e $10 \%$ para o tipo $C_{2}$ ). Os resultados de $E_{m}, E_{1}+E_{2}$ e 
$e_{1}+e_{2}$ foram comparados para diferentes porcentagens dos caminhões $C_{1}$ e $C_{2}$. Os autores concluíram que a obtenção do $E_{m}$ pode implicar em erros, porém menores do que os outros fatores de equivalência veicular isolados.

Após a identificação das diferentes formas de cálculo de fatores de equivalência existentes na literatura, decidiu-se utilizar o método proposto por Huber (1982) para o desenvolvimento do estudo, conforme apresentado no próximo capítulo. 


\section{Capítulo}

\section{Capiculo \\ Estimativa dos fatores de equivalência veicular}

Neste capítulo é apresentado o método como foram estimados os fatores de equivalência veicular. Utilizou-se como base o método proposto por Huber (1982), que calcula esses fatores comparando, para uma mesma impedância, os fluxos de uma corrente com automóveis e caminhões com os fluxos de uma corrente apenas com automóveis. Esse fator foi usado para a avaliação do impacto dos veículos pesados nas rodovias de pista dupla usando dados empíricos (observações de fluxo e velocidade).

\subsection{Características do tráfego nas rodovias de pista dupla observadas}

O Código de Trânsito Brasileiro (DENATRAN, 2008, p. 24), define em seu artigo 29 que

IV - quando uma pista de rolamento comportar várias faixas de circulação no mesmo sentido, são as da direita destinadas ao deslocamento dos veículos mais lentos e de maior porte, quando não houver faixa especial a eles destinada, e as da esquerda, destinadas à ultrapassagem e ao deslocamento dos veículos de maior velocidade.

A Figura 3.1 apresenta observações da velocidade média dos automóveis em função da taxa de fluxo de tráfego para intervalos de 6 minutos de duração obtidas no km 32, sentido norte, da SP348 (Rodovia dos Bandeirantes), estratificadas em função da faixa de tráfego (faixa 1 sendo a 
mais próxima do canteiro central e faixa 4, a faixa ao lado do acostamento). As médias apresentadas na Figura 3.1 foram calculadas pelas médias das porcentagens de caminhões calculados para cada intervalo de curta duração. Comparando-se a composição de tráfego entre as quatro faixas de rolamento, verifica-se que a faixa 1 apresenta, em média, 99\% de automóveis, enquanto a faixa mais próxima ao acostamento (faixa 4) apresenta $85 \%$ de veículos pesados, na média. Portanto, nesse quesito, a legislação é respeitada por grande parte dos condutores.

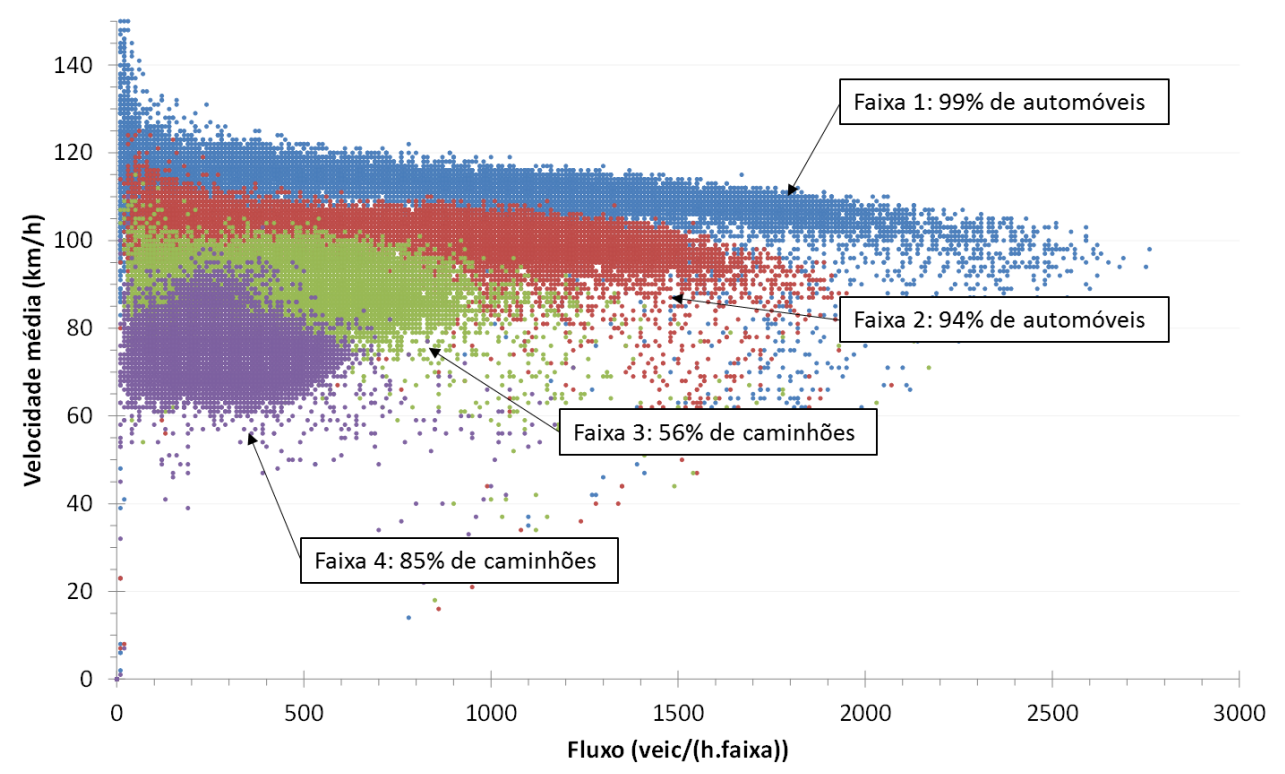

Figura 3.1 - Velocidade média em função do fluxo, em cada faixa de tráfego, na SP348, km 32, sentido norte

A Figura 3.2 apresenta a porcentagem de veículos em cada faixa de tráfego, em função do fluxo observado na rodovia. Foram utilizadas as observações de 6 minutos (pontos em cinza) do sensor localizado no km 32, sentido norte, da Rodovia dos Bandeirantes (SP348). Em preto, são representadas as médias das porcentagens de veículos em cada uma das faixas.

Na Figura 3.2 (a), que representa a porcentagem de veículos na faixa 1 (faixa mais próxima ao canteiro central), observa-se a ocupação crescente conforme aumenta o fluxo na rodovia. A porcentagem de veículos aumenta de $10 \%$ de média para o fluxo de 500 veic/h, para mais de $40 \%$ de média com fluxo de 4000 veic/h. A faixa 2, que é mostrada na Figura 3.2 (b), apresenta uma distribuição mais constante, com a média variando entre $30 \%$ e $40 \%$. A Figura 3.2 (c), que ilustra as observações da faixa 3, nota-se que a porcentagem de veículos decresce conforme aumenta o fluxo da rodovia. As médias variam entre $26 \%$, para fluxo de 500 veic/h, até $17 \%$, para 6000 veic/h. A faixa 4 (mais próxima ao acostamento), que é apresentada na Figura 3.2 (d), 
observa-se uma ocupação decrescente conforme o fluxo aumenta na seção da rodovia. Assim, quando o carregamento da rodovia é de 500 veic/h, essa faixa apresenta média de $30 \%$ dos veículos, quando o fluxo ultrapassa os 5000 veic/h, a média do carregamento dessa faixa fica abaixo dos $10 \%$.

(a) Faixa 1

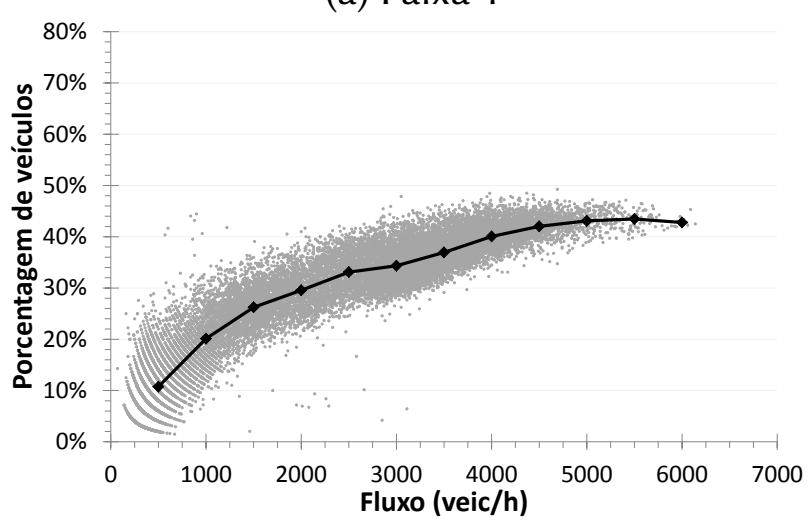

(c) Faixa 3

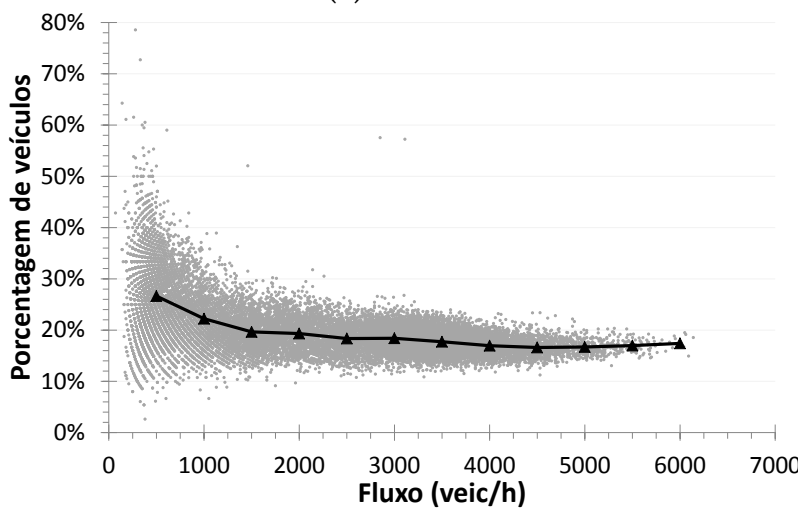

(b) Faixa 2

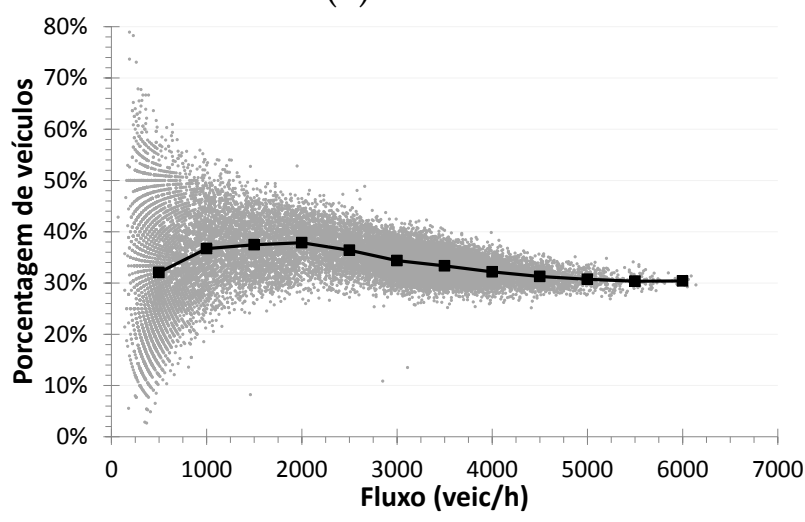

(d) Faixa 4

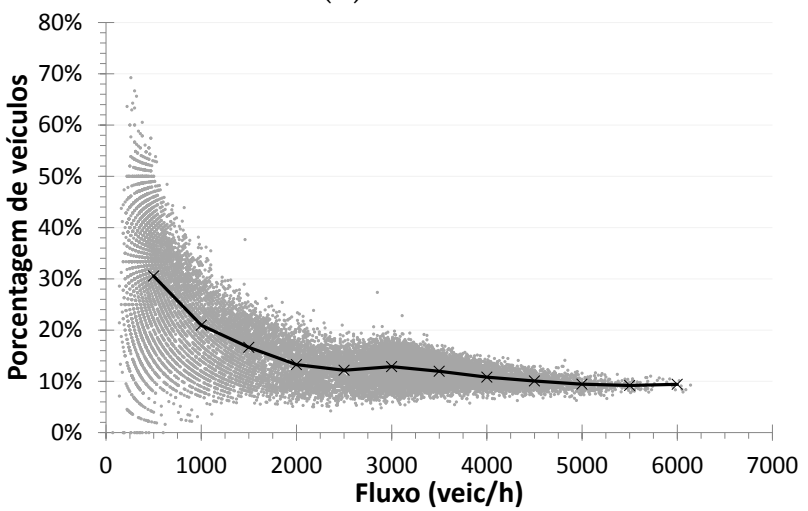

Figura 3.2 - Porcentagem de veículos, para cada uma das faixas de tráfego, em função do fluxo total observado na rodovia $(\mathrm{SP} 348, \mathrm{~km} 32 \mathrm{~N})$

Verifica-se que, em todas as faixas, a dispersão das observações em relação a média é menor quando o carregamento da rodovia ultrapassa os 3000 veic/h. Pode-se observar que para carregamentos abaixo de $500 \mathrm{veic} / \mathrm{h}$, as porcentagens de veículos em uma faixa pode variar de $2 \%$ a $80 \%$. Identifica-se que, para carregamentos baixos, o comportamento dos motoristas nem sempre segue um padrão na escolha da sua faixa de tráfego.

A Figura 3.3 apresenta a comparação das médias de porcentagem dos veículos nas quatro faixas de tráfego, apresentadas na Figura 3.2. É possível observar que, para o fluxo de 3000 veic/h, a faixa 1 (mais próxima ao canteiro central), é mais carregada. A faixa 4 (mais próxima ao acostamento) apresenta o menor carregamento da rodovia quando o fluxo é maior que $1000 \mathrm{veic} / \mathrm{h}$. 


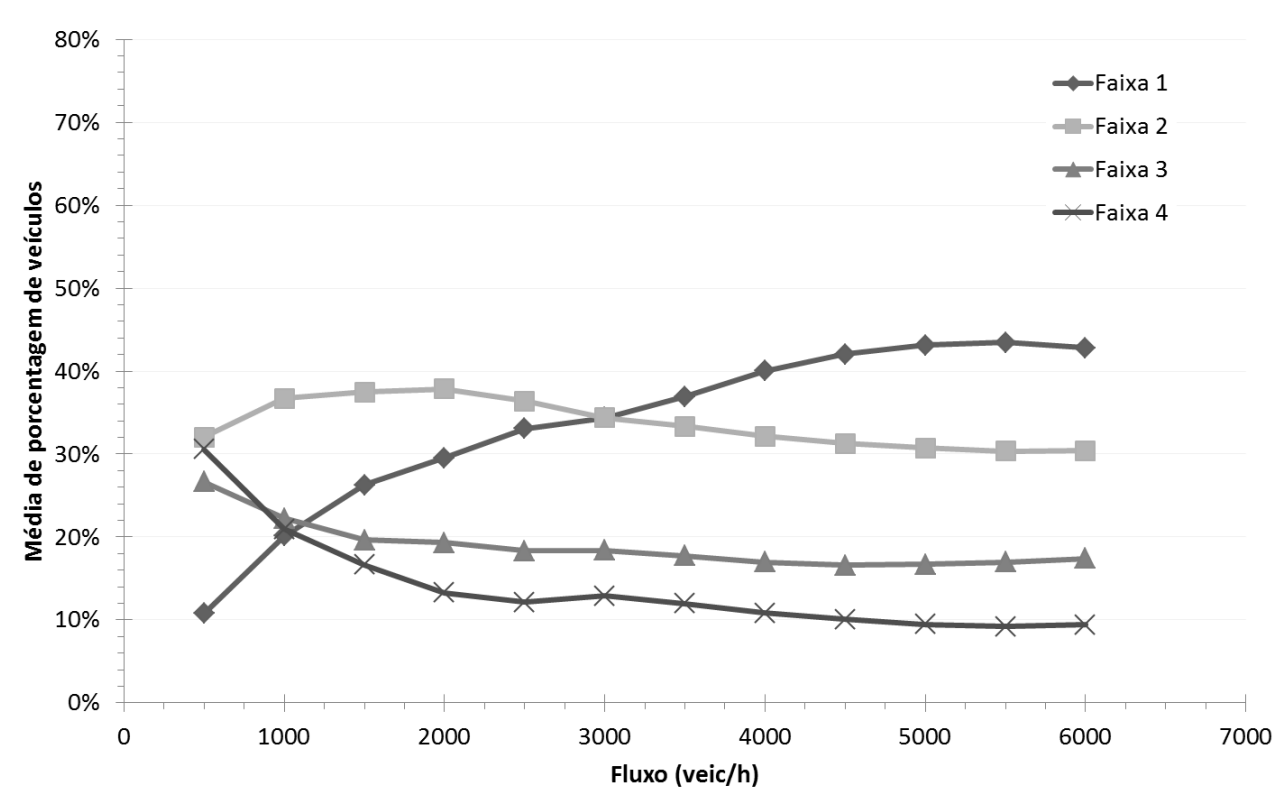

Figura 3.3 - Comparação das médias de porcentagem de veículos por faixa de tráfego em função do fluxo da rodovia

A faixa 2 sempre apresenta carregamento superior a faixa 3. Identifica-se que, quanto maior o carregamento da rodovia, maior percentual de veículos trafegam na faixa mais à esquerda. Para fluxos maiores que 1500 veic/h, observa-se que o tráfego nas duas faixas mais à direita, em que existe uma concentração maior de caminhões, a média das porcentagens de veículos é inferior a $20 \%$ em cada uma das faixas.

Uma vez que a corrente de tráfego da faixa 1 (próxima ao canteiro central) apresentava 99\% de automóveis, considerou-se que essa faixa representa uma corrente composta apenas por carros de passeio. Por sua vez, as faixas 3 e 4 (as duas mais próximas ao acostamento) foram consideradas como correntes de tráfego mista, ou seja, com a presença de automóveis e caminhões. Como a faixa 2 apresentava $94 \%$ de automóveis, essa poderia representar uma corrente composta apenas por carros de passeio. Porém, verificou-se que menos de $20 \%$ dos dados continham apenas automóveis nessa faixa. Dessa forma, seus dados não foram utilizados.

A exemplo do HCM, aceitando-se a hipótese de que a qualidade de serviço é a mesma ao longo de todas as faixas de tráfego, considerando um intervalo de tempo de curta duração, é possível estimar o fator de equivalência para os veículos pesados a partir da velocidade e do fluxo observados em cada faixa, conforme se explica a seguir. 


\subsection{Equivalência veicular a partir do método de Huber}

Admitindo-se um intervalo de tempo $i$, com duração curta (cinco ou seis minutos), observa-se um fluxo composto apenas por automóveis, definido aqui como fluxo básico, $q_{e}(i)$ na faixa mais próxima ao canteiro central. Nesse mesmo intervalo de tempo $i$, observa-se um fluxo misto, $q_{d}(i)$ na faixa mais próxima ao acostamento. Considerando a hipótese de que, nesse intervalo $i$, a qualidade de serviço é a mesma em todas as faixas de rolamento (TRB, 2010), esses dois fluxos $q_{e}(i)$ e $q_{d}(i)$ apresentam mesma impedância (HUBER, 1982), conforme mostrado na Figura 3.4.

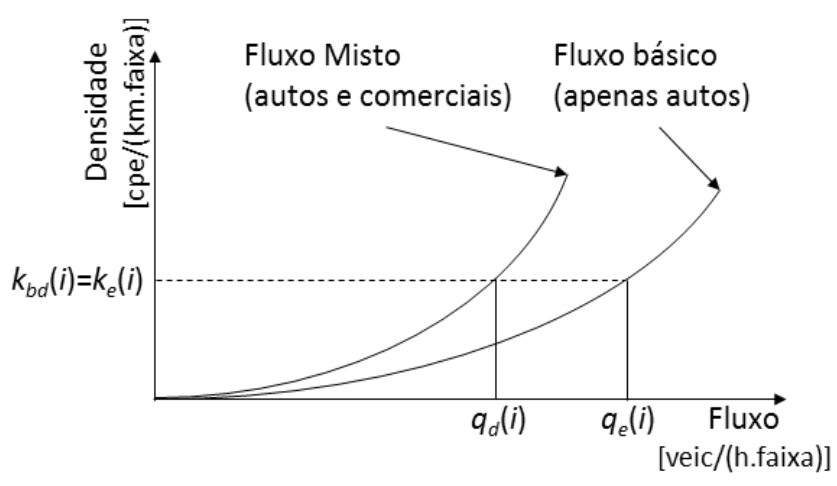

Figura 3.4 - Representação das diferenças entre os fluxos $q_{e}(i)$ e $q_{d}(i)$ para a mesma densidade

Admitindo-se a impedância como sendo a densidade, tem-se a seguinte igualdade:

$$
k_{b d}(i)=k_{e}(i)
$$

em que $\quad k_{b d}(i)$ : densidade,em veículos equivalentes, da corrente de tráfego da faixa da direita (fluxo misto), durante o $i$-ésimo intervalo de tempo, em cpe $/(\mathrm{km} \cdot$ faixa $)$;

$k_{e}(i)$ densidade, em veículos equivalentes, da corrente de tráfego da faixa da esquerda (fluxo básico), durante o $i$-ésimo intervalo de tempo, em cpe/(km·faixa); e

$i$ : $\quad$ intervalo de tempo com duração curta (5 ou 6 minutos).

Utilizando-se a equação fundamental do tráfego $(q=k \cdot u)$, pode-se reescrever a Equação 3.1:

$$
\frac{q_{b d}(i)}{u_{d}(i)}=k_{e}(i)
$$


em que $q_{b d}(i)$ : fluxo, em veículos equivalentes, da corrente de tráfego da faixa da direita (fluxo misto), durante o intervalo $i$, em cpe/(h·faixa);

$u_{d}(i): \quad$ velocidade média da corrente de tráfego da faixa da direita, no intervalo $i$, em $\mathrm{km} / \mathrm{h}$.

Pelo método de Huber (1982), pode-se considerar que a relação entre o fluxo básico e o fluxo misto seja representada pela Equação 2.13 (veja página 36):

$$
q_{b d}(i)=q_{d}(i) \cdot[1-p(i)]+E(i) \cdot p(i) \cdot q_{d}(i)
$$

em que $q_{d}(i)$ : fluxo, em veículos, da corrente de tráfego da faixa da direita (fluxo misto), no intervalo $i$, em veic/(h.faixa);

$E(i): \quad$ fator de equivalência veicular para o intervalo $i$;

$p(i)$ : fração de veículos pesados na faixa da direita (fluxo misto) no intervalo $i$; e $[1-p(i)]$ : fração de automóveis no fluxo misto, no intervalo $i$.

Substituindo-se a Equação 3.3 em 3.2, tem-se:

$$
\frac{q_{d}(i)[1-p(i)]+E(i) \cdot p(i) \cdot q_{d}(i)}{u_{d}(i)}=k_{e}(i) .
$$

Isolando-se $q_{d}(i)$ no numerador do primeiro termo da expressão 3.4, pode-se escrever:

$$
\frac{q_{d}(i) \cdot[E(i) \cdot p(i)+1-p(i)]}{u_{d}(i)}=k_{e}(i)
$$

Pela equação fundamental do tráfego $(k=q / u)$, obtém-se a equação:

$$
k_{d}(i) \cdot[E(i) \cdot p(i)+1-p(i)]=k_{e}(i)
$$

em que $k_{d}(i)$ densidade, em veículos, da corrente de tráfego da faixa da direita (fluxo misto), no intervalo $i$, em veic/(km·faixa).

Isolando-se $E(i)$ do lado esquerdo da equação, têm-se que:

$$
E(i)=\frac{1}{p(i)} \cdot\left[\frac{k_{e}(i)}{k_{d}(i)}-1\right]+1 .
$$


A partir da Equação 3.7, deve-se impor uma restrição tal que $E(i)>1$, uma vez que não faz sentido um caminhão ter um impacto inferior ao de um automóvel na qualidade de serviço. Isso pode ser verificado, pelo fato de as dimensões dos caminhões serem superiores às dos automóveis e as características de desempenho dos caminhões serem inferiores às dos automóveis. Por exemplo, em uma rodovia em que existam $3 \mathrm{veic} / \mathrm{km}$ na faixa da esquerda, contendo apenas automóveis e 6 veic/ $\mathrm{km}$ na faixa da direita, com $50 \%$ de caminhões. Pela Equação 3.7, tem-se que:

$$
E(i)=\frac{1}{0,50} \cdot\left[\frac{3}{6}-1\right]+1=0,0
$$

Ou seja, o equivalente veicular é 0,0. Neste caso, porém, observa-se que a qualidade de serviço na faixa da direita é pior do que na faixa da esquerda. Desta forma, observações que resultem em $E(i) \leq 1$ devem ser removidas da base de dados, pois representam situações em que não é válida a hipótese de que a qualidade de serviço é a mesma nas duas faixas de tráfego durante o intervalo de tempo $i$.

A partir dos dados de fluxo-velocidade coletados em estações permanentes de monitoramento de tráfego, localizadas em rodovias de pista dupla paulistas com três ou mais faixas de tráfego, foram identificados intervalos apenas com automóveis na faixa mais próxima ao canteiro central (fluxo básico). Também foi observado que nas faixas mais próximas ao acostamento a corrente apresentava automóveis e caminhões (fluxo misto). Desta forma, a Equação 3.7 foi utilizada para calcular os fatores de equivalência dos veículos pesados para cada intervalo de cinco ou seis minutos. Após esse cálculo, os resultados foram agrupados por nível de serviço e por greide no trecho da rodovia em que os dados foram coletados. Esses fatores foram plotados em função da porcentagem de veículos pesados na faixa da direita. A partir dos gráficos foram aproximadas funções hiperbólicas, as quais foram utilizadas para avaliar o impacto dos veículos pesados nas rodovias. 


\section{Capítulo}

\section{Dados Coletados}

Neste estudo, foram utilizados dados de tráfego coletados em estações permanentes de monitoramento, fornecidos por concessionárias rodoviárias do estado de São Paulo. Esses dados foram obtidos em intervalos de 5 ou 6 minutos, coletados em rodovias com três ou mais faixas de tráfego, nos anos de 2010 e 2011. Os pontos de coleta foram escolhidos considerando-se aspectos geométricos, operacionais, assim como o tipo e a qualidade dos dados de tráfego. Também foram identificadas as condições do tempo (com ou sem chuva) no intervalo da coleta. Essas informações meteorológicas e os dados de tráfego foram consolidados em um único banco de dados.

\subsection{Dados de tráfego}

Os dados de fluxo e velocidade foram obtidos por laços indutivos, que atualmente são os sensores mais utilizados no gerenciamento de tráfego (KLEIN, 2001). Eles permitem obter as informações de número de veículos, divididos entre automóveis, comerciais e motos. Também é fornecida a velocidade média da corrente de tráfego. Essas informações são desagregadas por faixa e agrupadas em intervalos de cinco ou seis minutos, dependendo da estação de coleta. Para obter a densidade de tráfego em cada faixa, que foi utilizada para calcular o equivalente veicular pela Equação 3.7, utilizou-se a equação fundamental do tráfego, fazendo a razão entre o fluxo e a velocidade média de cada intervalo de coleta. 
O laço indutivo é composto por uma ou mais espiras de fio isolado, enterrado em um recorte raso na faixa de rodagem; um cabo de entrada, que vai de uma caixa de passagem, localizada ao lado da rodovia, para o gabinete do controlador, que contém uma unidade eletrônica que armazena os dados. Quando um veículo para ou passa sobre as espiras, a indutância no fio diminui. Essa variação, causada pelo metal existente no veículo, envia pulsos ao controlador, indicando a presença ou passagem de um veículo (KLEIN, 2001). A Figura 4.1 apresenta um exemplo de um laço indutivo utilizado na coleta dos dados de tráfego.

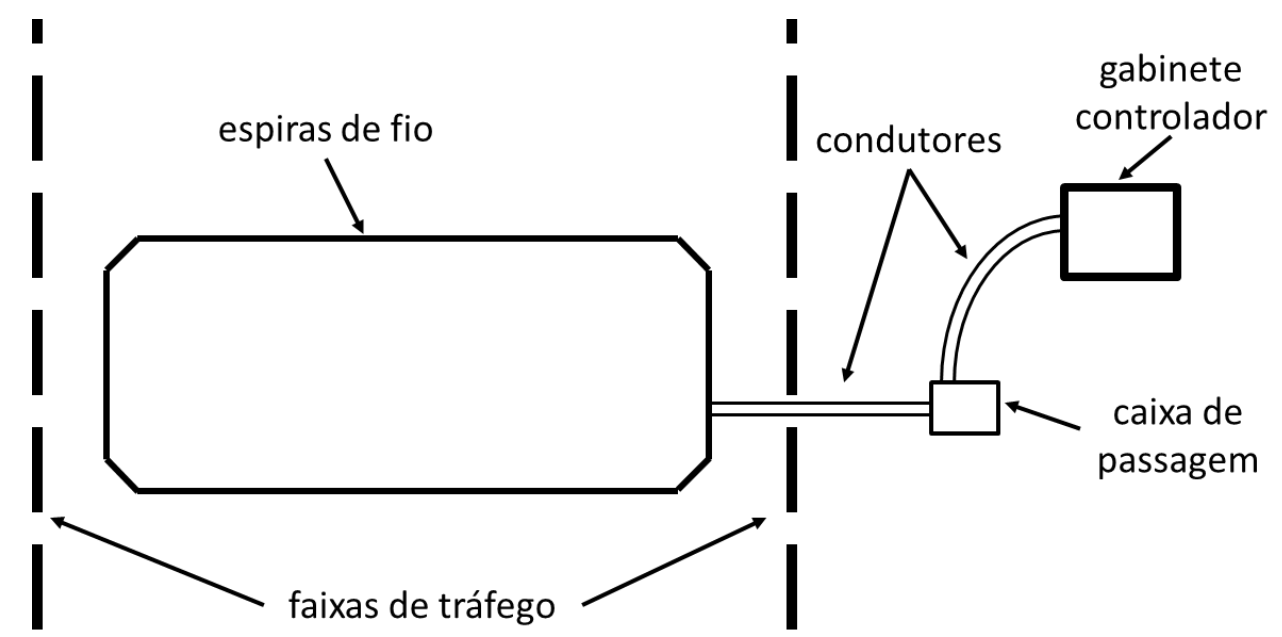

Figura 4.1 - Exemplo de laço indutivo utilizado na coleta dos dados de tráfego

Os dados utilizados na pesquisa foram coletados em estações permanentes de monitoramento de tráfego. A Tabela 4.1 fornece a localização dos pontos de coleta e as principais características referentes a cada um. As oito estações eram localizadas nas rodovias SP280 (Rodovia Castelo Branco) e a SP348 (Rodovia dos Bandeirantes) e os locais em que os pontos estão, apresentam pista dupla, com três ou mais faixas de tráfego. Os dados utilizados foram coletados, tanto durante o dia, quanto a noite, nos anos de 2010 e 2011. Apenas trechos em aclive foram escolhidos para compor a amostra, uma vez que o efeito dos veículos pesados na qualidade de serviço é mais notado em aclives, pela perda de velocidade que ocorre em subidas. Foram desconsiderados postos em que a rodovia apresentava características de tráfego urbano, ou seja, diversas entradas e saídas da rodovia. Isso pode causar uma distorção na corrente de tráfego, causado pelos veículos que estavam na faixa da direita para utilizar o acesso. As velocidades máximas permitidas em todos os trechos coletados são de $120 \mathrm{~km} / \mathrm{h}$ para veículos leves e $90 \mathrm{~km} / \mathrm{h}$ para veículos pesados. A Figura 4.2 apresenta a localização dos pontos, incluindo o traçado das rodovias em que eles estão instalados. 
Tabela 4.1 - Pontos de coleta utilizados

\begin{tabular}{ccclccc}
\hline Rodovia & $\begin{array}{c}\text { Local } \\
(\mathrm{km})\end{array}$ & Sentido & Tipo de via & $\begin{array}{c}\text { Ocupação } \\
\text { lindeira }\end{array}$ & $\begin{array}{c}\text { Atinge } \\
\text { capacidade }\end{array}$ & Greide \\
\hline SP280 & 27,0 & Leste & Autoestrada & Urbana & Sim & $3,5 \%$ \\
SP280 & 29,5 & Leste & Autoestrada & Urbana & Sim & $2,0 \%$ \\
SP280 & 37,0 & Leste & Rodovia de pista dupla & Rural & Sim & $5,0 \%$ \\
SP280 & 51,9 & Leste & Rodovia de pista dupla & Rural & Sim & $4,5 \%$ \\
SP280 & 59,6 & Leste & Rodovia de pista dupla & Rural & Não & $1,5 \%$ \\
SP348 & 32,0 & Norte & Autoestrada & Rural & Sim & $3,5 \%$ \\
SP348 & 59,0 & Norte & Autoestrada & Rural & Não & $1,0 \%$ \\
SP348 & 87,0 & Norte & Autoestrada & Rural & Não & $2,5 \%$ \\
\hline
\end{tabular}

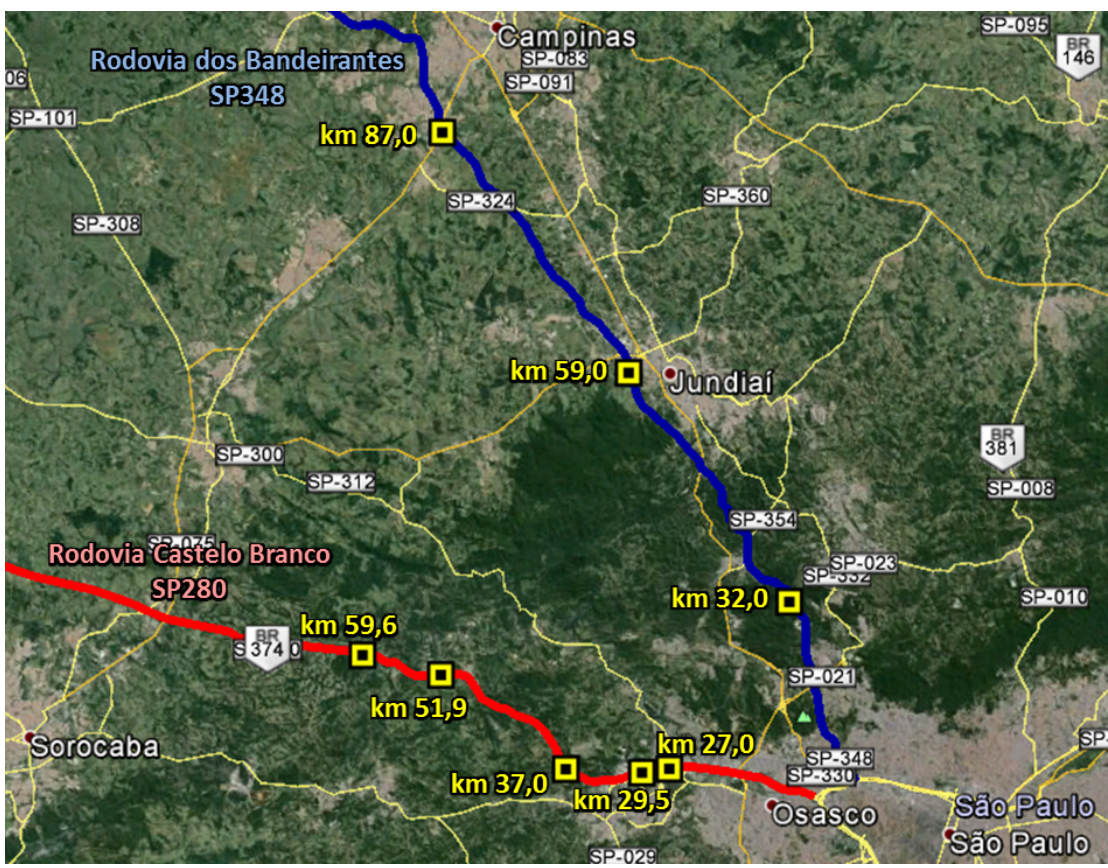

Figura 4.2 - Localização dos pontos de coleta de dados de tráfego Imagem: Google Earth

As planilhas eletrônicas em que foram armazenados os dados possuem duas formatações diferentes, uma referente a cada rodovia. No Apêndice A, são apresentadas as características dessas planilhas, com as descrições das informações existentes em cada uma.

\subsection{Dados meteorológicos}

Os dados meteorológicos fornecidos pelo Instituto de Pesquisas Meteorológicas da UNESP (IPMet) consistem em imagens, capturadas a cada 30 minutos, de radares meteorológicos lo- 
calizados nas cidade de Bauru e Presidente Prudente. A Figura 4.3 ilustra uma dessas imagens, que representa as áreas com diferentes intensidades de chuva (coloridas) e tempo bom (cinza).

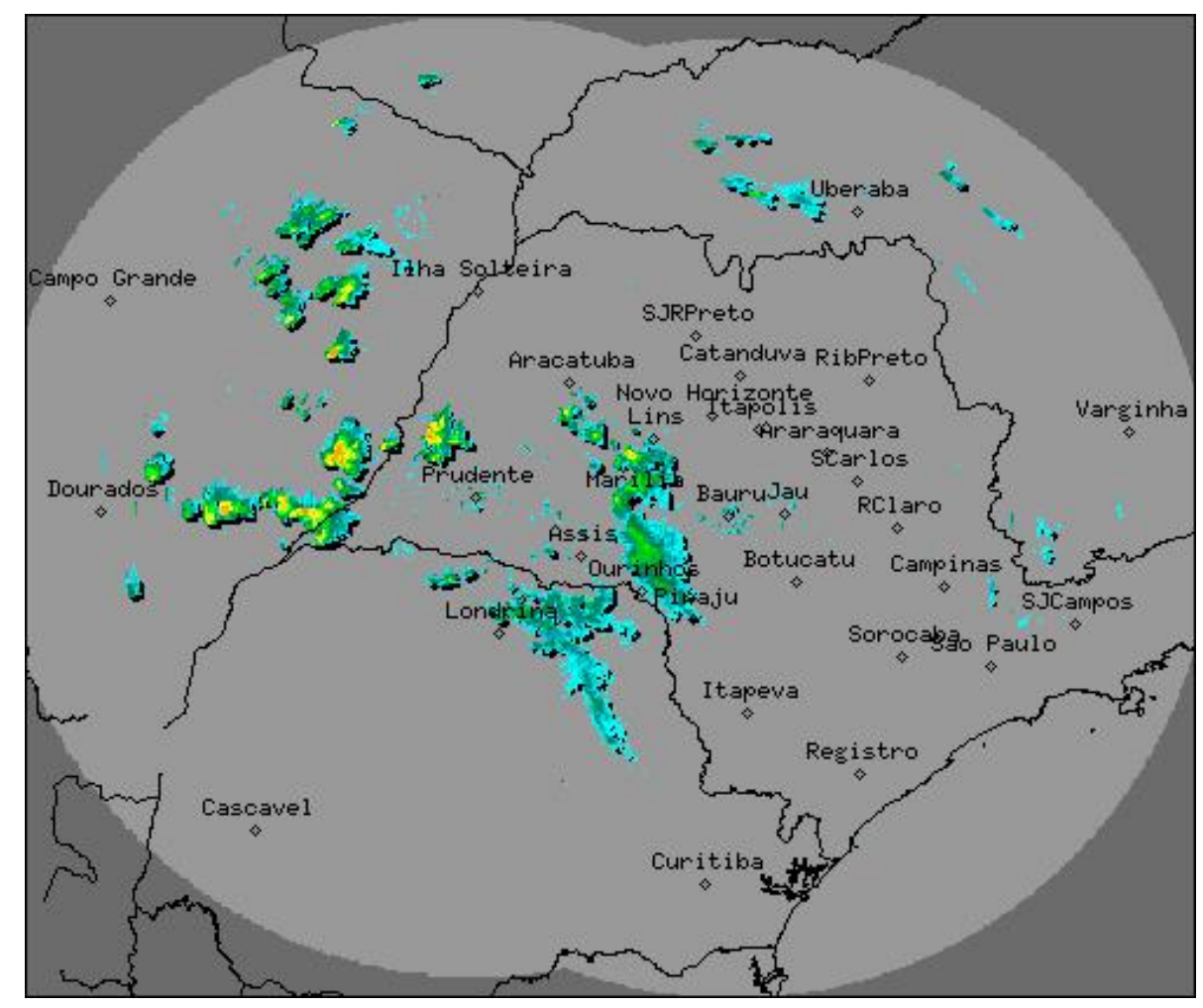

Figura 4.3 - Imagem dos radares meteorológicos do IPMet

As imagens foram processadas através do sistema de cores HSV. Desta forma, foi possível obter a condição do tempo nos pixels correspondentes aos locais de coletas dos dados de tráfego para cada intervalo de captura. Assim, a cada 30 minutos, foram atribuídas uma das três categorias diferentes nos postos de coleta dos dados de tráfego: "com chuva", "sem chuva" e “indeterminado" (PIZZOL; SETTI, 2013).

\subsection{Estruturação do banco de dados}

Com os dois bancos de dados prontos, os dados de fluxo e velocidade foram correlacionados com as condições de tempo. As imagens retratavam as condições meteorológicas a cada 30 minutos, e os dados de tráfego foram registrados a cada cinco ou seis minutos. Desta forma, os dados meteorológicos foram relacionados aos cinco ou seis dados de tráfego obtidos no mesmo período. Em seguida, dados de tráfego foram removido nos períodos em que existia troca da categoria atribuída à condição do tempo. Ou seja, foram mantidos os dados cuja 
condição de tempo se repetia em dois intervalos de tráfego antes e um intervalo depois. Desta forma, somente as condições de tempo que se mantiveram por no mínimo 20 minutos foram consideradas. Os dados que não atenderam a tal critério foram desprezados (PIZZOL, 2012).

Nesta fase, também foram removidos os dados que haviam sido previamente desconsiderados na pesquisa de Andrade (2012). Observações com aparente erro de medição, eventuais travamentos dos sensores, fluxos ou velocidades médias muito altas e restrições temporárias, como acidentes e esquemas de operações para obras estão entre os dados removidos.

Para todos os pontos de coleta, foi comparado o fluxo básico com o misto, sendo esse último obtido das correntes de tráfego das duas faixas mais próximas ao acostamento, separadamente. Identificou-se que, em alguns locais, a segunda faixa mais próxima ao acostamento não apresentava a mesma qualidade de serviço que a faixa mais próxima ao canteiro central, na maior parte do tempo. Desta forma, os dados da segunda faixa mais próxima ao acostamento foram utilizados somente para os pontos localizados na Rodovia dos Bandeirantes.

Após a obtenção de um único banco de dados e da remoção dos intervalos inconsistentes, obteve-se um total de 331.604 dados de curta duração. Porém, esses dados ainda não continham as características necessárias para aplicação do método proposto por Huber (1982). Ou seja, os dados não apresentavam apenas automóveis na faixa do fluxo básico, bem como automóveis e caminhões na faixa do fluxo misto. Os dados também continham motos na corrente de tráfego e ainda havia intervalos com tempo chuvoso. Assim, foi implementada uma sequência de filtros, apresentada no próximo capítulo, a fim de eliminar esses dados que impedem a aplicação do método proposto. 


\section{Capítulo}

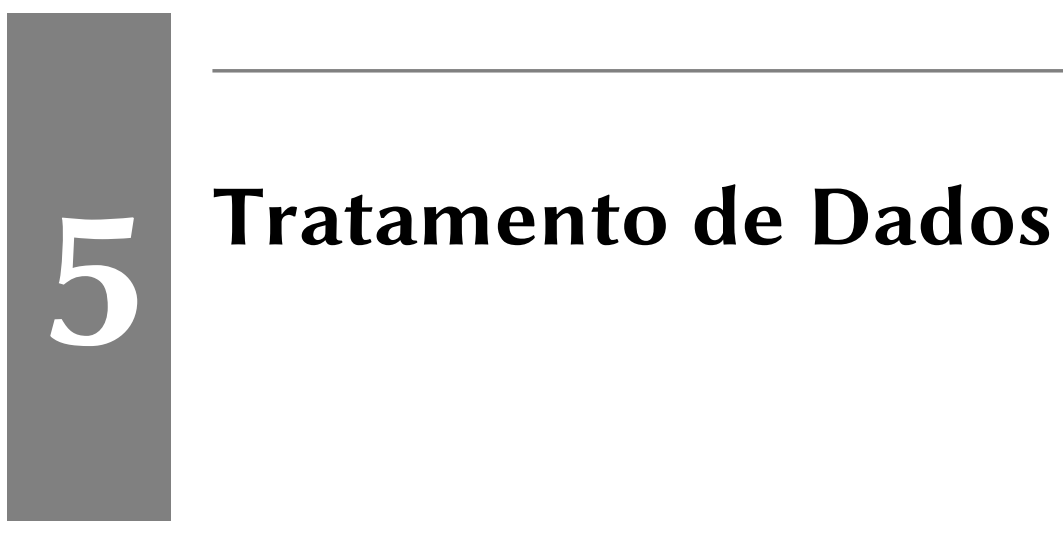

Após a criação do banco de dados com fluxo, velocidade e características meteorológicas de cada um dos intervalos de coleta, fez-se o tratamento dos dados. Para tanto, foi aplicada uma sequência de filtros para remover as observações indesejadas, nas quais não eram verificadas as condições necessárias para a aplicação da Equação 3.7. É importante ressaltar que esses filtros foram executados na ordem descrita a seguir.

\subsection{Filtro 1: Observações sob tempo chuvoso}

Nos locais observados, existe uma redução tanto na velocidade de fluxo livre quanto na capacidade, quando os dados são coletados com pista molhada (PIZZOL; SETTI, 2013). Deste modo, dados coletados sob chuva ou sob tempo indeterminado (isto é, não foi possível estabelecer com certeza se o tempo era bom ou chuvoso no intervalo) foram excluídos para evitar ruídos nas análises. Com o uso deste filtro, foi identificado que $85,7 \%$ das observações foram feitas com tempo bom, conforme ilustrado na Figura 5.1. Dos intervalos descartados, foi constatado que 6,6\% apresentaram tempo chuvoso e que, para 7,7\%, não foi possível determinar a condição climática durante o intervalo de coleta.

\subsection{Filtro 2: Observações sob fluxo congestionado}

Para não serem utilizados intervalos com fluxo congestionado (nível de serviço F), foram removidos aqueles nos quais a velocidade média na faixa da esquerda é inferior à velocidade na 
capacidade para o trecho em questão. A Tabela 5.1 apresenta as velocidades médias críticas na faixa da esquerda consideradas em cada um dos pontos de coleta ${ }^{1}$. Essas velocidades foram obtidas pela aplicação de uma análise de cluster nas observações de fluxo e velocidade dos pontos de coleta. Foram definidos dois clusters (fluxo livre e congestionado) e as distâncias entre os centroides de cada cluster e as observações de fluxo e velocidade foram calculadas (ANDRADE, 2012). Em três locais, não foi observado fluxo congestionado. A aplicação deste filtro mostrou que apenas 2,6\% das observações disponíveis foram coletadas em regime congestionado, conforme pode ser visto na Figura 5.2.

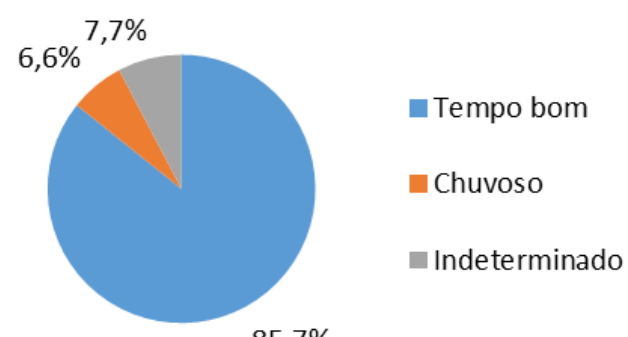

Figura 5.1 - Observações removidas em função de tempo chuvoso ou indeterminado

Tabela 5.1 - Velocidade média crítica na faixa da esquerda para o fluxo congestionado

\begin{tabular}{ccc}
\hline Rodovia & Local (km e sentido) & Velocidade crítica $(\mathrm{km} / \mathrm{h})$ \\
\hline SP280 & $27,0 \mathrm{~L}$ & 79 \\
SP280 & $29,5 \mathrm{~L}$ & 77 \\
SP280 & $37,0 \mathrm{~L}$ & 90 \\
SP280 & $51,9 \mathrm{~L}$ & 84 \\
SP348 & $32,0 \mathrm{~N}$ & 97 \\
\hline
\end{tabular}

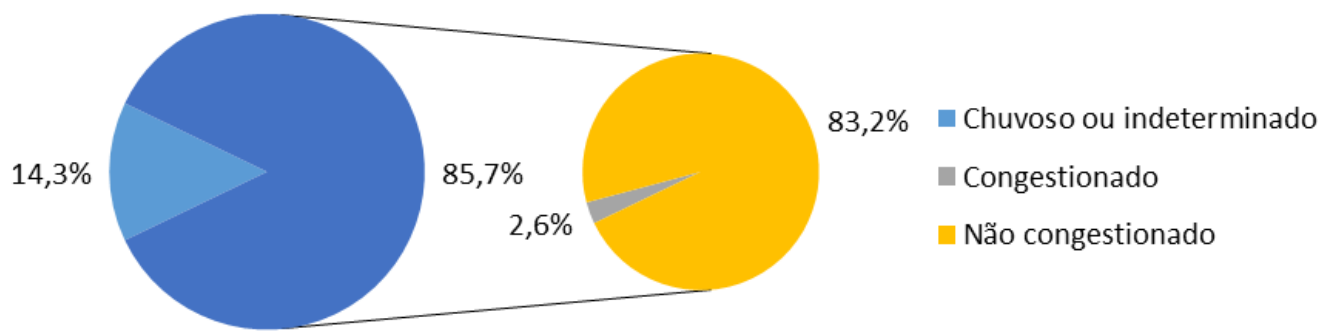

Figura 5.2 - Observações descartadas por operação em regime de fluxo congestionado

\footnotetext{
${ }^{1}$ As velocidades críticas foram fornecidas por Gustavo Riente de Andrade, tendo sido calculadas em sua pesquisa de mestrado (ANDRADE, 2012)
} 


\subsection{Filtro 3: Existência de veículos comerciais na faixa da esquerda}

Para obter o fluxo básico na faixa da esquerda, foram removidas as observações nas quais foram detectados veículos pesados nessa faixa de tráfego. Assim, pode-se garantir que o fluxo na faixa mais próxima ao canteiro central é composto apenas por automóveis. A Figura 5.3 mostra que em $26,3 \%$ dos intervalos havia caminhões na faixa da esquerda.

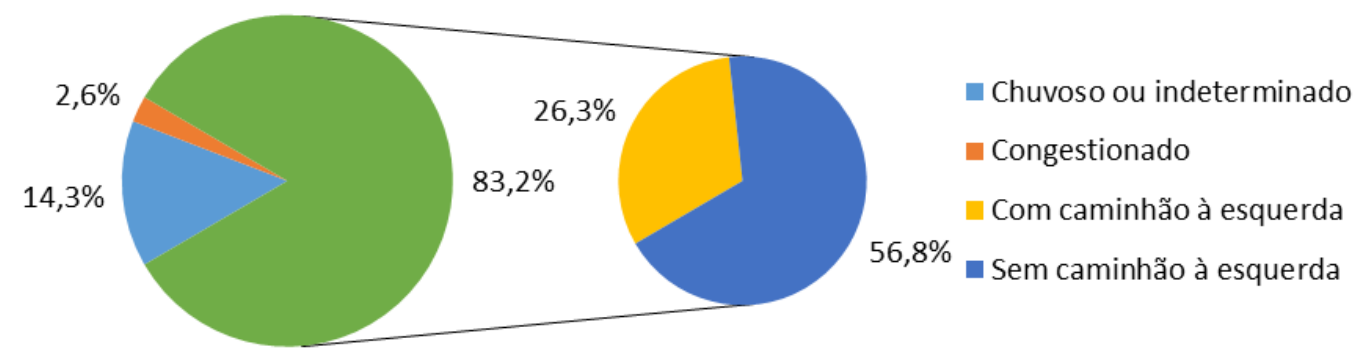

Figura 5.3 - Observações removidas em função da presença de caminhões na faixa da esquerda

\subsection{Filtro 4: Motos na corrente de tráfego}

Em função do comportamento dos condutores de motos, que muitas vezes preferem viajar entre as faixas de tráfego, torna-se difícil determinar o seu impacto na corrente de tráfego. Desta forma, foram removidos os intervalos em que foi constatada a presença desses veículos nas faixas analisadas. Como se pode ver na Figura 5.4, 9,3\% das observações foram removidas da amostra pela aplicação deste filtro.

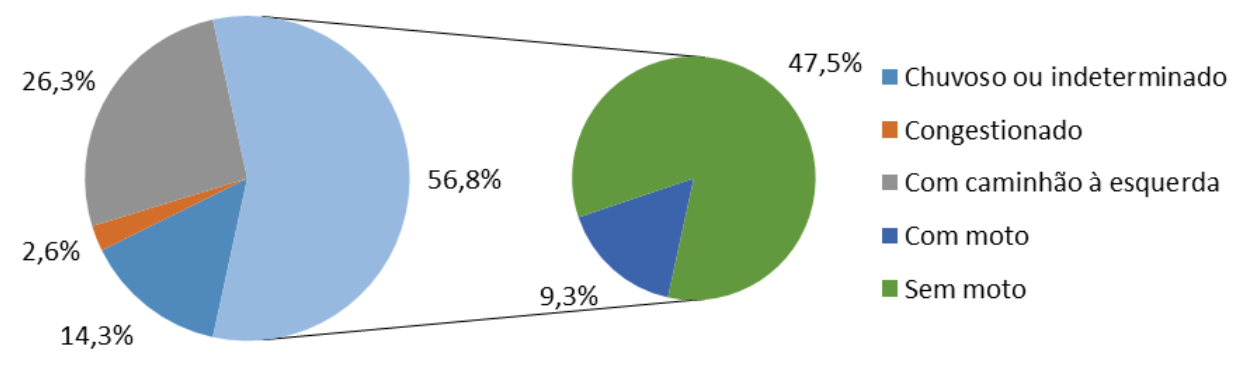

Figura 5.4 - Observações removidas pela presença de motos na corrente de tráfego

\subsection{Filtro 5: Intervalos com $p(i)=100 \%$ ou $0 \%$ na faixa da direita}

Para obter-se o fluxo misto na faixa da direita é necessário que a corrente de tráfego contenha tanto carros quanto caminhões. Além disso, quando aplica-se a Equação 3.7, para intervalos 
com $p(i)=0 \%$, o fator de equivalência veicular tende a infinito. Assim, foram descartados da amostra os intervalos nos quais a porcentagem de caminhões na faixa da direita era $100 \%$ (só caminhões) ou 0\% (só automóveis). A Figura 5.5 mostra que 5,5\% das observações foram removidas nesta etapa.

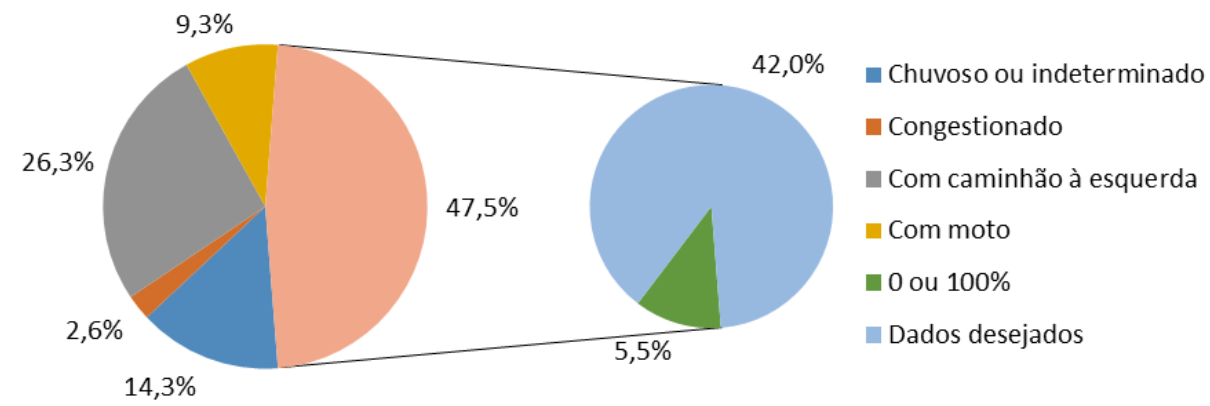

Figura 5.5 - Observações descartadas pela ausência ou totalidade de caminhões na faixa da direita

\subsection{Remoção das observações em que a qualidade de serviço não é a mesma nas faixas de tráfego}

Os primeiros cinco filtros serviram para eliminar observações que introduziriam condições não controladas na estimativa do fator de equivalência veicular. Após a aplicação desses filtros, obteve-se um banco de dados com 139.253 observações (intervalos de cinco ou seis minutos).

Após aplicar a Equação 3.7 em cada intervalo, obteve-se o valor do fator de equivalência veicular para cada um deles. Nos intervalos em que se obteve $E(i) \leq 1$, não é válida a hipótese de que a qualidade de serviço (medida de impedância) é a mesma nas duas correntes de tráfego, pois um caminhão deve, necessariamente, ter $E(i)>1$. Isso deve ocorrer, porque os caminhões são mais longos que os automóveis, ocupando mais espaço na faixa de tráfego. Além disso, os caminhões apresentam relação massa/potência significativamente superior a dos automóveis. Ou seja, o desempenho dos caminhões é inferior ao dos automóveis. Aliado a isto, nas rodovias estudadas, existem limites de velocidade diferenciadas para os veículos pesados. Em todos os pontos de coleta, a velocidade máxima permitida era $120 \mathrm{~km} / \mathrm{h}$, para os veículos leves, e $90 \mathrm{~km} / \mathrm{h}$, para os veículos pesados. A Figura 5.6 ilustra os valores obtidos para $E(i)$ em função da porcentagem de caminhões $p(i)$ na faixa que representa o fluxo misto para as 139.253 observações disponíveis após a aplicação dos cinco primeiros filtros. 


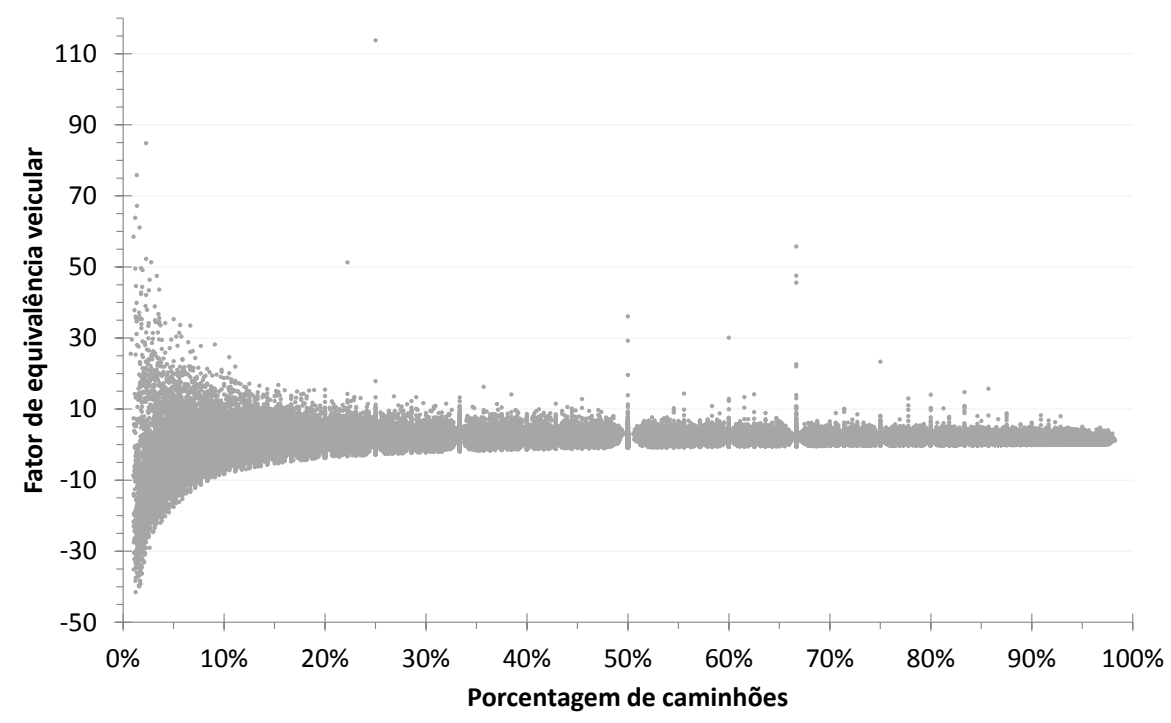

Figura 5.6 - Variação do fator de equivalência veicular em função da porcentagem de caminhões após a aplicação dos primeiros cinco filtros

Verificou-se que em $52 \%$ das observações, $E(i) \leq 1$, sugerindo que a hipótese adotada no HCM (a qualidade de serviço é a mesma em todas as faixas de tráfego) não é válida o tempo todo. Desta forma, foram avaliados os motivos pelos quais o fator de equivalência veicular é menor ou igual a 1,0 nesta etapa do tratamento de dados.

\subsubsection{Filtro 6: Remoção de observações em função da densidade}

A Figura 5.7 apresenta o total de intervalos existentes para diferentes densidades de tráfego na faixa da esquerda, separando a quantidade de intervalos nos quais o fator de equivalência veicular era maior que 1,0 (em azul) dos intervalos com $E(i)$ menores ou iguais a 1,0 (em vermelho). Também é apontada a porcentagem de dados com $E(i)>1$. Verifica-se que, a partir de $10 \mathrm{cpe} /(\mathrm{km} \cdot$ faixa) as observações removidas são menores do que 1\%. A Figura 5.7 sugere que, quando a densidade da corrente é muito baixa, os motoristas não escolhem a faixa de tráfego da mesma forma que escolhem quando a densidade é mais alta, acima de $9 \mathrm{cpe} /(\mathrm{km} \cdot f a i x a)$. Sob baixas densidades, pode ser que a escolha seja feita por imposição da lei, que obriga os condutores de veículos pesados a trafegar nas faixas mais à direita. Outro motivo pode ser a preferência do motorista em conduzir em uma das faixas, quando o fluxo da rodovia é baixo $(k<10 \mathrm{cpe} /(\mathrm{km} \cdot$ faixa $))$. No Apêndice B, na Tabela B.1, são apresentadas as quantidades de observações para cada densidade na faixa da esquerda e as respectivas porcentagens de observações utilizadas. 


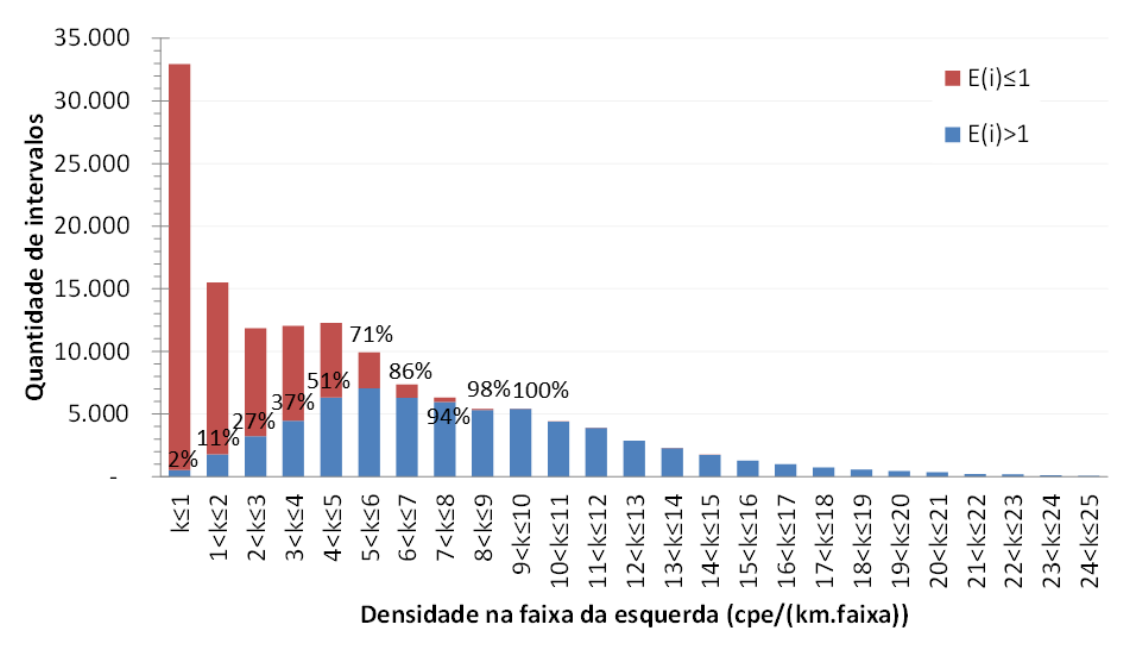

Figura 5.7 - Ocorrência de $E(i) \leq 1$ para densidade na faixa de fluxo básico

A Figura 5.8 mostra as observações com fatores de equivalência veicular menores ou igual a 1,0 (em vermelho) e com $E(i)>1$ (em azul), em função das densidades mínimas nas duas faixas de tráfego (fluxo básico e fluxo misto). Também são apontadas as porcentagens das observações que seriam validadas para cada densidade. Desta forma, foram descartadas as observações com densidade menor do que $3 \mathrm{veic} /(\mathrm{km} \cdot$ faixa), tanto na faixa do fluxo básico, quanto do fluxo misto. Esse limiar foi escolhido porque, para este valor, 25\% das observações seriam descartadas e 75\% seriam submetidas ao próximo filtro. No Apêndice B, na Tabela B.2, é possível verificar as quantidade de intervalos e as porcentagens de dados utilizados para cada densidade mínima.

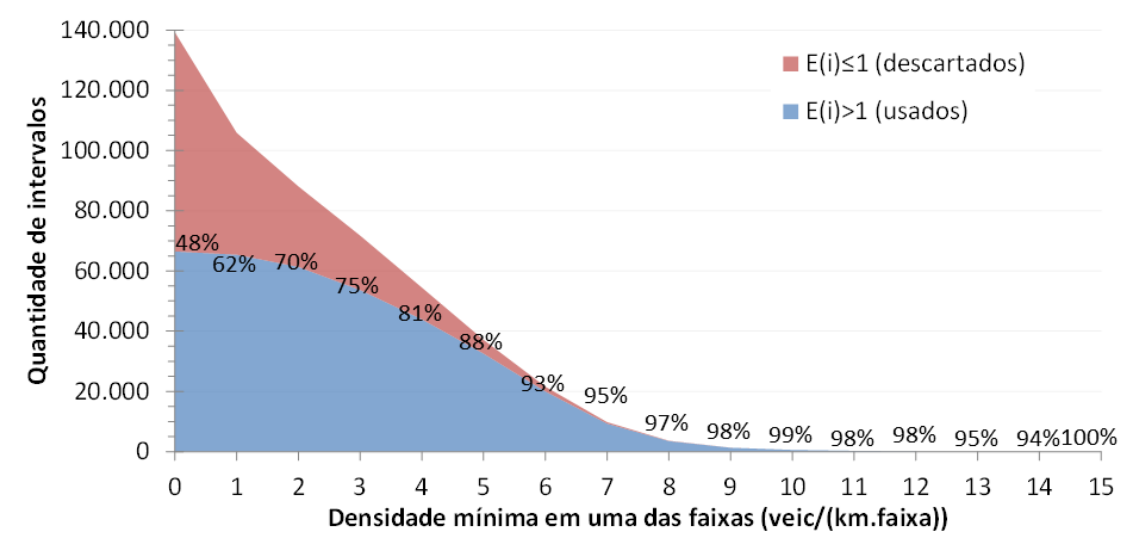

Figura 5.8 - Fração de observações removidas em função da densidade mínima nas faixas de fluxo básico ou misto 
Descartadas as observações realizadas em condições tais que a densidade é menor que 3 veic/(km·faixa) no fluxo básico ou no fluxo misto, restam 21,6\% das observações originalmente disponíveis, como mostra a Figura 5.9.
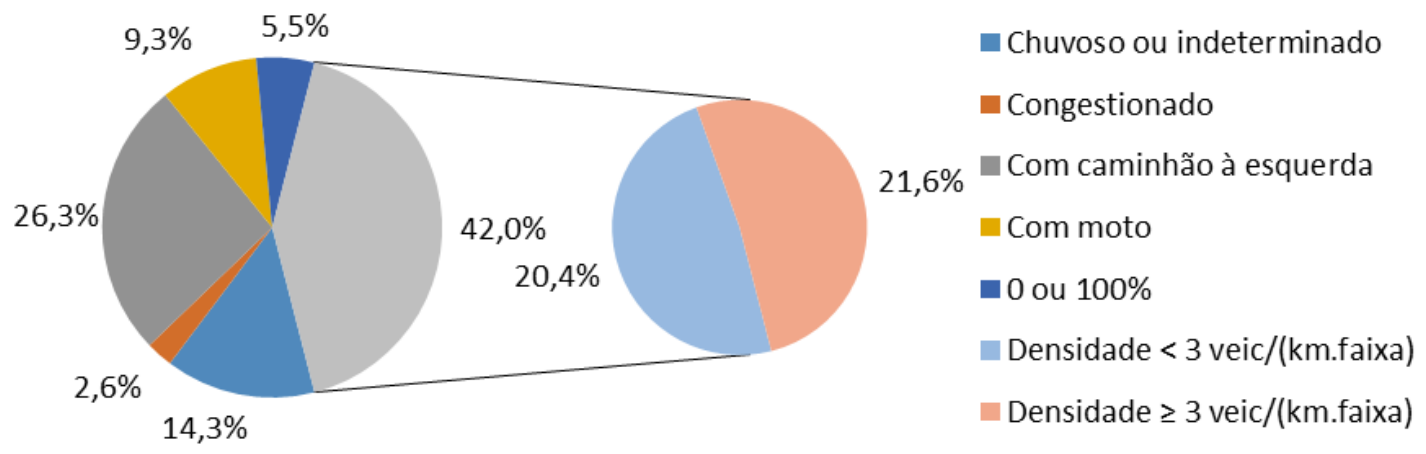

Figura 5.9 - Observações descartadas em função da densidade limite $k<3$ veic( $\mathrm{km} \cdot$ faixa $)$

A Figura 5.10 mostra os valores de $E(i)$ em função de $p(i)$ após a aplicação deste filtro. É importante verificar que até mesmo alguns outliers que apareciam na Figura 5.6 foram eliminados do banco de dados após a aplicação deste filtro. Foi verificado que os outliers, em sua grande maioria, apresentavam poucos veículos na faixa da direita (dois ou três veículos) e uma quantidade muito superior na faixa da esquerda (50 até 70 veículos) durante o intervalo de coleta. Isso indica que, provavelmente, houve acidente, manutenção da via ou problema na coleta dos dados durante este intervalo. Nota-se que ainda existem valores de $E(i)$ menores que 1.

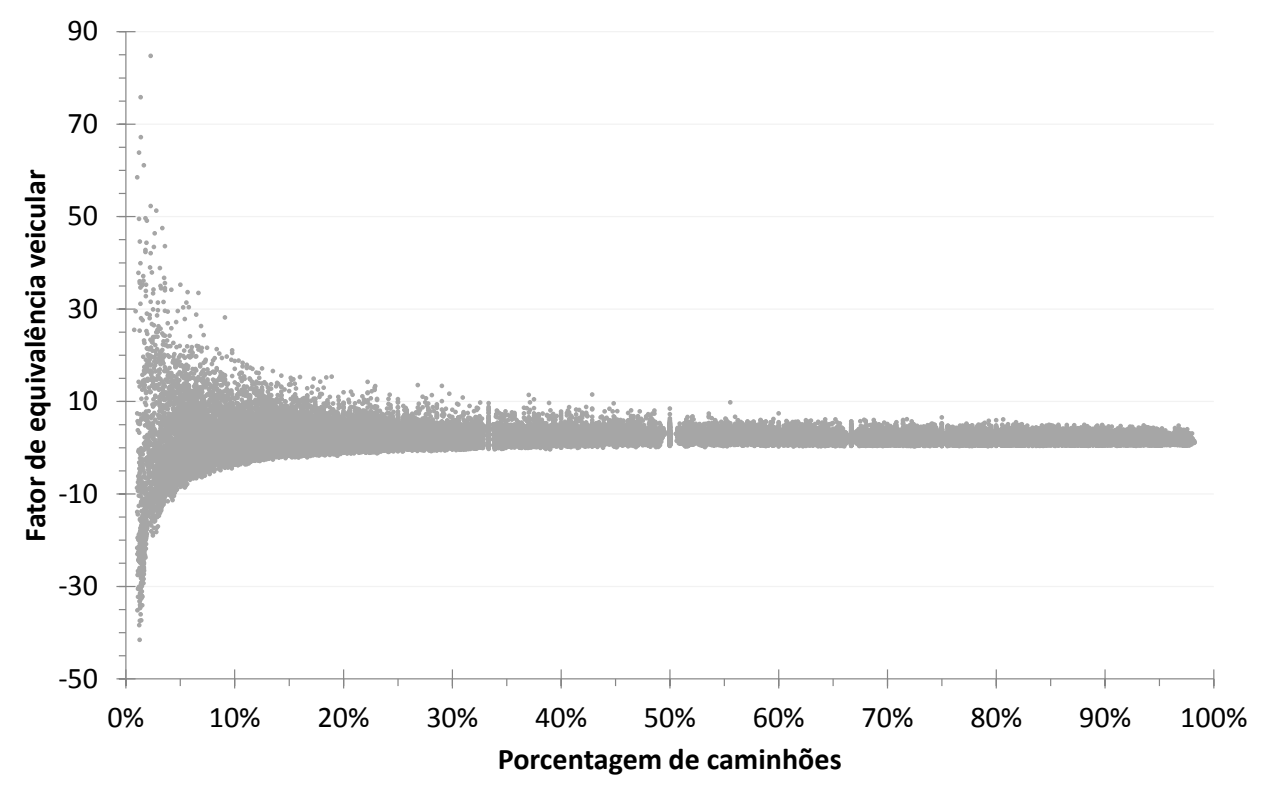

Figura 5.10 - Variação do fator de equivalência veicular em função da porcentagem de caminhões após a remoção dos dados com $k<3$ veic/(km·faixa) 


\subsubsection{Filtro 7: Equivalentes veiculares menores ou iguais a 1,0}

O último filtro a ser aplicado é aquele que descarta os intervalos que apresentam $E(i) \leq 1$, que não fazem sentido na prática, pois derivam de situações em que as impedâncias das duas correntes não são iguais. A Figura 5.11 mostra que 5,4\% das observações foram removidas após a implementação desse filtro.

Ou seja, 16,2\% das observações disponíveis após a fusão dos dados de tráfego e meteorológicos foram consideradas adequadas para uso nas análises subsequentes. Na Figura 5.12 são apresentados os fatores de equivalência $E(i)$ em função da porcentagem de caminhões na faixa da direita $p(i)$, depois da aplicação dos sete filtros.

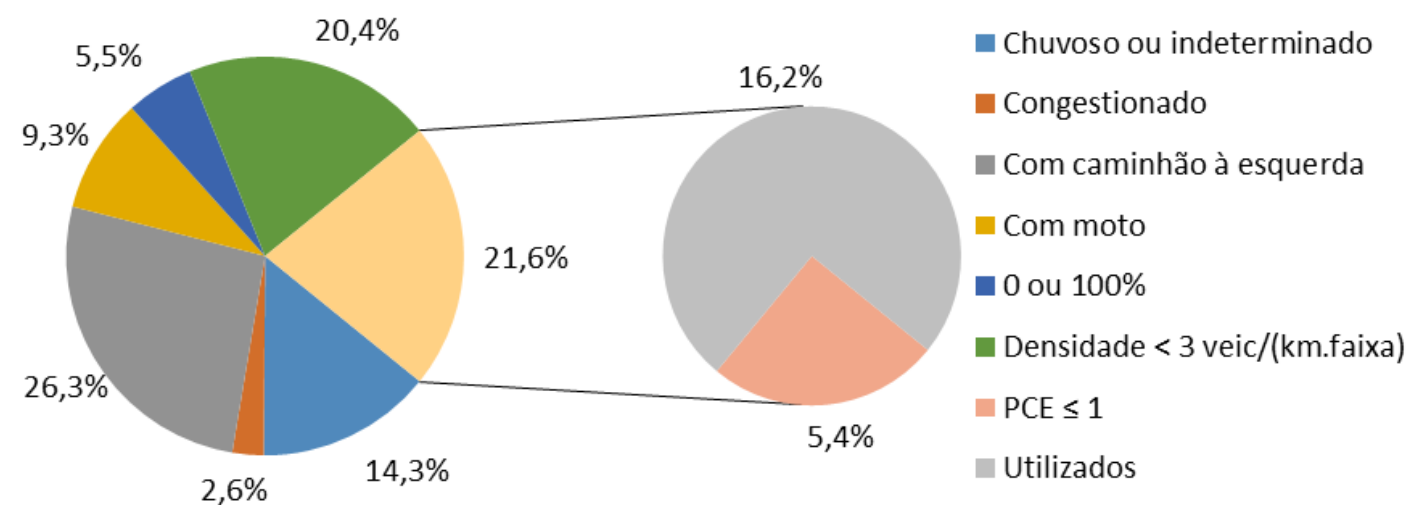

Figura 5.11 - Quantidade de dados removidos por $E(i) \leq 1$

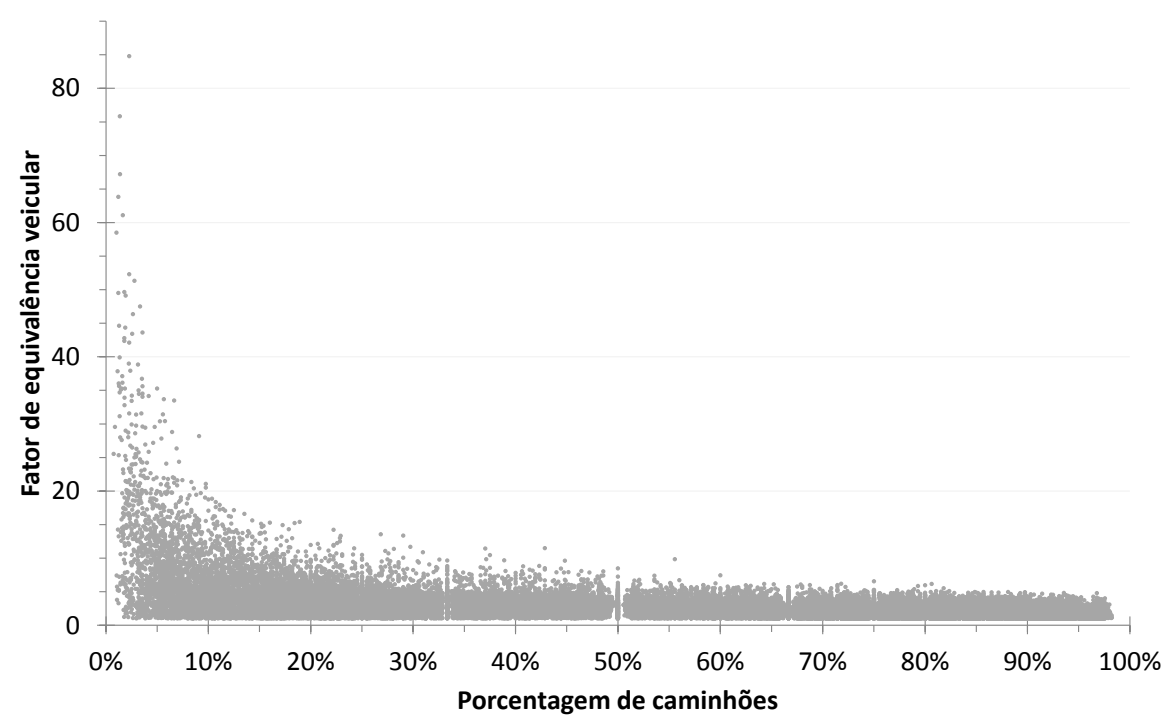

Figura 5.12 - Variação do fator de equivalência veicular em função da porcentagem de caminhões após a remoção dos dados $\operatorname{com} E(i)<1$ 
Após utilizar os filtros, restaram 53.655 observações válidas. A soma do tempo desses intervalos representa 312.451 minutos, ou mais de 200 dias de coleta. Esse conjunto de dados pode ser considerado satisfatório, devido à grande quantidade de observações disponíveis.

No próximo capítulo, são apresentadas análises dos valores encontrados para os equivalentes $E(i)$ e são feitas comparações com estimativas do fator de equivalência obtidas em outros estudos. 


\section{Capítulo}

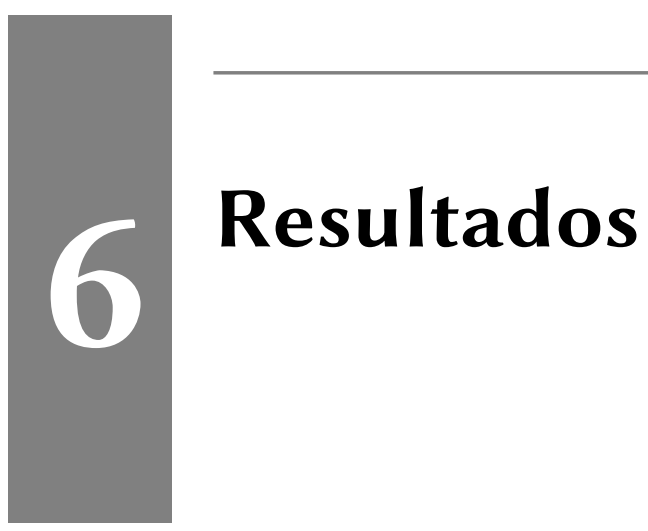

Neste capítulo, as estimativas do fator de equivalência $E(i)$ são analisadas em função de diversos aspectos e os resultados obtidos são comparados com os valores propostos em outros estudos.

\subsection{Parâmetros de agrupamento}

Para facilitar a compreensão e análise dos resultados, foram definidos dois parâmetros de agrupamento para os fatores de equivalência. Primeiro, os resultados foram agrupados pela declividade da seção na qual os laços indutivos estavam instalados. A seguir, os valores de $E(i)$ foram agrupados para diferentes níveis de serviço, calculados pela densidade de veículos na faixa correspondendo ao fluxo básico. Foram usadas cinco classes de níveis de serviço, como definido pelo HCM (TRB, 2010).

\subsubsection{Agrupamento em função dos greides}

Para estimar os greides nos trechos de coleta de dados, foram executados os seguintes passos (ANDRADE, 2012):

1. Obteve-se o perfil vertical dos trechos estudados utilizando os dados produzidos pelo programa Shuttle Radar Topography Mission (SRTM), feito pela NASA (National Aeronautics and Space Administration); 
2. Foi utilizado o método de suavização de média móvel, com 21 pontos, ponderada segundo uma distribuição de Gauss para eliminar erros na altimetria;

3. Identificaram-se subtrechos em greides específicos que, segundo o HCM (TRB, 2010), possuem:

a) Rampa inferior a 3\% e comprimento superior a $800 \mathrm{~m}$ ou;

b) Rampa igual ou maior do que $3 \%$ e comprimento superior a $400 \mathrm{~m}$; e

4. A partir do ponto inicial e final de cada subtrecho, foi calculada a declividade em cada um dos locais de coleta de dados.

Na Tabela 6.1, são apresentados os intervalos de cada uma das classes de greides utilizadas para agrupar os pontos de coleta. Na Tabela 6.2, são identificadas as classe as quais cada um dos pontos de coleta foi agregado. Pode-se notar que as classes 1 e 2 apresentam três postos de coleta e que a classe 3 contém dois postos. Também é importante ressaltar que em todas as classes existem fluxos observados que atingem a capacidade, contemplando assim, todos os níveis de serviço.

Tabela 6.1 - Limites de declividades para cada classe de greide

\begin{tabular}{cl}
\hline Classe de Greide & Declividade (\%) \\
\hline Greide 1 & $0 \%<I \leq 2 \%$ \\
Greide 2 & $2 \%<I \leq 4 \%$ \\
Greide 3 & $4 \%<I$ \\
\hline
\end{tabular}

Tabela 6.2 - Identificação da classe de greide para cada local de coleta

\begin{tabular}{cccccc}
\hline Rodovia & Local $(\mathrm{km})$ & Sentido & Atinge capacidade & Greide & Classe de greide \\
\hline SP280 & 27,0 & Leste & Sim & $3,5 \%$ & Greide 2 \\
SP280 & 29,5 & Leste & Sim & $2,0 \%$ & Greide 1 \\
SP280 & 37,0 & Leste & Sim & $5,0 \%$ & Greide 3 \\
SP280 & 51,9 & Leste & Sim & $4,5 \%$ & Greide 3 \\
SP280 & 59,6 & Leste & Não & $1,5 \%$ & Greide 1 \\
SP348 & 32,0 & Norte & Sim & $3,5 \%$ & Greide 2 \\
SP348 & 59,0 & Norte & Não & $1,0 \%$ & Greide 1 \\
SP348 & 87,0 & Norte & Não & $2,5 \%$ & Greide 2 \\
\hline
\end{tabular}




\subsubsection{Definição dos limites dos níveis de serviço}

A segunda forma utilizada para agrupar os resultados foi baseada no nível de serviço. Os intervalos foram separados pela densidade calculada na faixa mais próxima ao canteiro central (fluxo básico). Foram definidas cinco classes, as quais foram agrupadas conforme os limites de densidade adotados pelo HCM (TRB, 2010). A Tabela 6.3 mostra os valores limites existentes no HCM e a sua conversão em carros de passeio equivalentes por quilômetro por faixa, $\mathrm{cpe} /(\mathrm{km} \cdot$ faixa $)$.

Pode-se perceber que, para o nível de serviço A, a densidade máxima na via é de 6,8 cpe/(km·faixa), sendo que a distância média entre os veículos é menor que $150 \mathrm{~m}$. Esse espaçamento é maior do que o $\operatorname{HCM}$ (TRB, 2010) considera como formação de pelotão, que é de $100 \mathrm{~m}$.

Tabela 6.3 - Limites de densidade para os níveis de serviço

\begin{tabular}{crr}
\hline Limites do NS & Densidade [pce/(mi.faixa)] & Densidade $[\mathrm{cpe} /(\mathrm{km} \cdot$ faixa $)]$ \\
\hline A & $k_{e} \leq 11$ & $k_{e} \leq 6,8$ \\
B & $11<k_{e} \leq 18$ & $6,8<k_{e} \leq 11,2$ \\
C & $18<k_{e} \leq 26$ & $11,2<k_{e} \leq 16,2$ \\
D & $26<k_{e} \leq 35$ & $16,2<k_{e} \leq 21,7$ \\
E & $35<k_{e}$ & $21,7<k_{e}$ \\
\hline
\end{tabular}

Após o agrupamento, a quantidade de observações disponíveis em cada uma das 15 categorias obtidas é apresentada na Tabela 6.4. Verifica-se que, os níveis de serviço A e B apresentam as maiores quantidades, que somadas representam mais de $70 \%$ do total. A classe de greide 2 , que inclui os trechos com inclinação entre $2 \%$ e $4 \%$, apresenta a maior quantidade de observações, totalizando pouco mais de $80 \%$ dos dados. Nota-se também que, o nível de serviço E representa menos de $1 \%$ das observações, já que a operação nesse nível de serviço é muito mais rara do que em qualquer outro. Em dois casos (greides 1 e 3), a quantidade de dados disponível para este nível de serviço, se somados, não chega a uma hora de coleta. Em função disso, as observações referentes ao nível de serviço E foram descartadas da base de dados usada nesta pesquisa. 
Tabela 6.4 - Observações em cada um dos grupos de nível de serviço e greides

\begin{tabular}{crrrr}
\hline Nível de serviço & Greide 1 & Greide 2 & Greide 3 & Total \\
\hline A & 3.843 & 10.705 & 2.262 & 16.810 \\
B & 1.847 & 18.553 & 1.466 & 21.866 \\
C & 500 & 10.682 & 155 & 11.337 \\
D & 103 & 2.997 & 44 & 3.144 \\
E & 10 & 486 & 2 & 498 \\
Total & 6.303 & 43.423 & 3.929 & 53.655 \\
\hline
\end{tabular}

\subsection{Variação do fator de equivalência em função da porcentagem de veículos pesados}

A variação do fator de equivalência em função da porcentagem de caminhões pode ser analisada fixando-se os valores de $k_{d}$ e $k_{e}$ na Equação 3.7. A Figura 6.1 apresenta o gráfico do fator de equivalência veicular $E(i)$ em função da fração de caminhões na faixa da direita $p(i)$, obtido usando-se a Equação 3.7 e fixando-se a densidade de tráfego na faixa da direita como $k_{d}=5 \mathrm{veic} /(\mathrm{km} \cdot$ faixa). Desta forma, foram traçadas quatro curvas diferentes, variando-se a densidade na faixa da esquerda $k_{e}$. Nota-se que, conforme aumenta a porcentagem de caminhões, menor o impacto marginal da adição de veículos pesados na corrente de tráfego.

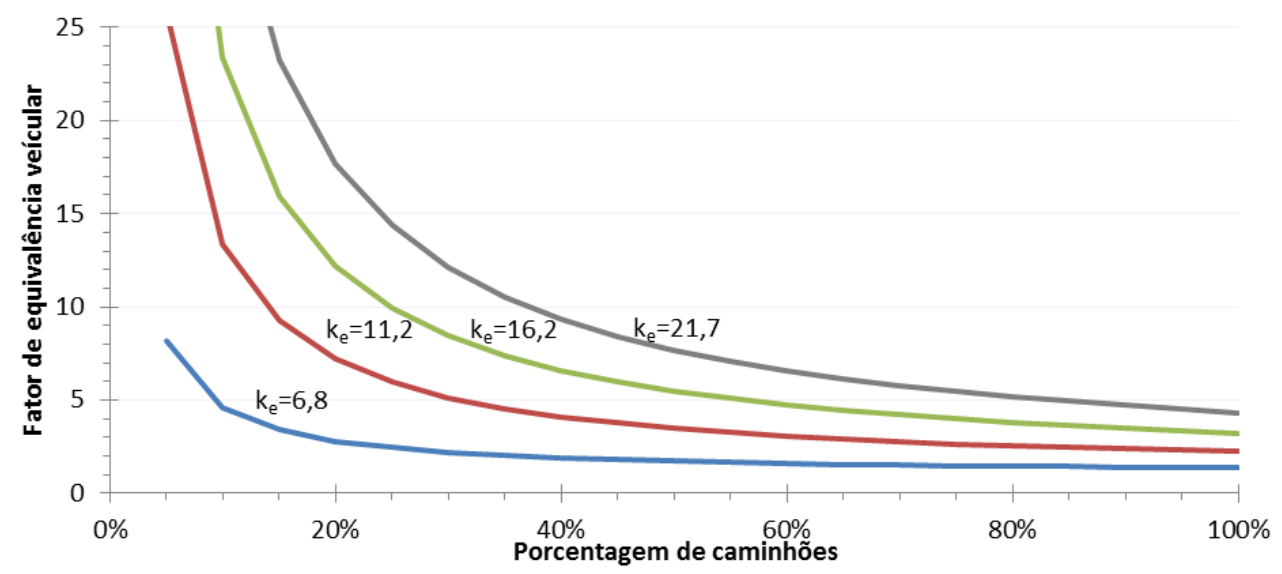

Figura 6.1 - Relação entre fator de equivalência veicular e porcentagem de caminhões na faixa da direita para quatro densidades na faixa da esquerda, $k_{d}=5 \mathrm{veic} /(\mathrm{km} \cdot \mathrm{faixa})$

A Figura 6.2 apresenta os resultados de $E(i)$ em função de $p(i)$ para dados empíricos da classe de greide 2 (inclinação entre $2 \%$ e 4\%), com densidade na faixa da direita de $4,5 \mathrm{veic} /(\mathrm{km} \cdot$ faixa) $\leq k_{d} \leq 5,5 \mathrm{veic} /(\mathrm{km} \cdot$ faixa $)$. 


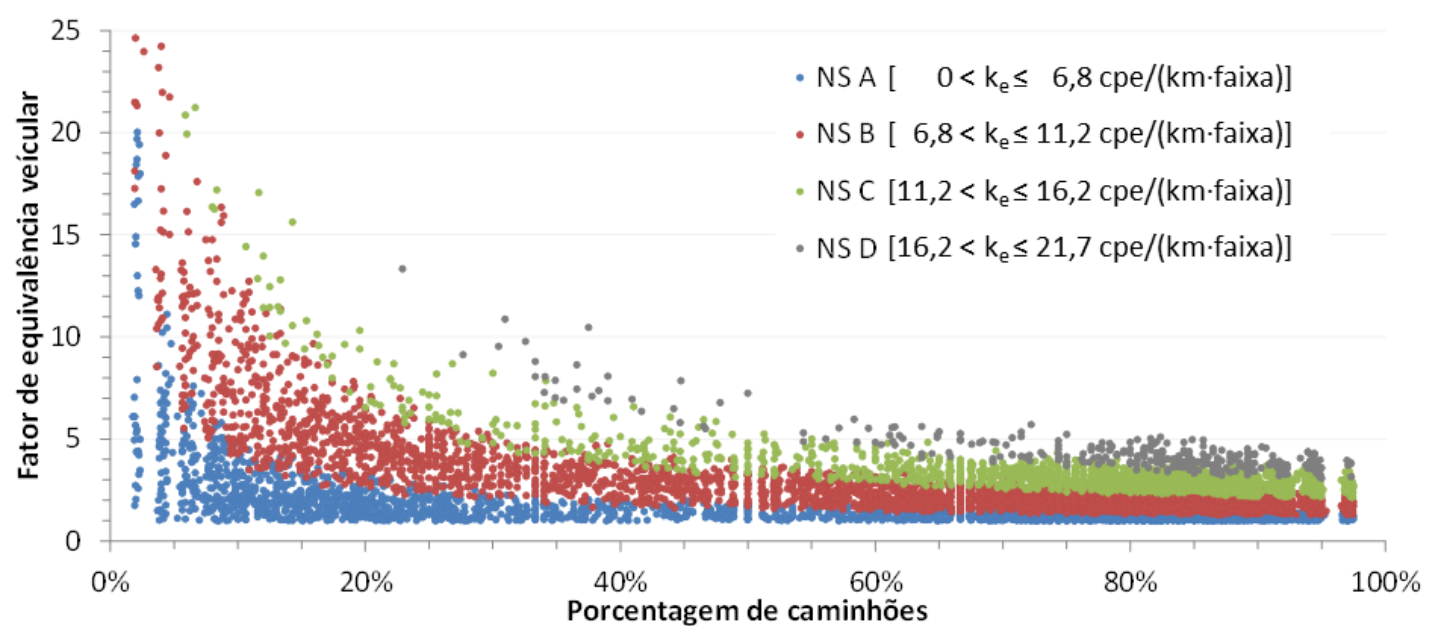

Figura 6.2 - Relação entre fator de equivalência veicular e porcentagem de caminhões obtidos através de dados empíricos para $4,5 \leq k_{d} \leq 5,5 \mathrm{veic} /(\mathrm{km} \cdot$ faixa $)$

Pode-se verificar que, tanto as curvas mostradas na Figura 6.1, quanto os pontos existentes na Figura 6.2 são similares. Desta forma, decidiu-se representar a variação dos fatores de equivalência veicular em função da porcentagem de caminhões por funções hiperbólicas, do tipo

$$
E(i)=a \cdot p(i)^{-b}
$$

em que $\quad E(i)$ : fator de equivalência no $i$-ésima observação;

$p(i)$ : $\quad$ porcentagem de caminhões no $i$-ésima observação; e

$a$ e $b: \quad$ constantes de calibração.

A Figura 6.3 apresenta a frequência acumulada relativa dos valores obtidos para o fator de equivalência veicular $E(i)$. A curva aponta que 99,85\% dos resultados estão contidos até 25 cpe. Desta forma, para melhor visualização e comparação dos resultados, as Figuras 6.4 a 6.8 têm o eixo das ordenadas com máximo de 25 cpe. Vale ressaltar que os resultados superiores a este valor continuarão sendo utilizados no ajuste das funções por regressão linear, mesmo não aparecendo nos gráficos.

As Figuras 6.4 a 6.6 mostram as funções obtidas através de regressão linear para os equivalentes veiculares, para as três classes de greides e para os quatro níveis de serviço considerados nesta pesquisa. 


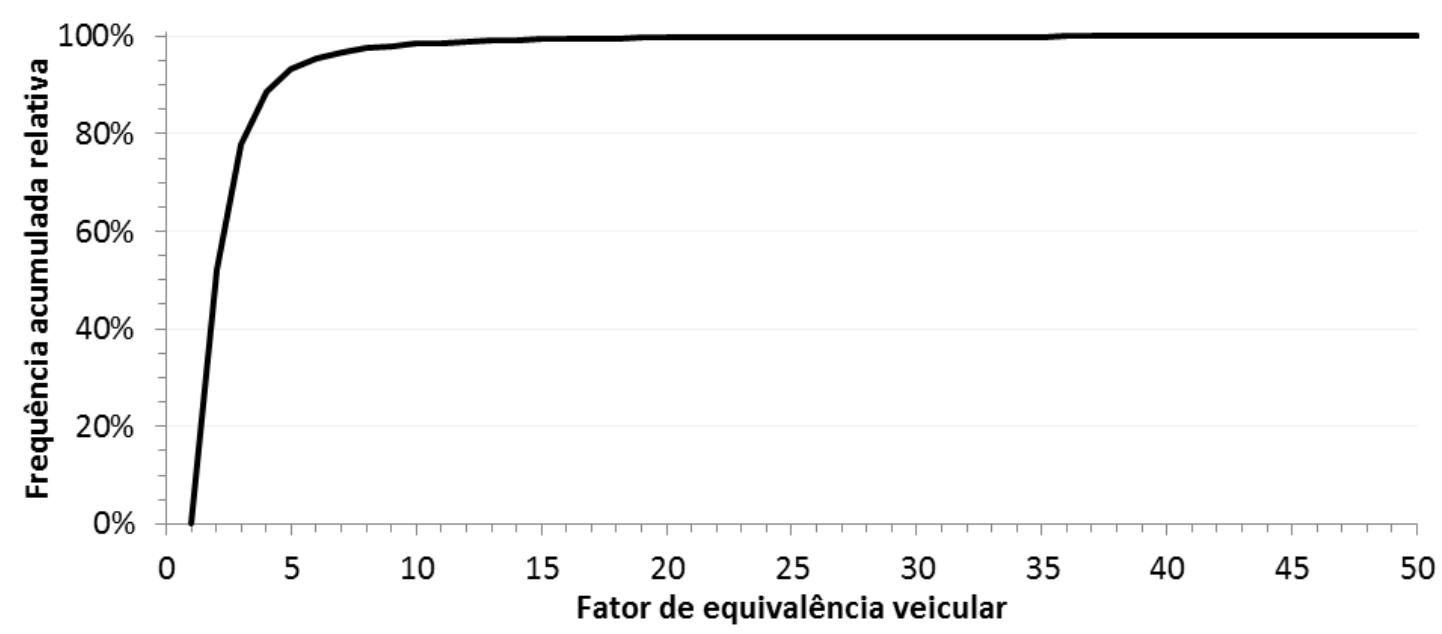

Figura 6.3 - Frequência acumulada relativa em função do fator de equivalência veicular

(a) Nível de Serviço A

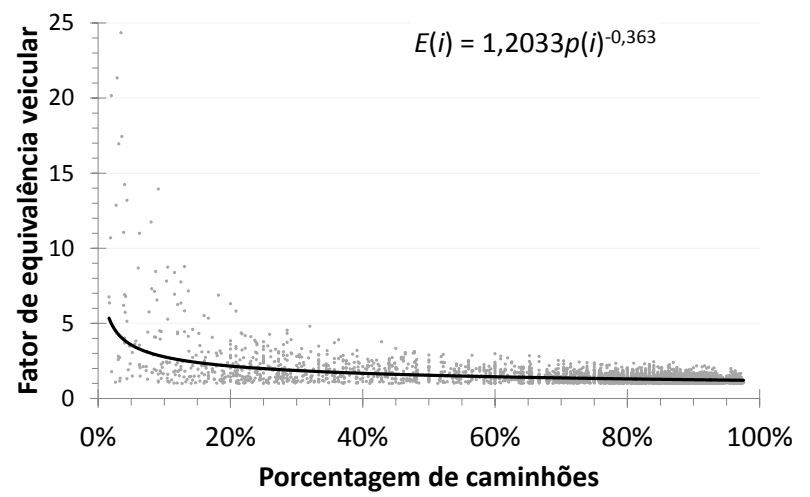

(c) Nível de Serviço C

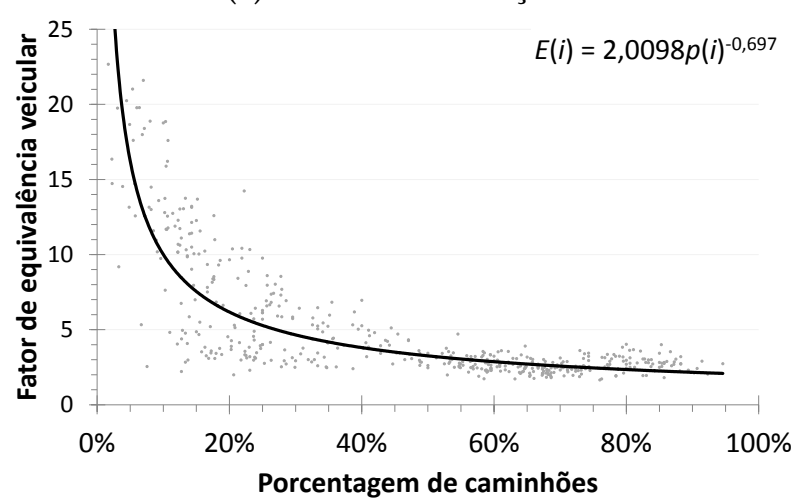

(b) Nível de Serviço B

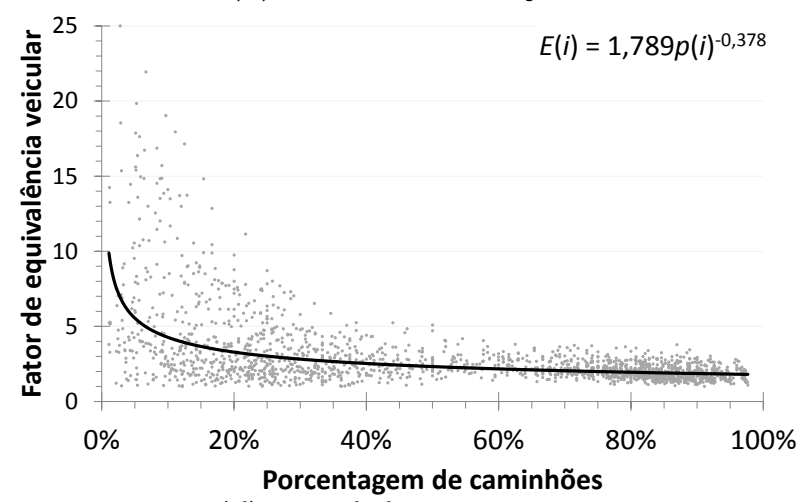

(d) Nível de Serviço D

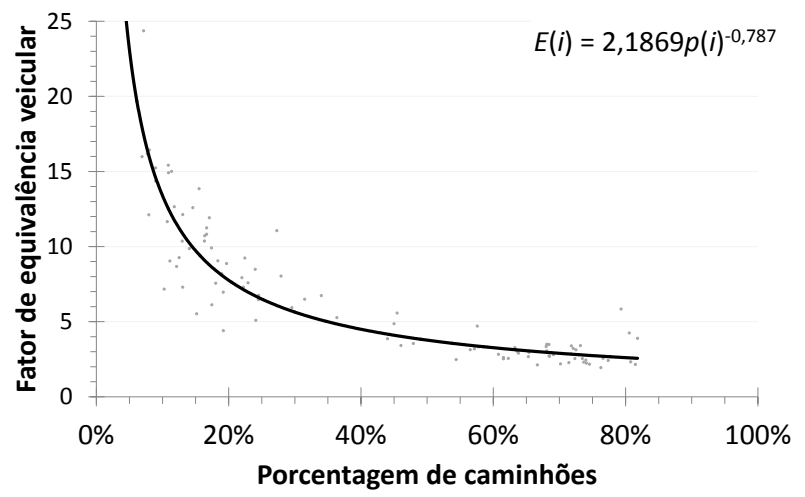

Figura 6.4 - Funções obtidas para o fator de equivalência veicular para a classe de inclinação $1(0 \%<I \leq 2 \%)$, para os níveis de serviço A a D

A Figura 6.4, com as curvas para greides de $0 \%$ a $2 \%$, mostra que os níveis de serviço A e B apresentam maior número de observações do que os níveis de serviço C e D. Contudo, pode-se também, perceber que há uma maior dispersão dos valores calculados para $E(i)$ quando o nível de serviço é A ou B. Pode-se perceber que, quando a porcentagem de caminhões na faixa da direita chega a 40\%, a dispersão dos pontos é menor. 
Na Figura 6.5, que apresenta as curvas da classe de greide $2(2 \%<I \leq 4 \%)$, nota-se que existem mais dados para se fazer a regressão, em relação às outras classes de greide. No nível de serviço A a dispersão das estimativas do fator de equivalência $E(i)$ é maior na comparação com outros níveis. A dispersão dos valores encontrados para $E(i)$, de modo semelhante ao observado para os trechos com greide entre $0 \%$ e $2 \%$, é maior para os níveis de serviço melhores (A e B). Há uma aparente maior coerência do comportamento observado nos níveis de serviço C e D.

(a) Nível de Serviço A

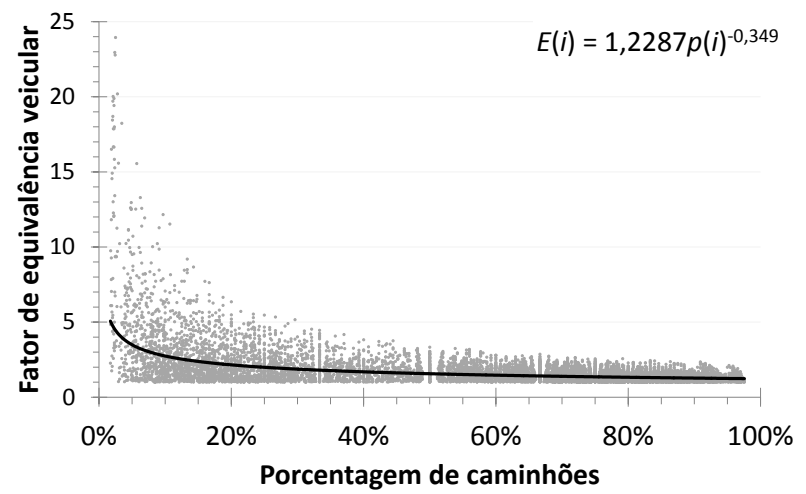

(c) Nível de Serviço C

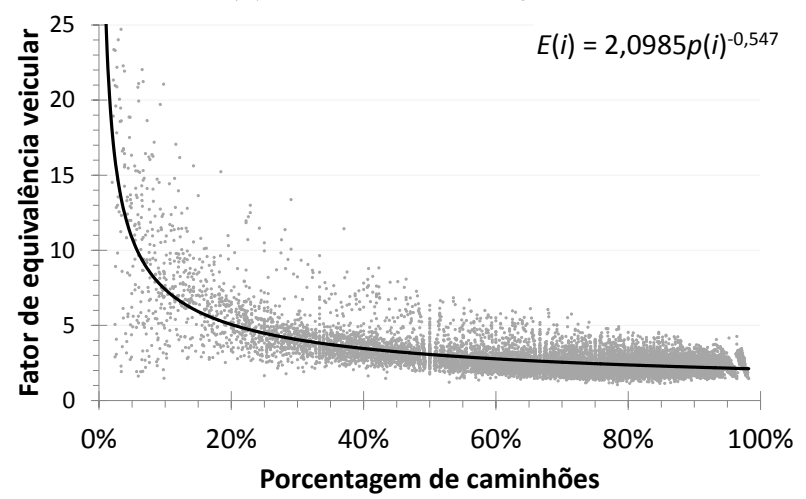

(b) Nível de Serviço B

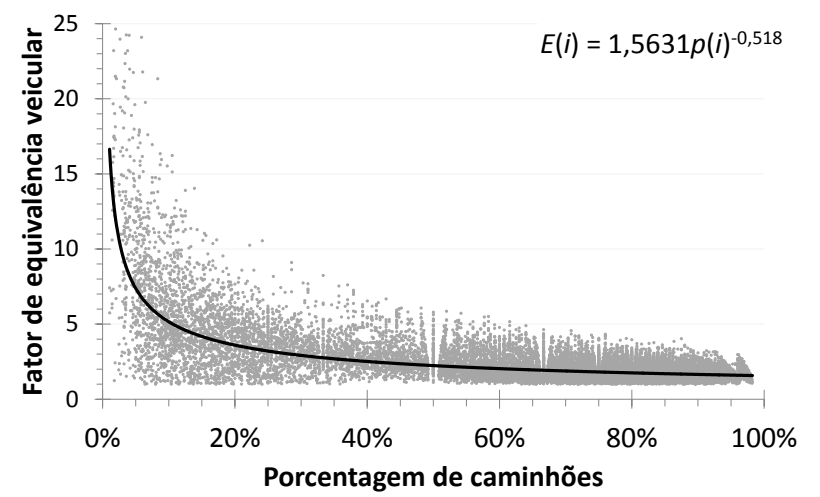

(d) Nível de Serviço D

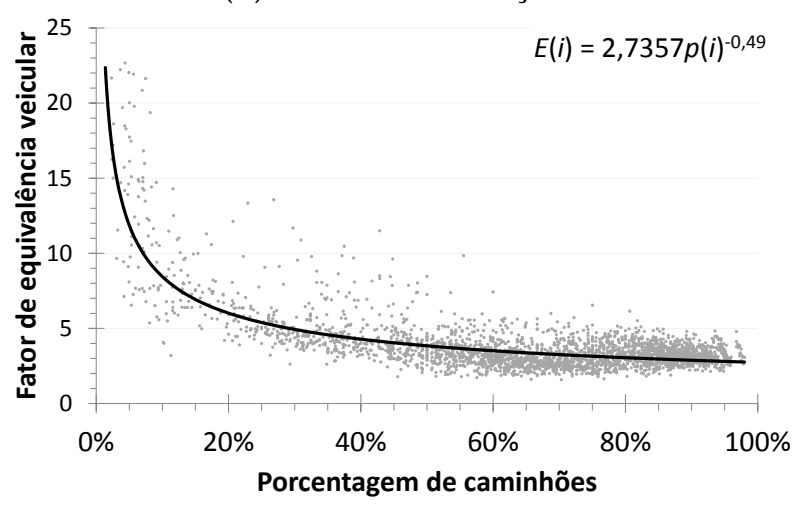

Figura 6.5 - Funções obtidas para aproximar uma curva às estimativas do fator de equivalência veicular obtidas para o greide $2(2 \%<I \leq 4 \%)$, para os diferentes níveis de serviço

A Figura 6.6, que apresenta as curvas da classe de greide $3(4 \%<I)$ mostra comportamento similar ao observado nas Figuras 6.4 e 6.5. Observa-se uma menor dispersão que nas classes de greide 1 e 2 .

Em todos os casos apresentados nas Figuras 6.4 a 6.6, o fator de equivalência decresce conforme a porcentagem de caminhões aumenta. Isso comprova a hipótese apresentada na verificação analítica da Equação 3.7, ilustrada nas Figuras 6.1 e 6.2. Verifica-se também que para porcentagens de caminhões maiores que $40 \%$, a dispersão dos pontos diminui. Possivelmente 
(a) Nível de Serviço A

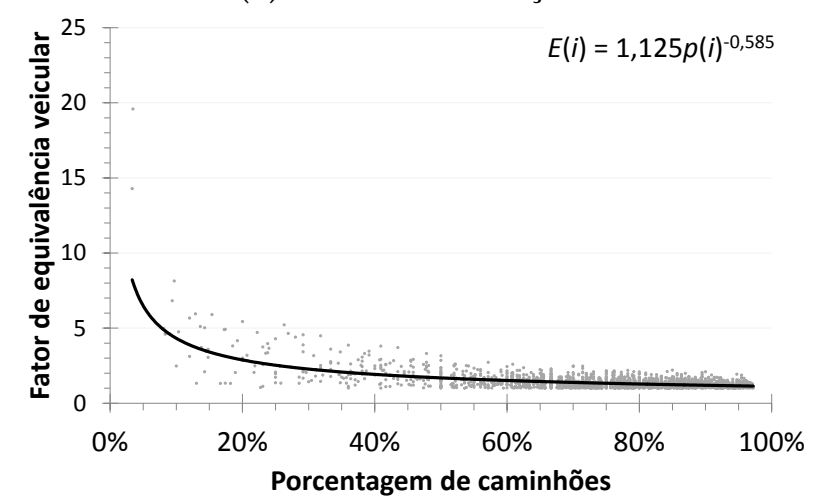

(c) Nível de Serviço C

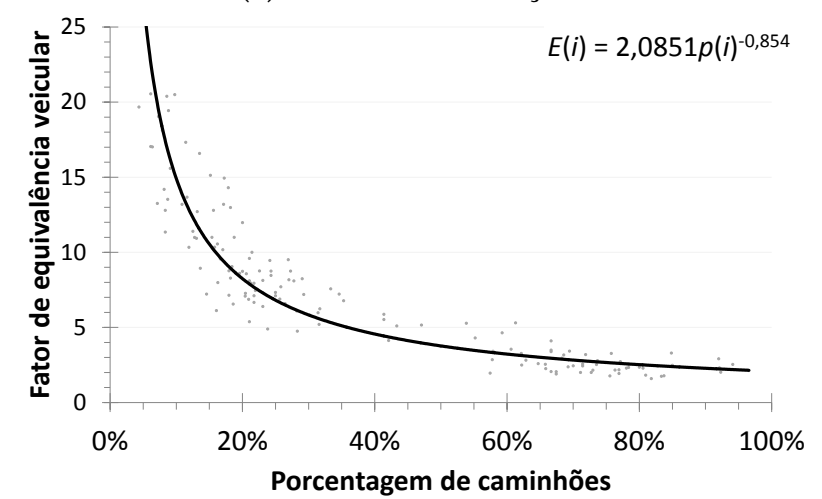

(b) Nível de Serviço B

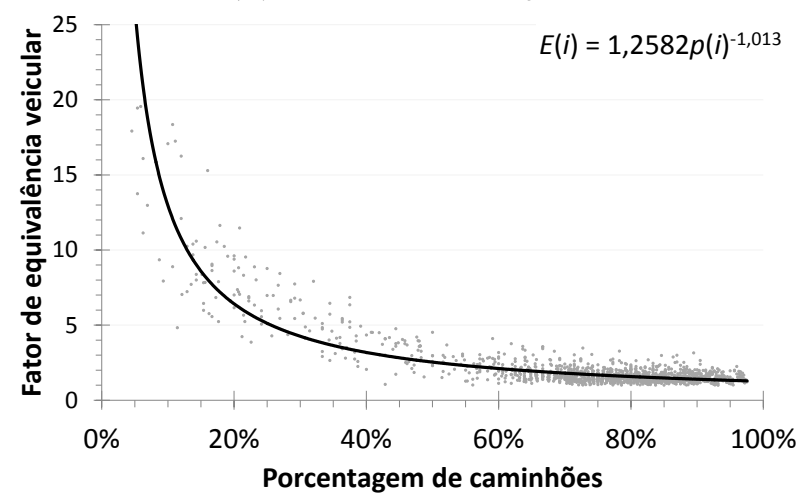

(d) Nível de Serviço D

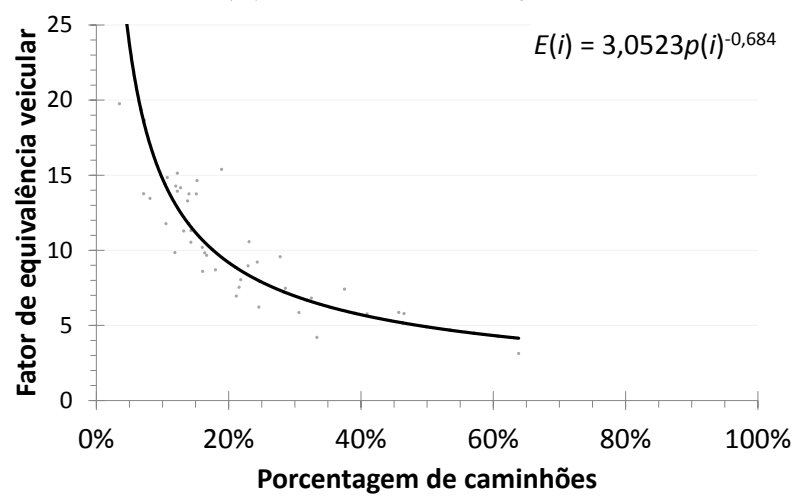

Figura 6.6 - Funções obtidas para aproximar uma curva às estimativas do fator de equivalência veicular obtidas para o greide $3(4 \%<I)$, para os diferentes níveis de serviço

isso ocorre pois quando existe uma quantidade maior de caminhões, esses formam uma corrente de tráfego segregada dos automóveis.

A Tabela 6.5 apresenta as constantes $a$ e $b$ para as 12 curvas apresentadas anteriormente. Verifica-se que, em todas as classes de greides, conforme o nível de serviço piora, maior a constante de calibração $a$, variando entre 1,20 até 3,05. Esse mesmo comportamento não foi observado na constante $b$, que apresentou variação entre 0,349 e 1,013.

Na Tabela 6.6 são apontados os valores de fator de equivalência para greides, níveis de serviço e porcentagem de caminhões calculados através das funções mostradas na Tabela 6.5. É importante ressaltar que em algumas classes de agrupamentos não existiam dados para altas porcentagens de caminhões (superiores a 80\%). Dessa forma, os fatores de equivalência foram extrapolados pelos parâmetros obtidos na Tabela 6.5 para todas as porcentagens entre 5\% e $100 \%$. 
Tabela 6.5 - Parâmetros de $a$ e $b$ das funções $E(i)=a \cdot p(i)^{-b}$ das Figuras 6.4 a 6.6

\begin{tabular}{cccc}
\hline Greide & Nível de serviço & $a$ & $b$ \\
\hline 1 & $\mathrm{~A}$ & 1,2033 & 0,363 \\
& $\mathrm{~B}$ & 1,7890 & 0,378 \\
& $\mathrm{C}$ & 2,0098 & 0,697 \\
& $\mathrm{D}$ & 2,1869 & 0,787 \\
\hline 2 & $\mathrm{~A}$ & 1,2287 & 0,349 \\
& $\mathrm{~B}$ & 1,5631 & 0,518 \\
& $\mathrm{C}$ & 2,0985 & 0,547 \\
& $\mathrm{D}$ & 2,7357 & 0,490 \\
\hline 3 & $\mathrm{~A}$ & 1,1250 & 0,585 \\
& $\mathrm{~B}$ & 1,2582 & 1,013 \\
& $\mathrm{C}$ & 2,0851 & 0,854 \\
& $\mathrm{D}$ & 3,0523 & 0,684 \\
\hline
\end{tabular}

Tabela 6.6 - Fator de equivalência para greides, níveis de serviço e porcentagem de caminhões

\begin{tabular}{|c|c|c|c|c|c|c|c|c|c|c|c|c|}
\hline \multirow[b]{2}{*}{$p(i)$} & \multicolumn{4}{|c|}{ Greide 1 (0 a $2 \%)$} & \multicolumn{4}{|c|}{ Greide 2 (2 a 4\%) } & \multicolumn{4}{|c|}{ Greide $3(>4 \%)$} \\
\hline & NS A & NS B & NS C & NS D & NS A & NS B & NS C & NS D & NS A & NS B & NS C & NS D \\
\hline $5 \%$ & 3,6 & 5,6 & 16,2 & 23,1 & 3,5 & 7,4 & 10,8 & 11,9 & 6,5 & 26,2 & 26,9 & 23,7 \\
\hline $10 \%$ & 2,8 & 4,3 & 10,0 & 13,4 & 2,7 & 5,2 & 7,4 & 8,5 & 4,3 & 13,0 & 14,9 & 14,7 \\
\hline $15 \%$ & 2,4 & 3,7 & 7,5 & 9,7 & 2,4 & 4,2 & 5,9 & 6,9 & 3,4 & 8,6 & 10,5 & 11,2 \\
\hline $20 \%$ & 2,2 & 3,3 & 6,2 & 7,8 & 2,2 & 3,6 & 5,1 & 6,0 & 2,9 & 6,4 & 8,2 & 9,2 \\
\hline $25 \%$ & 2,0 & 3,0 & 5,3 & 6,5 & 2,0 & 3,2 & 4,5 & 5,4 & 2,5 & 5,1 & 6,8 & 7,9 \\
\hline $30 \%$ & 1,9 & 2,8 & 4,7 & 5,6 & 1,9 & 2,9 & 4,1 & 4,9 & 2,3 & 4,3 & 5,8 & 7,0 \\
\hline $35 \%$ & 1,8 & 2,7 & 4,2 & 5,0 & 1,8 & 2,7 & 3,7 & 4,6 & 2,1 & 3,6 & 5,1 & 6,3 \\
\hline $40 \%$ & 1,7 & 2,5 & 3,8 & 4,5 & 1,7 & 2,5 & 3,5 & 4,3 & 1,9 & 3,2 & 4,6 & 5,7 \\
\hline $45 \%$ & 1,6 & 2,4 & 3,5 & 4,1 & 1,6 & 2,4 & 3,2 & 4,0 & 1,8 & 2,8 & 4,1 & 5,3 \\
\hline $50 \%$ & 1,5 & 2,3 & 3,3 & 3,8 & 1,6 & 2,2 & 3,1 & 3,8 & 1,7 & 2,5 & 3,8 & 4,9 \\
\hline $55 \%$ & 1,5 & 2,2 & 3,0 & 3,5 & 1,5 & 2,1 & 2,9 & 3,7 & 1,6 & 2,3 & 3,5 & 4,6 \\
\hline $60 \%$ & 1,4 & 2,2 & 2,9 & 3,3 & 1,5 & 2,0 & 2,8 & 3,5 & 1,5 & 2,1 & 3,2 & 4,3 \\
\hline $65 \%$ & 1,4 & 2,1 & 2,7 & 3,1 & 1,4 & 2,0 & 2,7 & 3,4 & 1,4 & 1,9 & 3,0 & 4,1 \\
\hline $70 \%$ & 1,4 & 2,0 & 2,6 & 2,9 & 1,4 & 1,9 & 2,6 & 3,3 & 1,4 & 1,8 & 2,8 & 3,9 \\
\hline $75 \%$ & 1,3 & 2,0 & 2,5 & 2,7 & 1,4 & 1,8 & 2,5 & 3,1 & 1,3 & 1,7 & 2,7 & 3,7 \\
\hline $80 \%$ & 1,3 & 1,9 & 2,3 & 2,6 & 1,3 & 1,8 & 2,4 & 3,1 & 1,3 & 1,6 & 2,5 & 3,6 \\
\hline $85 \%$ & 1,3 & 1,9 & 2,3 & 2,5 & 1,3 & 1,7 & 2,3 & 3,0 & 1,2 & 1,5 & 2,4 & 3,4 \\
\hline $90 \%$ & 1,3 & 1,9 & 2,2 & 2,4 & 1,3 & 1,7 & 2,2 & 2,9 & 1,2 & 1,4 & 2,3 & 3,3 \\
\hline $95 \%$ & 1,2 & 1,8 & 2,1 & 2,3 & 1,3 & 1,6 & 2,2 & 2,8 & 1,2 & 1,3 & 2,2 & 3,2 \\
\hline $100 \%$ & 1,2 & 1,8 & 2,0 & 2,2 & 1,2 & 1,6 & 2,1 & 2,7 & 1,1 & 1,3 & 2,1 & 3,1 \\
\hline
\end{tabular}

\subsection{Análise dos resultados}

As funções $E(i)$ da Tabela 6.5 foram analisadas em duas abordagens diferentes. Primeiro, foi feita uma análise dos valores de $E(i)$ comparando os diferentes níveis de serviço para os mesmos greides. Depois, foram comparados os valores de $E(i)$ de diferentes greides para o mesmo 
nível de serviço. É importante ressaltar que as curvas foram traçadas a partir das constantes $a$ e $b$ obtidas na Tabela 6.5. As curvas foram geradas para porcentagens de caminhões na faixa da direita de 5\% até 100\%, mesmo não havendo observações para esses valores de $p(i)$.

\subsubsection{Comparação por greide}

A Figura 6.7 apresenta as comparações para um mesmo greide e diferentes níveis de serviço. Observa-se na Figura 6.7 (a), na qual são apresentadas as funções para a classe de greide 1 $(0 \%<I \leq 2 \%)$, quanto pior o nível de serviço, maior o fator de equivalência veicular para uma mesma porcentagem de caminhões. Também verifica-se que as funções apresentam uma clara separação entre os níveis de serviço A e B em relação aos níveis de serviço C e D. É possível identificar que, para $p(i) \geq 60 \%$, os fatores de equivalência veicular apresentam valores próximos para todos os níveis de serviço.

Na Figura 6.7 (b), que mostra as funções para a classe de greide 2 (greide variando entre $2 \%$ e 4\%), as curvas são mais próximas para os diferentes níveis de serviço. Pode-se verificar que os níveis de serviço C e D apresentam valores de fator de equivalência veicular superior aos correspondentes aos níveis de serviço A e B. Também pode-se notar que o valor máximo para o fator de equivalência veicular neste greide $[p(i)=5 \%]$ é de aproximadamente 12 , enquanto nos outros greides, a mesma porcentagem de veículos pesados fornece fatores próximos a 25 .

Para a classe de inclinação 3 (greides superiores a 4\%), a comparação entre as diferentes funções pode ser vista na Figura 6.7 (c). Neste caso, verifica-se que, para porcentagens de caminhões inferiores a $10 \%$, os níveis de serviço B, C e D apresentam valores de equivalentes veiculares muito próximos e significativamente maiores que os estimados para o nível de serviço A. A partir de $60 \%$ de caminhões, os fatores também apresentam similaridade nos resultados, principalmente entre os níveis A e B.

Para trechos com inclinação inferior a 4\%, a facilidade de manobra dos níveis de serviço A e B e dos níveis C e D são parecidos entre si, sendo indicados pelos fatores de equivalência veicular similares. Para trechos mais íngremes (maiores que 4\%) e baixas porcentagens de caminhões, a facilidade em troca de faixa dos automóveis para ultrapassar os caminhões também pode ser uma hipótese para os baixos valores de $E(i)$ do nível de serviço A. 
(a) Greide $1(0 \%<I \leq 2 \%)$

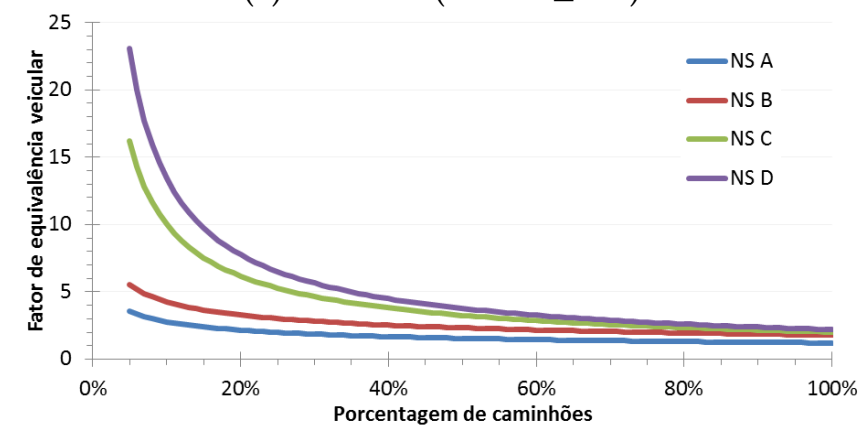

(b) Greide $2(2 \%<I \leq 4 \%)$

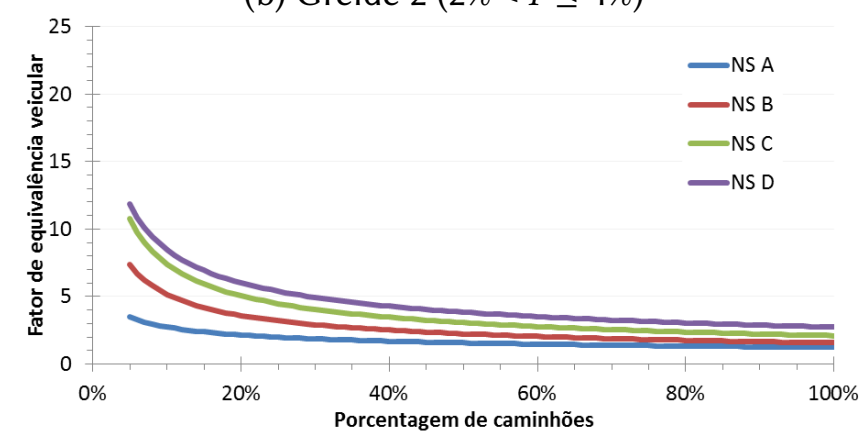

(c) Greide $3(I>4 \%)$

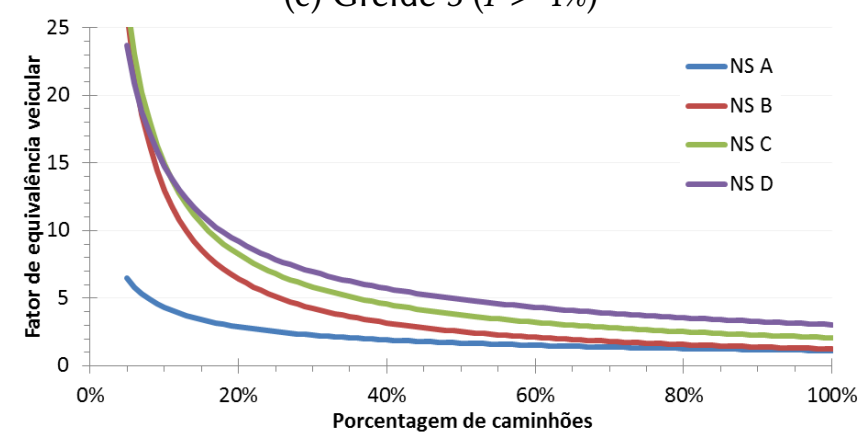

Figura 6.7 - Comparação entre as curvas dos níveis de serviço para a mesma classe de greide

\subsubsection{Comparação por nível de serviço}

A Figura 6.8 apresenta as comparações para um mesmo nível de serviço e diferentes greides. É importante salientar que para $p(i)>50 \%$, em todos os casos, os equivalentes veiculares são muito próximos para um mesmo nível de serviço.

Na Figura 6.8 (a), que compara as funções dos três greides para o nível de serviço A, é possível identificar que esse nível de serviço apresenta os menores valores de equivalentes veiculares. Também verifica-se que, os fatores de equivalência para os greides 1 e 2 são praticamente idênticos e que o greide 3 apresenta valores maiores até a porcentagem de caminhões de $50 \%$.

A Figura 6.8 (b), que compara as curvas dos greides para o nível de serviço B, mostra que os greides 1 e 2 apresentam fatores de equivalência veiculares próximos. Para $p(i)<50 \%$, o 
(a) Nível de serviço $\mathrm{A}$

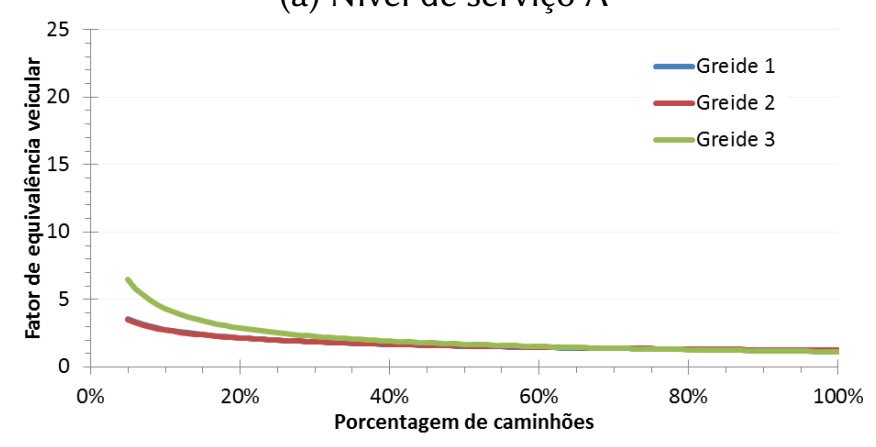

(b) Nível de serviço B

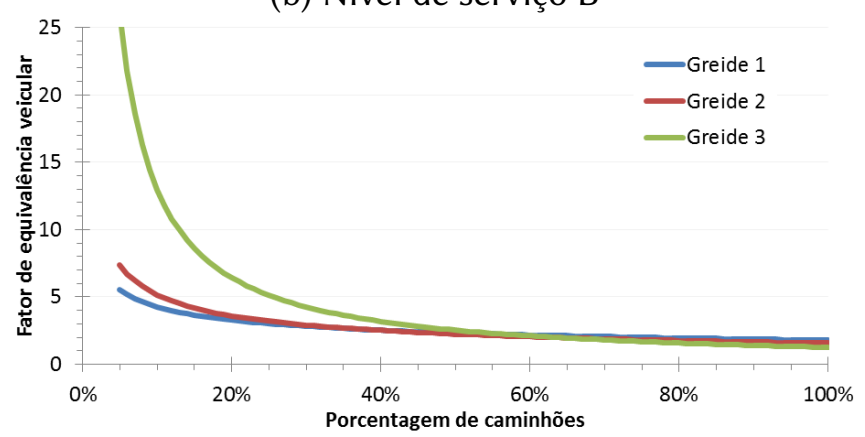

(c) Nível de serviço C

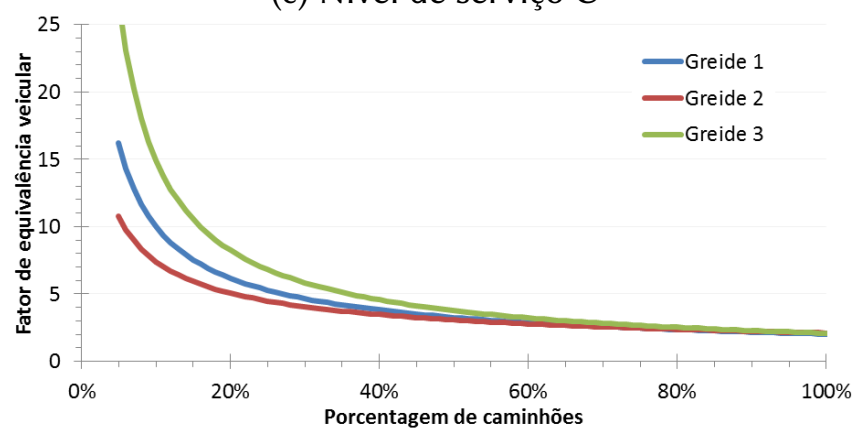

(d) Nível de serviço D

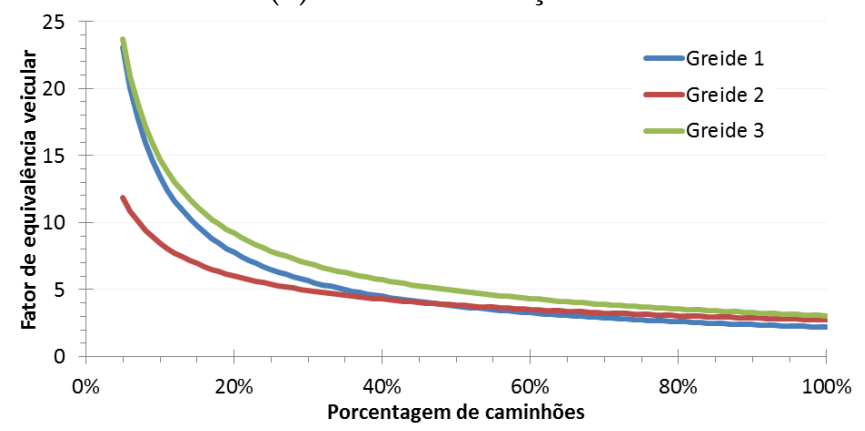

Figura 6.8 - Comparação entre as curvas das classes de greide para um mesmo nível de serviço

greide 3 apresenta $E(i)$ maiores que as outras duas classes de greide. Isso indica que o impacto dos veículos pesados é maior em rampas mais íngremes.

Na Figura 6.8 (c), que compara as funções para cada classe de greide para o nível de serviço C, pode-se observar que existe uma inversão na ordem das curvas. Até a porcentagem de $50 \%$ de caminhões, a curva que apresenta menores fatores de equivalência veicular é a curva do 
greide 2. A curva de greide 3 apresenta os maiores equivalentes veiculares e o greide 1 mostra valores intermediários.

Para o nível de serviço D, a Figura 6.8 (d) mostra que até os $10 \%$ de caminhões na faixa de fluxo misto, os valores do greide 1 e 3 estão próximos, enquanto o greide 2 apresenta valores inferiores a estes. Nos $40 \%$, a curva de greide 2 se aproxima da curva do greide 1 . Quando as porcentagens de caminhões ultrapassam o valor de $60 \%$, os fatores de equivalência veicular ficam próximos para os 3 greides.

Verificou-se, portanto, que quanto maior o fluxo de veículos (pior nível de serviço), maior o valor de $E(i)$ para uma mesma porcentagem de caminhões. Além disso, para os níveis de serviço A e B, o fator de equivalência é maior quanto mais íngreme a rampa. Essa relação não é observada para os níveis de serviço C e D.

O impacto dos caminhões é menor nos níveis de serviço A e B pela facilidade de manobra dos automóveis a densidade de veículos é menor. Os maiores fatores de equivalência das classes de greide 1 em relação ao greide 2 nos níveis de serviço C e D pode estar relacionado com a limitação diferenciada de velocidade para os caminhões.

\subsection{Análise comparativa com outros estudos}

Foram comparados os resultados de $E(i)$ calculados nesta pesquisa e os fatores de equivalência para rodovias de pista dupla paulistas obtidos em outros dois estudos (DEMARCHI, 2000; CUNHA, 2007).

Esta pesquisa obtém funções para o cálculo de equivalentes veiculares através de dados empíricos; nas outras duas, o tráfego foi gerado em simuladores. Através da simulação, é possível criar trechos homogêneos, ou seja, aclives com inclinação e distância definidos pelos parâmetros de entrada do simulador. Por sua vez, os dados empíricos nem sempre são coletados em trechos homogêneos e estão repletos de ruídos.

A Tabela 6.7 fornece a extensão do greide e a distância entre o início do greide e o laço indutivo nos pontos de coleta usados neste estudo. Deve-se ressaltar que, em todos os sensores, os trechos anteriores são declives. Observa-se que, em cinco locais, a distância entre o laço e o início do aclive é menor que $500 \mathrm{~m}$. Em apenas um caso esta distância é superior a 1,25 km. 
Tabela 6.7 - Características do local de instalação dos laços indutivos: extensão do greide, distância entre o laço e o início do trecho inclinado

\begin{tabular}{rrrrrr}
\hline Rodovia & Local $(\mathrm{km})$ & Sentido & Greide & $\begin{array}{c}\text { Extensão } \\
\text { greide }(\mathrm{km})\end{array}$ & $\begin{array}{c}\text { Distância do } \\
\text { início }(\mathrm{km})\end{array}$ \\
\hline SP280 & 27,0 & Leste & $3,5 \%$ & 1,4 & 1,3 \\
SP280 & 29,5 & Leste & $2,0 \%$ & 0,3 & 0,1 \\
SP280 & 37,0 & Leste & $5,0 \%$ & 0,3 & 0,1 \\
SP280 & 51,9 & Leste & $4,5 \%$ & 1,7 & 0,3 \\
SP280 & 59,6 & Leste & $1,5 \%$ & 0,4 & 0,2 \\
SP348 & 32,0 & Norte & $3,5 \%$ & 1,9 & 0,7 \\
SP348 & 59,0 & Norte & $1,0 \%$ & 0,3 & 0,1 \\
SP348 & 87,0 & Norte & $2,5 \%$ & 1,9 & 1,1 \\
\hline
\end{tabular}

Desta forma, foram feitas algumas considerações para comparar os resultados disponíveis na literatura com os valores obtidos neste estudo. Os níveis de serviço foram considerados os mesmos em todos os estudos, ainda que os da literatura apresentem limites de níveis de serviço diferentes dos utilizados nesta pesquisa. De Cunha (2007), foram utilizados os resultados baseados na densidade, com velocidade de fluxo livre de $110 \mathrm{~km} / \mathrm{h}$.

Conforme apresentado na Tabela 6.7, a maioria dos laços indutivos estão localizada a menos de $500 \mathrm{~m}$ do início do aclive. Assim, em relação ao comprimento da rampa, dos estudos de Demarchi (2000) e Cunha (2007), foram utilizados equivalentes veiculares de rampas de 0,5 km de comprimento.

Para comparar os resultados da classe de greide 1 (inclinação menor do que 2\%), foi usada a média aritmética dos resultados obtidos por Demarchi (2000) e Cunha (2007) para os aclives de $0 \%$ e $2 \%$. Para a comparação da classe de greide 2 (greides entre $2 \%$ e $4 \%$ ), foi usada a média aritmética dos equivalentes para as rampas de $2 \%$ e $4 \%$. Os resultados para a classe de greide 3 (greide maior que 4\%), foram comparados com a média aritmética dos equivalentes para as rampas de $4 \%$ e $6 \%$.

A Figura 6.9 compara os resultados obtidos neste estudo com os obtidos em estudos anteriores para greides menores que $2 \%$. Pode-se observar que os valores obtidos nesta pesquisa são maiores do que os dos outros estudos. Quando os resultados se aproximam dos $40 \%$ de caminhões, a diferença diminui. Também pode ser observado que nos níveis de serviço A e B as diferenças dos fatores de equivalência veicular são menores do que as observadas nos níveis C e D. 
(a) Nível de Serviço A

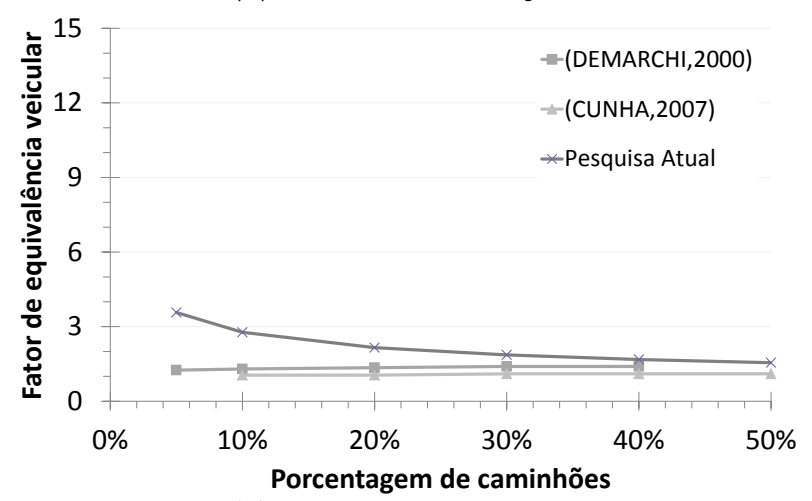

(c) Nível de Serviço C

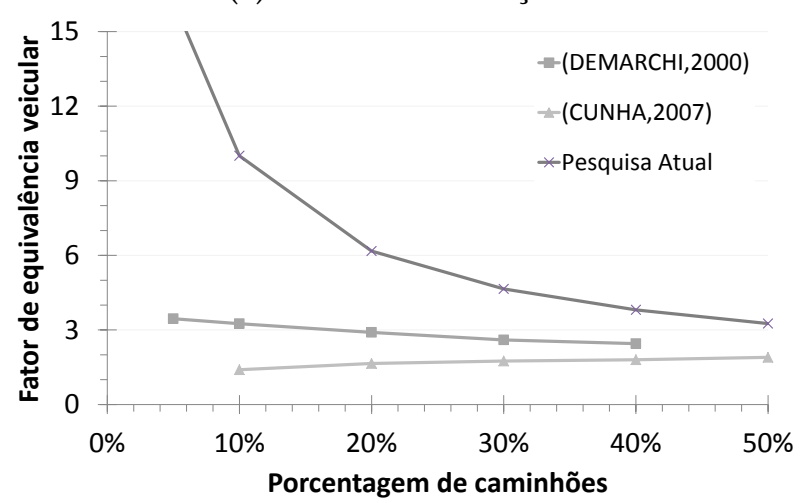

(b) Nível de Serviço B

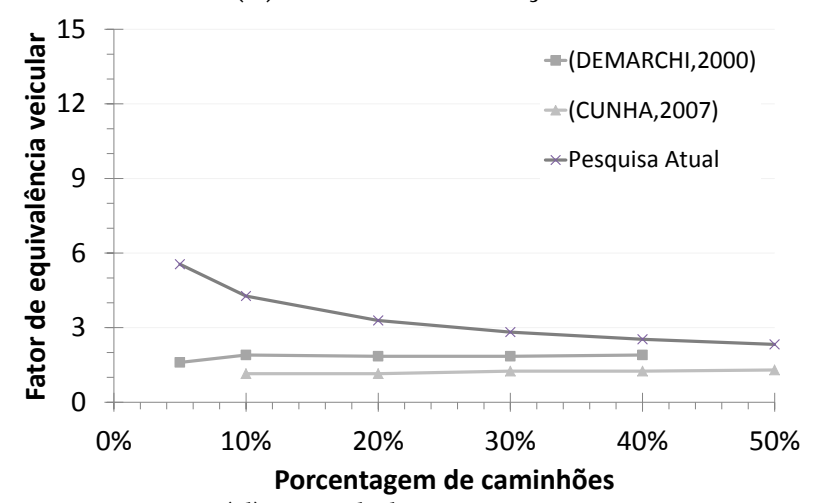

(d) Nível de Serviço D

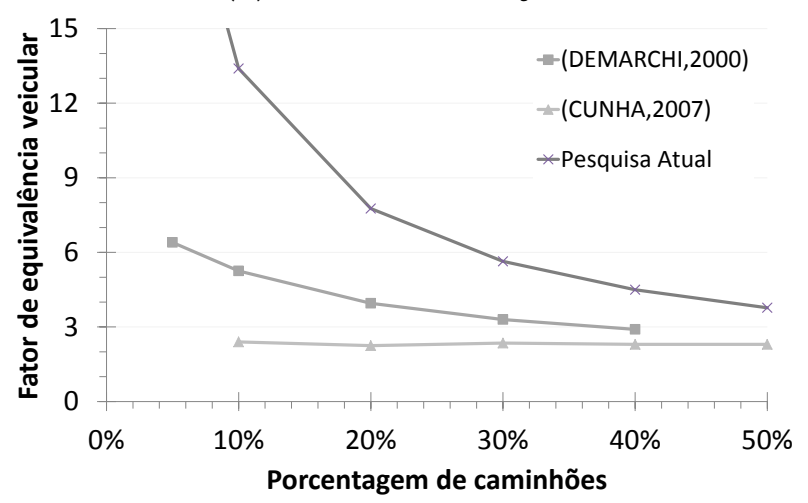

Figura 6.9 - Comparação entre os estudos para a classe de greide 1, para os diferentes níveis de serviço

A Figura 6.10, que compreende as comparações dos valores de $E(i)$ para greides entre $2 \%$ e $4 \%$, observa-se que, para porcentagem de caminhões inferiores a $10 \%$, os valores encontrados nesta pesquisa são muito maiores que os das anteriores. Para o nível de serviço D, os resultados de Demarchi (2000) estão próximos aos obtidos nesta pesquisa para todas as porcentagens de caminhões. Novamente, observa-se que, quando $p(i)$ aproxima-se de $40 \%$, os valores encontrados nesta pesquisa se aproximam aos dos encontrados nos outros estudos.

Ao observar-se a comparação mostrada na Figura 6.11 (classe de greide 3, com aclives superiores a $4 \%$ ), nota-se que a dispersão dos resultados comparados é maior do que nas outras classes de greide. Apenas para o nível de serviço A os valores encontrados estão próximos. Para $p(i)<10 \%$ verifica-se que os resultados desta pesquisa são muito superiores aos outros estudos, principalmente para os níveis de serviço B, C e D.

Mesmo com pequenas aproximações feitas para comparar os resultados desta pesquisa com outros estudos encontrados na literatura, é possível verificar que os equivalentes veiculares 
(a) Nível de Serviço A

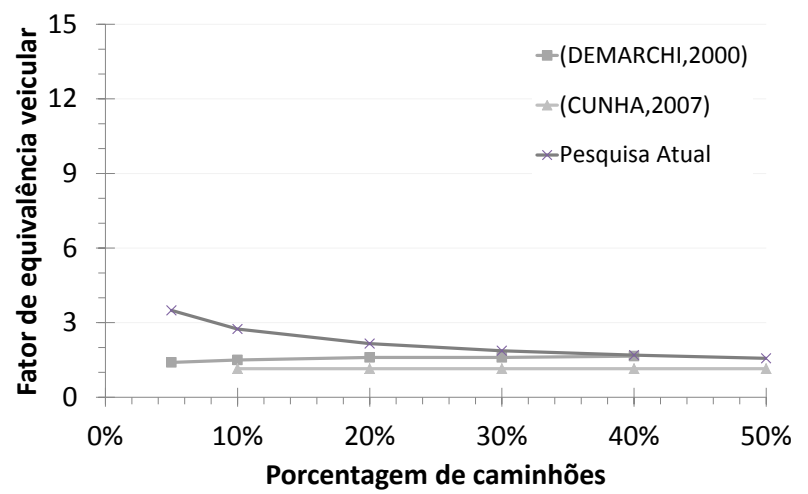

(c) Nível de Serviço C

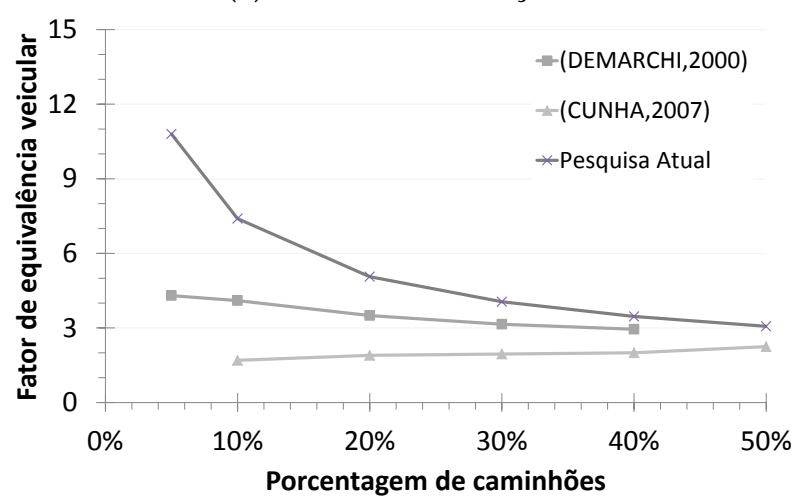

(b) Nível de Serviço B

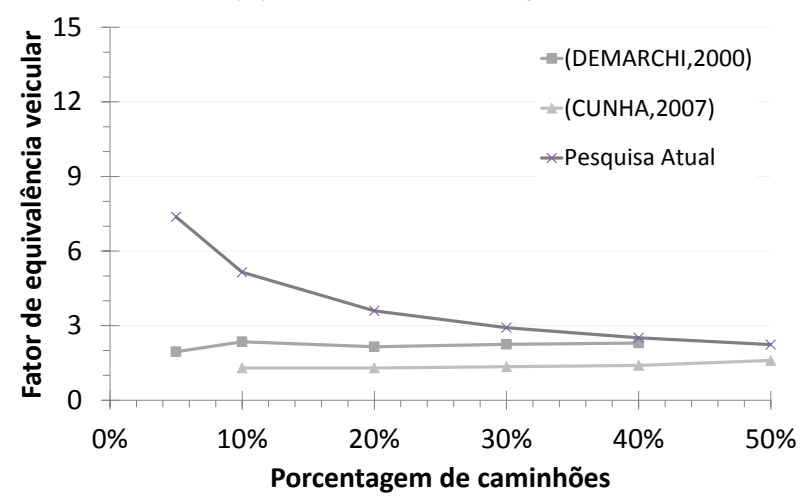

(d) Nível de Serviço D

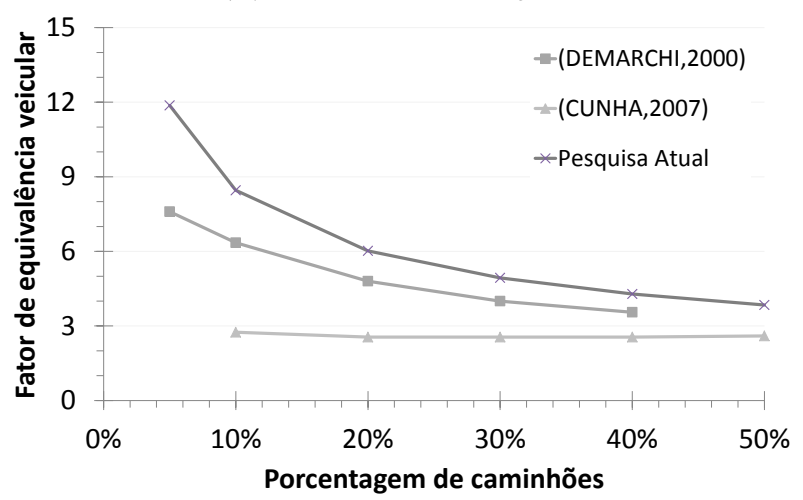

Figura 6.10 - Comparação entre os estudos para a classe de greide 2, para os diferentes níveis de serviço

obtidos por meio de observações empíricas apresentam valores maiores do que os obtidos com a utilização dos simuladores de tráfego. A divergência dos resultados é maior quando comparadas as porcentagens de caminhões inferiores a $10 \%$.

Nos outros estudos comparados, em Demarchi (2000) os dados coletados não continham diferença na limitação da velocidade dos caminhões. Em Cunha (2007), por restrição do simulador, não foi incorporada a limitação de velocidade diferenciada durante a simulação. Essa pode ser a principal causa das diferenças dos resultados com a presente pesquisa.

\subsection{Considerações finais}

O HCM define fatores de equivalência veicular de caminhões dos Estados Unidos. Atualmente é o manual mais utilizado em projetos de rodovias paulistas (ANDRADE; RODRIGUES-SILVA; PUTY FILHO, 2011) e apresenta equivalentes veiculares subestimados em relação aos resultados obtidos nesta pesquisa. Desta forma, há indícios de que os fatores de equivalência veicular do 
(a) Nível de Serviço A

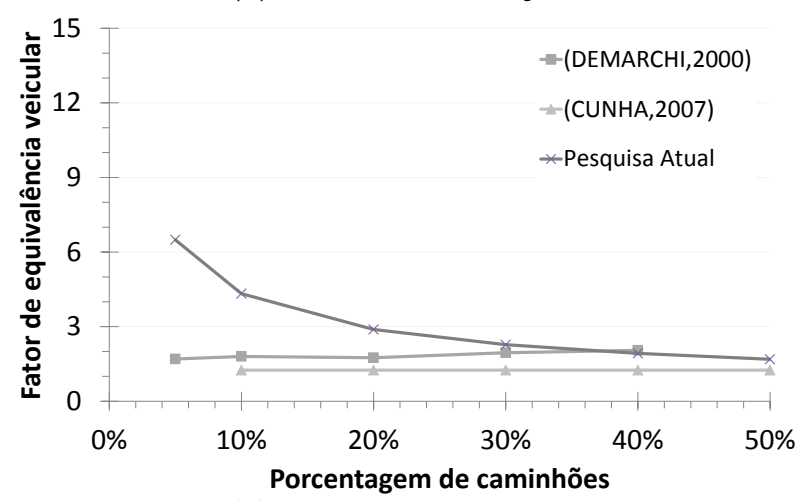

(c) Nível de Serviço C

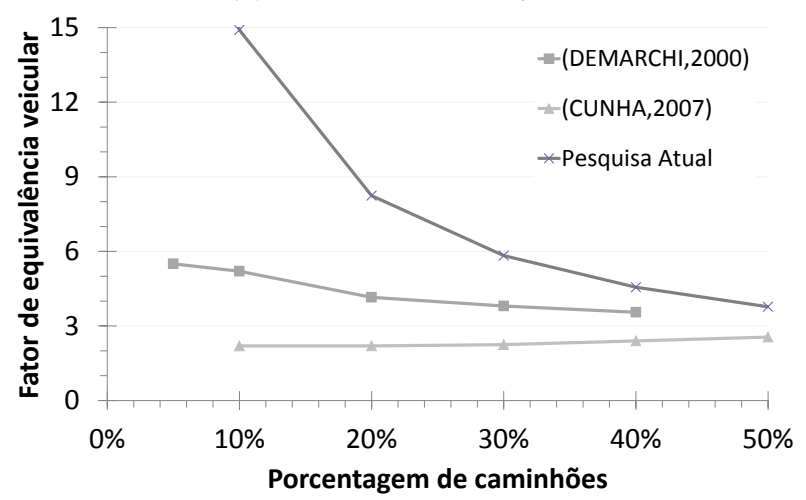

(b) Nível de Serviço B

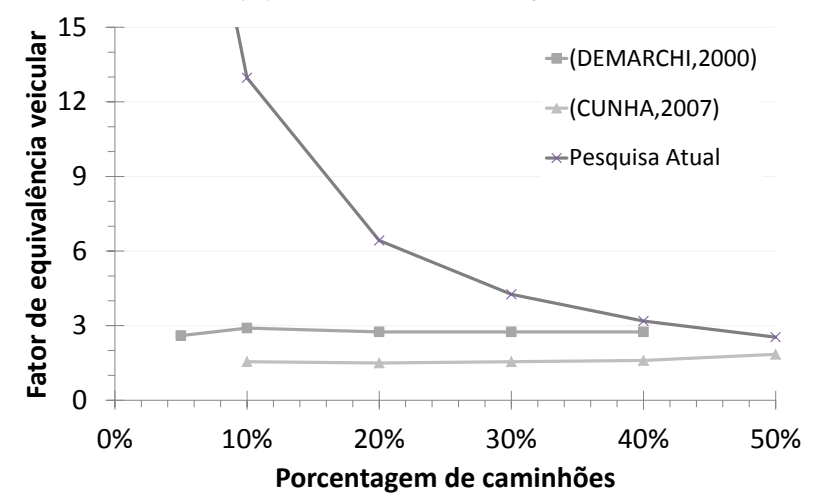

(d) Nível de Serviço D

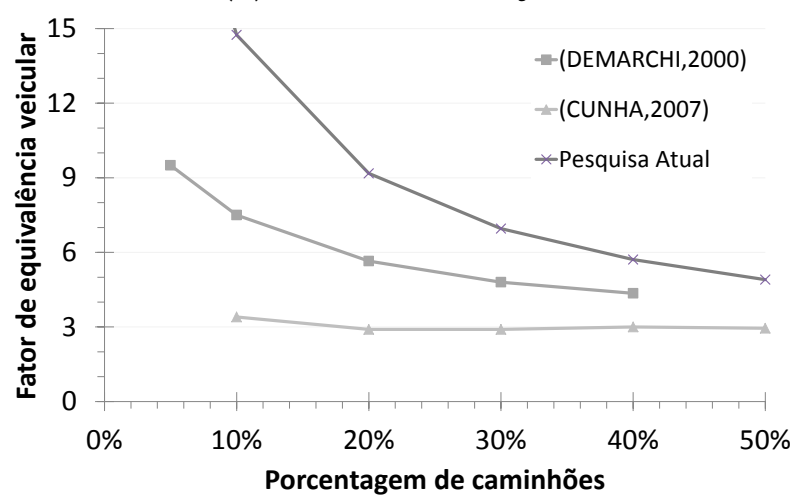

Figura 6.11 - Comparação entre os estudos para a classe de greide 3, para os diferentes níveis de serviço

HCM não são representativos. Se os equivalentes veiculares da Tabela 6.6 fossem utilizados para calcular os níveis de serviço das rodovias paulistas, seriam obtidos resultados piores do que os verificados atualmente.

Como exemplo, a Tabela 6.8 compara os níveis de serviço calculados usando-se os fatores de equivalência desta pesquisa com os calculados com valores dos estudos anteriores. Para isso, foi suposta uma rodovia com 3 faixas de tráfego, fluxo de 4000 veic/h, $20 \%$ de caminhões, fator de pico horário de 0,90 e fator de ajuste para tipo de motorista igual a 1,0. Os equivalentes veiculares utilizados são do greide de $4 \%$ (greide 2), 0,5 km de comprimento e nível de serviço C.

Com velocidade de fluxo livre de $120 \mathrm{~km} / \mathrm{h}$, obteve-se densidade média de 19,3 cpe/(km ·faixa), correspondendo ao nível de serviço D, para os valores do estudo de Demarchi (2000). Com a mesma velocidade de fluxo livre, calculou-se a densidade de 14,8 cpe/(km·faixa), que corresponde ao nível de serviço C, para os valores do estudo de Cunha (2007). Para os valores da atual pesquisa, obteve-se 22,4 $\mathrm{cpe} /(\mathrm{km} \cdot$ faixa $)$, que corresponde ao nivel de serviço E. Para 
Tabela 6.8 - Comparação dos cálculos do nível de serviço

\begin{tabular}{lll}
\hline Demarchi (2000) & Cunha (2007) & Este estudo \\
\hline$E_{T}=3,8$ & $E_{T}=2,0$ & $E_{T}=5,1$ \\
$f_{H V}=\frac{1}{1+0,20(3,8-1)}$ & $f_{H V}=\frac{1}{1+0,20(2,0-1)}$ & $f_{H V}=\frac{1}{1+0,20(5,1-1)}$ \\
$f_{H V}=0,64$ & $f_{H V}=0,83$ & $f_{H V}=0,55$ \\
\hline$v_{p}=\frac{4000}{0,9 \cdot 3 \cdot 0,64 \cdot 1,0}$ & $v_{p}=\frac{4000}{0,9 \cdot 3 \cdot 0,83 \cdot 1,0}$ & $v_{p}=\frac{4000}{0,9 \cdot 3 \cdot 0,55 \cdot 1,0}$ \\
$v_{p}=2311 \mathrm{cpe} /(\mathrm{h} \cdot$ faixa) & $v_{p}=1778 \mathrm{cpe} /(\mathrm{h} \cdot \mathrm{faixa})$ & $v_{p}=2685 \mathrm{cpe} /(\mathrm{h} \cdot$ faixa) \\
$k=19,3 \mathrm{cpe} /(\mathrm{km} \cdot \mathrm{faixa})(\mathrm{NS} \mathrm{D})$ & $k=14,8 \mathrm{cpe} /(\mathrm{km} \cdot \mathrm{faixa})(\mathrm{NS} \mathrm{C})$ & $k=22,4 \mathrm{cpe} /(\mathrm{km} \cdot \mathrm{faixa})(\mathrm{NS} \mathrm{E})$ \\
\hline
\end{tabular}

os fatores de equivalência veicular obtidos neste estudo, o nível de serviço sempre será igual ou pior do que os obtidos com os valores dos outros estudos.

No capítulo 7, são apresentadas as conclusões da pesquisa. Também são feitas recomendações para futuras investigações acadêmicas. 


\section{Capítulo}

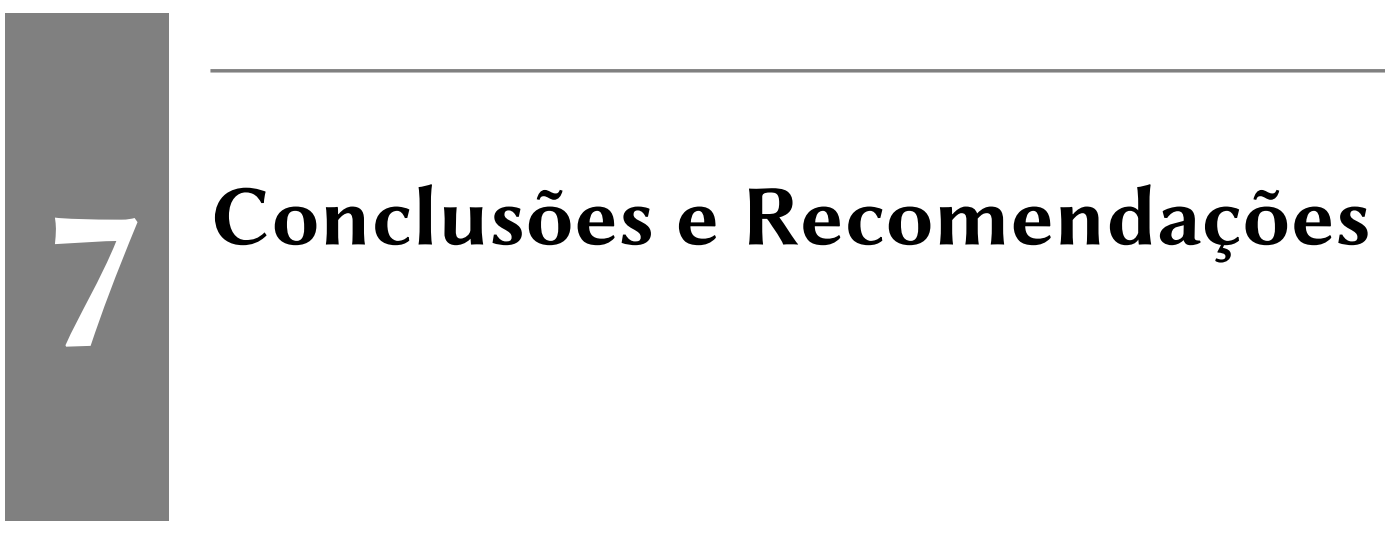

A meta desta pesquisa foi estudar o impacto combinado das características de desempenho dos caminhões e do limite de velocidade diferenciado por tipo de veículos nos fatores de equivalência de veículos pesados, através da análise de observações de tráfego coletados em rodovias de pista dupla. Para tanto, o fator de equivalência veicular foi calculado por meio do método proposto por Huber (1982), com a hipótese de que a qualidade de serviço é a mesma em todas as faixas de tráfego em uma mesma seção da rodovia.

Os dados de tráfego foram obtidos por laços indutivos, que foram usados para coletar informações de fluxo e velocidade por faixa de rolamento, agregados em intervalos de cinco ou seis minutos. As informações sobre os veículos foram desagregadas em automóveis, veículos pesados e motos. Além disso, para cada um dos intervalos de tráfego, foi obtida a condição do tempo (bom ou chuvoso).

Após a criação deste banco de dados, foi aplicada uma sequência de filtros para descartar observações que não eram adequadas para a aplicação do método proposto. Após o tratamento dos dados, restaram 53.655 observações, que somadas correspondem a mais de 200 dias de coleta. Dentre esses dados, observou-se que a maior quantidade de intervalos era referente aos níveis de serviço A e B e que menos de $1 \%$ das observações eram correspondentes ao nível de serviço E. 
Os resultados da análise dos dados sugerem que a qualidade de serviço não é constante ao longo das faixas de tráfego da rodovia em cerca de $52 \%$ das observações disponíveis. Constatouse também que essas observações eram encontradas quando a densidade de tráfego na faixa da esquerda era baixa $\left(k_{e}<10 \mathrm{veic} /(\mathrm{km} \cdot\right.$ faixa $\left.)\right)$.

Nota-se que, em todos os cenários estudados, o impacto marginal dos caminhões decresce à medida em que a porcentagem de caminhões na corrente aumenta, conforme a teoria estabelece. Para trechos planos (greides $<2 \%$ ), notou-se que os valores estimados para o fator de equivalência são praticamente os mesmos para os níveis de serviço A e B; para porcentagens altas de caminhões $(p(i)>60 \%)$, as diferenças devidas ao nível de serviço virtualmente desaparecem. Para os aclives mais íngremes (greides $>4 \%$ ), o efeito aparece apenas para o nível de serviço A; as curvas para os níveis de serviço B, C e D são muito próximas, para qualquer porcentagem de caminhões. De fato, observando-se a Figura 6.7, percebe-se que as curvas dos níveis de serviço B, C e D aproximam-se a medida em que os aclives tornam-se mais íngremes, evidenciando o efeito das limitações de desempenho dos caminhões na qualidade de serviço.

Também foi mostrado que, comparando-se os diferentes greides para o mesmo nível de serviço, os greides mais íngremes (com inclinação > 4\%) apresentam os maiores valores de fator de equivalência veicular para uma mesma porcentagem de caminhões. Para os níveis de serviço A e B, os greides com menos de $4 \%$ apresentam fatores de equivalência veicular próximos. Isto indica que, quando a rodovia apresenta baixo volume de tráfego $[k<11,2$ veic/(km·faixa) $]$ e o aclive da pista é inferior a 4\%, o impacto dos caminhões é similar. Nos níveis de serviço C e D os equivalentes veiculares dos greides com inclinação < $2 \%$ apresentaram valores maiores que os calculados para greides entre $2 \%$ e $4 \%$. É importante ressaltar que, para a porcentagem de caminhões superior a 50\%, os fatores de equivalência veicular apresentam valores muito próximos em todos os casos.

Os fatores de equivalência calculados na presente pesquisa são maiores do que os obtidos a partir de simulações de tráfego [Demarchi (2000) e Cunha (2007)]. Os fatores de equivalência também são maiores que os apresentados pelo HCM. 


\subsection{Recomendações}

Pelas avaliações feitas durante a pesquisa, é possível indicar algumas recomendações para futuras investigações acadêmicas. Como primeira recomendação, utilizando-se dos dados de tráfego das rodovias de pista dupla com três ou mais faixas, identificar o motivo pelo qual a qualidade de serviço pode não ser a mesma em todas as faixas da rodovia. Outra avaliação é identificar qual a densidade de tráfego em que os condutores escolhem a faixa de tráfego para igualar a qualidade de serviço em toda a seção da rodovia.

Nesta pesquisa verificou-se que os fatores de equivalência apresentam uma grande variação, mesmo considerando-se um mesmo cenário (mesma inclinação, nível de serviço da rodovia e porcentagem de caminhões). Essa variação é maior quando a porcentagem de caminhões é menor que $40 \%$. Assim, recomenda-se que seja feito um estudo sobre as causas e as variáveis que influenciam nessa variação.

A literatura apresenta que, uma vez que o carregamento das faixas não é homogêneo, podese sugerir uma diminuição da capacidade da rodovia. Além disso, em uma análise feita nesta pesquisa, os dados sugerem que a faixa mais próxima ao canteiro central é mais utilizada quando o carregamento da rodovia está próximo à capacidade da rodovia. Portanto, recomendase um estudo sobre distribuição dos veículos por faixa de tráfego em rodovias de pista dupla.

Em rodovias com quatro ou mais faixas de tráfego por sentido, sugere-se um estudo para identificar se a corrente é formada basicamente por: faixas próximas ao canteiro central com maioria de automóveis e faixas próximas ao acostamento com maior quantidade de caminhões. Esse comportamento pode sugerir que o tráfego é formado por duas correntes distintas, com grande interação dentro de cada uma, mas pouca entre elas.

O comprimento de rampa pode ser uma variável no cálculo dos fatores de equivalência. Dessa forma, recomenda-se avaliar o impacto dessa variável na qualidade de serviço das rodovias, utilizando dados empíricos. 


\section{Referências}

AGHABAYK, K.; SARVI, M.; YOUNG, W. (2012). Understanding the dynamics of heavy vehicle interactions in car-following. Journal of Transportation Engineering, American Society of Civil Engineers, v. 138, n. 12, p. 1468-1475.

ALECSANDRU, C.; ISHAK, S.; QI, Y. (2012). Passenger car equivalents of trucks on four-lane rural freeways under lane restriction and different traffic conditions. Canadian fournal of Civil Engineering, NRC Research Press, v. 39, n. 10, p. 1145-1155.

ANDRADE, G. R. (2012). Capacidade e relação fluxo-velocidade em autoestradas e rodovias de pista dupla paulistas. 144 p. Dissertação (Mestrado) - EESC-USP, São Carlos, SP.

ANDRADE, G. R.; RODRIGUES-SILVA, K. C.; PUTY FILHO, S. A. (2011). Panorama normativo e tecnológico da avaliação operacional das concessões rodoviárias. In: CBR\&C. Anais do $7^{\circ}$ Congresso Brasileiro de Rodovias e Concessões. Foz do Iguaçú, PR, p. 14.

BAINS, M. S.; PONNU, B.; ARKATKAR, S. S. (2012). Modeling of traffic flow on indian expressways using simulation technique. Procedia-Social and Behavioral Sciences, Elsevier, v. 43 , p. $475-493$.

BALBO, J. (2007). Pavimentação asfáltica: materiais, projeto e restauração. São Paulo, SP: Oficina de Textos. ISBN 9788586238567.

CHANDRA, S. (2004). Capacity estimation procedure for two lane roads under mixed traffic conditions. In: INDIAN ROAD CONGRESS. Journal of Indian Road Congress. New Delhi, India, v. 65, n. 1, p. 139-170.

CHANDRA, S.; ZALA, L. B.; KUMAR, V. (1997). Comparing the methods of passengar car unit estimation. Fournal of the Institution of Engineers. India. Civil Engineering Division, Institution of Engineers, v. 78, n. 5, p. 13-16.

CNT (2015). Boletim Estatístico CNT Fevereiro 2015. Brasília, DF. Disponível em: <http://www.cnt.org.br/Paginas/Boletins_Detalhes.aspx?b=3>.

CUNAGIN, W. D.; MESSER, C. J. (1983). Passenger-car equivalents for rural highways. Washington, D. C., EUA, 61-68 p.

CUNHA, A. L. B. N. (2007). Avaliação do impacto da medida de desempenho no equivalente veicular de caminhões. 147 p. Dissertação (Mestrado) - EESC-USP, São Carlos, SP. 
DEMARCHI, S. H. (2000). Influência dos veículos pesados na capacidade e nível de serviço de rodovias de pista dupla. 166 p. Tese (Doutorado) - EESC-USP, São Carlos, SP.

DEMARCHI, S. H.; SETTI, J. R. (2003). Limitations of passenger-car equivalent derivation for traffic streams with more than one truck type. Transportation Research Record: Fournal of the Transportation Research Board, Trans Res Board, v. 1852, n. 1, p. 96-104.

DENATRAN (2008). Código de Trânsito Brasileiro e Legislação Complementar em Vigor. Brasília, DF. Disponível em: <http://www.denatran.gov.br/publicacoes/download/ctb_e_legislacao_complementar.pdf $>$.

DER (2014). Malha Rodoviária do Estado de São Paulo. São Paulo, SP. Disponível em: <http://www.der.sp.gov.br/website/Malha/estat_malha/Malha_oficial_2013.pdf >.

DURET, A.; AHN, S.; BUISSON, C. (2012). Lane flow distribution on a three-lane freeway: General features and the effects of traffic controls. Transportation research part C: emerging technologies, Elsevier, v. 24, p. 157-167.

ELEFTERIADOU, L.; TORBIC, D.; WEBSTER, N. (1997). Development of passenger car equivalents for freeways, two-lane highways, and arterials. Transportation Research Record: Fournal of the Transportation Research Board, Transortation Research Board, v. 1572, n. 1, p. 51-58.

FDOT (2013). Quality/Level of Service Handbook. Tallahassee, FL, EUA. Disponível em: <http://www.dot.state.fl.us/planning/systems/programs/SM/los/pdfs/2013\%20QLOS\%20Handbook$. p d f>$.

GARTNER, N. H.; MESSER, C. J.; RATHI, A. K. (1997). Monograph on traffic flow theory. Washington, D.C., EUA: Federal Highway Administration. Disponível em: <http://www.fhwa.dot.gov/publications/research/operations/tft/chap1.pdf $>$.

GREENSHIELDS, B. D. (1935). A study of traffic capacity. In: HIGHWAY RESEARCH BOARD. Highway Research Board Proceedings. Washington, D.C., EUA, v. 14, p. 448-477.

HRB (1965). Highway Capacity Manual. Washington, D.C., EUA.

HUBER, M. J. (1982). Estimation of passenger-car equivalents of trucks in traffic stream. Transportation Research Record, n. 869, p. 60-70.

KLEIN, L. (2001). Sensor Technologies and Data Requirements for ITS. Boston, MA, EUA: Artech House. (Artech House ITS library). ISBN 9781580530774.

KRAMMES, R. A.; CROWLEY, K. W. (1986). Passenger car equivalents for trucks on level freeway segments. Transportation Research Record, Washington, D. C., EUA, n. 1091, p. 10-17.

LINZER, E. M.; ROESS, R. P.; McSHANE, W. R. (1979). Effect of trucks, buses, and recreational vehicles on freeway capacity and service volume. Transportation Research Record, Washington, D. C., EUA, n. 699, p. 17-25.

MEHAR, A.; CHANDRA, S.; VELMURUGAN, S. (2014). Passenger car units at different levels of service for capacity analysis of multilane interurban highways in india. fournal of transportation engineering, American Society of Civil Engineers, v. 140, n. 1, p. 81-88. 
MODI, V. et al. (2014). Freeway capacity estimation method for planning applications. fournal of Transportation Engineering, American Society of Civil Engineers, v. 140, n. 9.

PIZZOL, B. (2012). Efeito das condições meteorológicas no fluxo de veículos em rodovias de pista dupla do estado de São Paulo. São Carlos, SP: Fundação de Amparo a Pesquisa do Estado de São Paulo.

PIZZOL, B.; SETTI, J. R. (2013). Fusão de bancos de dados para estudo do efeito das condições meteorológicas no fluxo de veículos em rodovias paulistas. In: ANPET. Anais do XXVII Congresso de Pesquisa e Ensino em Transportes. Belém, PA.

REILLY, E. F.; SEIFERT, J. (1969). Truck equivalency. Highway Research Record, n. 28, p. 25-37.

ROESS, R. P.; PRASSAS, E. S.; McSHANE, W. R. (2004). Traffic engineering. $3^{\text {a }}$. ed. Upper Saddle River, NJ, EUA: Pearson/Prentice Hall.

SETTI, J. R. (2009). Highway capacity manual ou manual de capacidade viária. In: CBR\&C. Anais do $6^{\circ}$ Congresso Brasileiro de Rodovias e Concessões. Florianópolis, SC, p. 11.

ST-SP (1997). Edital de licitação 007/CIC/97, Lote 1: Sistema Anhanguera-Bandeirantes. São Paulo, SP. Disponível em: <http://www.artesp.sp.gov.br/Media/Default/Concessionaria/Edital/2622/1\%20AUTOBAN.rar>.

SUMNER, R.; HILL, D.; SHAPIRO, S. (1984). Segment passenger car equivalent values for cost allocation on urban arterial roads. Transportation Research Part A: General, Elsevier, v. 18, n. 5, p. 399-406.

TRB (2010). Highway Capacity Manual. Washington, D.C., EUA.

WEBSTER, N.; ELEFTERIADOU, L. (1999). A simulation study of truck passenger car equivalents (pce) on basic freeway sections. Transportation Research Part B: Methodological, Elsevier, v. 33, n. 5, p. 323-336.

WU, N. (2006). Equilibrium of lane flow distribution on motorways. Transportation Research Record: Fournal of the Transportation Research Board, Trans Res Board, v. 1965, n. 1, p. 48-59.

YOUSIF, S.; AL-OBAEDI, J.; HENSON, R. (2012). Drivers' lane utilization for united kingdom motorways. Journal of Transportation Engineering, American Society of Civil Engineers, v. 139 , n. 5 , p. $441-447$. 
Apêndices 


\section{APÊNDICE}

\section{A Apêndice $\mathrm{A}$}

\section{A.1 Dados da Rodovia Castelo Branco}

Na Tabela A.1 é apresentado um exemplo dos dados coletados em uma faixa de tráfego da

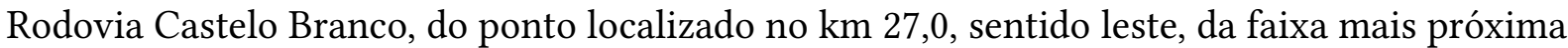
ao canteiro central. O cabeçalho da tabela é o código que identifica a localização do ponto, bem como a sua faixa de tráfego. Este código é identificado da seguinte forma:

- "A";

- Número da estação (3 dígitos);

- Código da rodovia (2 dígitos);

- $\mathrm{km}$ da estação (4 dígitos, sendo o último a casa decimal); e

- Últimos 3 dígitos representam o sentido e a faixa de tráfego.

Os arquivos da Rodovia Castelo Branco contêm os dados de um mesmo ponto em um mesmo arquivo, sendo que cada uma das abas do arquivo representa uma faixa do tráfego. Por exemplo, a aba "LE1" são os dados coletados no sentido leste, na faixa mais próxima ao canteiro central. A aba "LE3" mostra os dados coletados no sentido leste, na faixa mais próxima ao acostamento. Ressalta-se também que os dados desta rodovia são coletados em intervalos de cinco minutos. As colunas da tabela representam as seguintes informações:

- Data: Data a qual se refere a informação;

- Hora: Intervalo ao qual se refere a informação. Exemplo: 23:55:00 indica que os dados pertencem ao intervalo 23:55:00 a 23:59:59;

- Volume total: Quantidade de veículos de passeio, comerciais e motos que passaram na faixa durante o intervalo especificado pelos campos "Data" e "Hora";

- Velocidade média $(\mathrm{km} / \mathrm{h})$ : Velocidade média dos veículos que passaram pela faixa no intervalo especificado, incluindo veículos de passeio, comerciais e motos;

- Taxa de ocupação (\%): Porcentagem de duração do intervalo em que o sensor esteve acionado, arredondada para a unidade mais próxima; 
- Volume de autos (veíc): Quantidade de veículos que passaram pela faixa durante o período especificado, com comprimento superior a $2 \mathrm{~m}$ e inferior ou igual a $6 \mathrm{~m}$;

- Velocidade média autos $(\mathrm{km} / \mathrm{h})$ : Velocidade média dos veículos que passaram pela faixa durante o período especificado, com comprimento superior a $2 \mathrm{~m}$ e inferior ou igual a $6 \mathrm{~m}$;

- Volume comerciais (veíc): Quantidade de veículos que passaram pela faixa durante o período especificado, com comprimento superior a $6 \mathrm{~m}$;

- Velocidade média comerciais $(\mathrm{km} / \mathrm{h})$ : Velocidade média dos veículos que passaram pela faixa durante o período especificado, com comprimento superior a $6 \mathrm{~m}$;

- Volume motos (veíc): Quantidade de veículos que passaram pela faixa durante o período especificado, com comprimento inferior ou igual a $2 \mathrm{~m}$; e

- Velocidade média motos $(\mathrm{km} / \mathrm{h})$ : Velocidade média dos veículos que passaram pela faixa durante o período especificado, com comprimento inferior ou igual a $2 \mathrm{~m}$.

\section{A.2 Dados da Rodovia dos Bandeirantes}

Na Tabela A.2 é mostrado um exemplo da formatação da planilha da Rodovia dos Bandeirantes, do ponto localizado no $\mathrm{km} \mathrm{32}$, sentido norte, na faixa mais próxima ao canteiro central. $\mathrm{O}$ cabeçalho da tabela é o código que identifica a localização do ponto, bem como o horário de coleta. Este código é identificado da seguinte forma:

- "Equipamento";

- $\mathrm{km}$ da estação (3 dígitos);

- "B du ";

- data e horário do início das medições;

- " au ”; e

- data e horário do fim das medições.

Diferentemente dos dados da Rodovia Castelo Branco, os dados da Rodovia dos Bandeirantes são agregados em diferentes arquivos para cada uma das faixas. Por exemplo, em um arquivo existem dados da faixa mais próxima ao canteiro central e em outro arquivo dados da faixa mais próxima ao acostamento. Para identificar esses arquivos, em seu nome existe a numeração da faixa. O arquivo com os dados da faixa mais próxima ao canteiro central tem o nome "32N1B.xls" (identificado pelo algarismo 1), já os dados da faixa mais próxima ao acostamento tem o nome "32N4B.xls" (identificado pelo algarismo 4). Os dados coletados nesta rodovia possuem intervalos de coleta de seis minutos. Cada uma das colunas da tabela representam as seguintes informações:

- Data e hora: Intervalo, com data e horário, ao qual se refere a informação. Exemplo: 23:54:00 indica que os dados pertencem ao intervalo 23:54:00 a 23:59:59; 
- Volume de todos os veículos (veíc): Volume de todos os veículos que passaram na faixa durante o intervalo especificado pelo campo "Data e hora";

- Taxa de ocupação (\%): Porcentagem de duração do intervalo em que o sensor esteve acionado, arredondada para a unidade mais próxima;

- Velocidade de todos os veículos $(\mathrm{km} / \mathrm{h})$ : Velocidade média dos veículos que passaram pela faixa no intervalo especificado;

- Volume de comerciais (veíc): Quantidade de veículos comerciais que passaram pela faixa durante o período especificado; e

- A última coluna apresenta alguma observação sobre o ponto, como, por exemplo "recebido corretamente". 

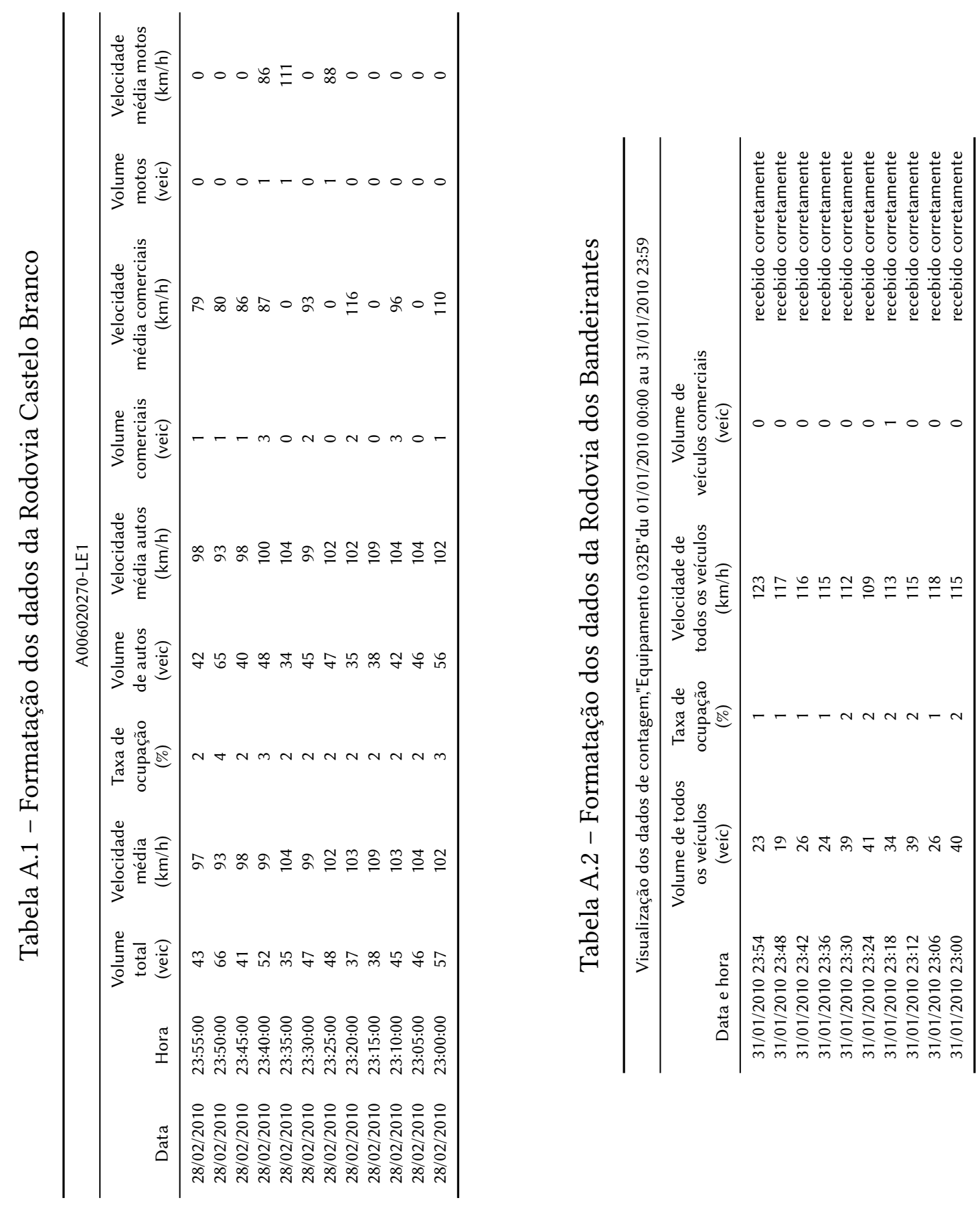


\section{APÊNDICE}

\section{Apêndice B}

Tabela B.1 - Quantidade de ocorrências com $E(i) \leq 1$ para densidade na faixa de fluxo básico

\begin{tabular}{|c|c|c|c|}
\hline $\begin{array}{c}k_{e} \\
{[\operatorname{veic} /(\mathrm{km} \cdot \text { faixa })]}\end{array}$ & $\begin{array}{c}\text { Total } \\
\text { Intervalos }\end{array}$ & $\begin{array}{l}\text { Intervalos com } \\
\qquad E(i)>1\end{array}$ & $\begin{array}{c}\text { Porcentagem de } \\
\text { Intervalos com } E(i)>1\end{array}$ \\
\hline $0<k_{e} \leq 1$ & 32.949 & 509 & $2 \%$ \\
\hline $1<k_{e} \leq 2$ & 15.525 & 1.767 & $11 \%$ \\
\hline $2<k_{e} \leq 3$ & 11.840 & 3.216 & $27 \%$ \\
\hline $3<k_{e} \leq 4$ & 12.021 & 4.464 & $37 \%$ \\
\hline $4<k_{e} \leq 5$ & 12.281 & 6.312 & $51 \%$ \\
\hline $5<k_{e} \leq 6$ & 9.929 & 7.045 & $71 \%$ \\
\hline $6<k_{e} \leq 7$ & 7.354 & 6.292 & $86 \%$ \\
\hline $7<k_{e} \leq 8$ & 6.314 & 5.949 & $94 \%$ \\
\hline $8<k_{e} \leq 9$ & 5.409 & 5.321 & $98 \%$ \\
\hline $9<k_{e} \leq 10$ & 5.434 & 5.411 & $100 \%$ \\
\hline $10<k_{e} \leq 11$ & 4.387 & 4.383 & $100 \%$ \\
\hline $11<k_{e} \leq 12$ & 3.883 & 3.881 & $100 \%$ \\
\hline $12<k_{e} \leq 13$ & 2.873 & 2.873 & $100 \%$ \\
\hline $13<k_{e} \leq 14$ & 2.269 & 2.268 & $100 \%$ \\
\hline $14<k_{e} \leq 15$ & 1.731 & 1.730 & $100 \%$ \\
\hline $15<k_{e} \leq 16$ & 1.278 & 1.278 & $100 \%$ \\
\hline $16<k_{e} \leq 17$ & 986 & 986 & $100 \%$ \\
\hline $17<k_{e} \leq 18$ & 736 & 736 & $100 \%$ \\
\hline $18<k_{e} \leq 19$ & 574 & 574 & $100 \%$ \\
\hline $19<k_{e} \leq 20$ & 455 & 455 & $100 \%$ \\
\hline $20<k_{e} \leq 21$ & 350 & 350 & $100 \%$ \\
\hline $21<k_{e} \leq 22$ & 222 & 222 & $100 \%$ \\
\hline $22<k_{e} \leq 23$ & 197 & 197 & $100 \%$ \\
\hline $23<k_{e} \leq 24$ & 125 & 125 & $100 \%$ \\
\hline $24<k_{e} \leq 25$ & 69 & 69 & $100 \%$ \\
\hline $25<k_{e} \leq 26$ & 40 & 40 & $100 \%$ \\
\hline $26<k_{e} \leq 27$ & 17 & 17 & $100 \%$ \\
\hline $27<k_{e} \leq 28$ & 2 & 2 & $100 \%$ \\
\hline $28<k_{e} \leq 29$ & 2 & 2 & $100 \%$ \\
\hline $29<k_{e} \leq 30$ & 1 & 1 & $100 \%$ \\
\hline Total & 139.253 & 66.475 & $48 \%$ \\
\hline
\end{tabular}


Tabela B.2 - Quantidade de observações removidas em função da densidade mínima nas faixas de fluxo básico ou misto

\begin{tabular}{crrr}
\hline $\begin{array}{c}\text { Densidade mínima } \\
\text { [veic/(km.faixa) }\end{array}$ & $\begin{array}{c}\text { Total } \\
\text { Intervalos }\end{array}$ & $\begin{array}{c}\text { Intervalos com } \\
E(i)>1\end{array}$ & $\begin{array}{c}\text { Porcentagem de } \\
\text { Intervalos com } E(i)>1\end{array}$ \\
\hline $0 k_{e}$ e $k_{d}$ & 139.253 & 66.475 & $48 \%$ \\
$1 \leq k_{e}$ e $k_{d}$ & 105.910 & 65.392 & $62 \%$ \\
$2 \leq k_{e}$ e $k_{d}$ & 88.099 & 61.337 & $70 \%$ \\
$3 \leq k_{e}$ e $k_{d}$ & 71.726 & 53.655 & $75 \%$ \\
$4 \leq k_{e}$ e $k_{d}$ & 54.466 & 43.922 & $81 \%$ \\
$5 \leq k_{e}$ e $k_{d}$ & 37.110 & 32.516 & $88 \%$ \\
$6 \leq k_{e}$ e $k_{d}$ & 21.545 & 19.958 & $93 \%$ \\
$7 \leq k_{e}$ e $k_{d}$ & 9.776 & 9.284 & $95 \%$ \\
$8 \leq k_{e}$ e $k_{d}$ & 3.622 & 3.501 & $97 \%$ \\
$9 \leq k_{e}$ e $k_{d}$ & 1.320 & 1.289 & $98 \%$ \\
$10 \leq k_{e}$ e $k_{d}$ & 566 & 558 & $99 \%$ \\
$11 \leq k_{e}$ e $k_{d}$ & 266 & 262 & $98 \%$ \\
$12 \leq k_{e}$ e $k_{d}$ & 106 & 104 & $98 \%$ \\
$13 \leq k_{e}$ e $k_{d}$ & 44 & 42 & $95 \%$ \\
$14 \leq k_{e}$ e $k_{d}$ & 18 & 17 & $94 \%$ \\
$15 \leq k_{e}$ e $k_{d}$ & 9 & 9 & $100 \%$ \\
$16 \leq k_{e}$ e $k_{d}$ & 5 & 5 & $100 \%$ \\
$17 \leq k_{e}$ e $k_{d}$ & 1 & 1 & $100 \%$ \\
\hline
\end{tabular}

